$$
\text { UNIVERSIDADE DE SÃO PAULO }
$$

ESCOLA DE ENGENHARIA DE SÃO CARLOS

LUIZ ARTHUR PIEDADE NASCIMENTO

\title{
ANÁLISE DINÂMICA DE MODOS DE PROPAGAÇÃO SONORA E PROJETO DE INSTRUMENTAÇÃO EXPANDIDA PARA TUBO DE IMPEDÂNCIA
}





\title{
ANÁLISE DINÂMICA DE MODOS DE PROPAGAÇÃO SONORA E PROJETO DE INSTRUMENTAÇÃO EXPANDIDA PARA TUBO DE IMPEDÂNCIA
}

\author{
Dissertação apresentada à Escola de \\ Engenharia de São Carlos da Universidade \\ de São Paulo, como requisito parcial para a \\ obtenção do Título de Mestre em Ciências \\ - Programa de Pós-Graduação em \\ Engenharia Mecânica. \\ Área de Concentração: Dinâmica das \\ Máquinas e Sistemas \\ Orientador: Prof. Dr. Leopoldo Pisanelli \\ Rodrigues de Oliveira
}

São Carlos 
AUTORIZO A REPRODUÇÃO TOTAL OU PARCIAL DESTE TRABALHO, POR QUALQUER MEIO CONVENCIONAL OU ELETRÔNICO, PARA FINS DE ESTUDO E PESQUISA, DESDE QUE CITADA A FONTE.

Ficha catalográfica elaborada pela Biblioteca Prof. Dr. Sérgio Rodrigues Fontes da EESC/USP com os dados inseridos pelo(a) autor(a).

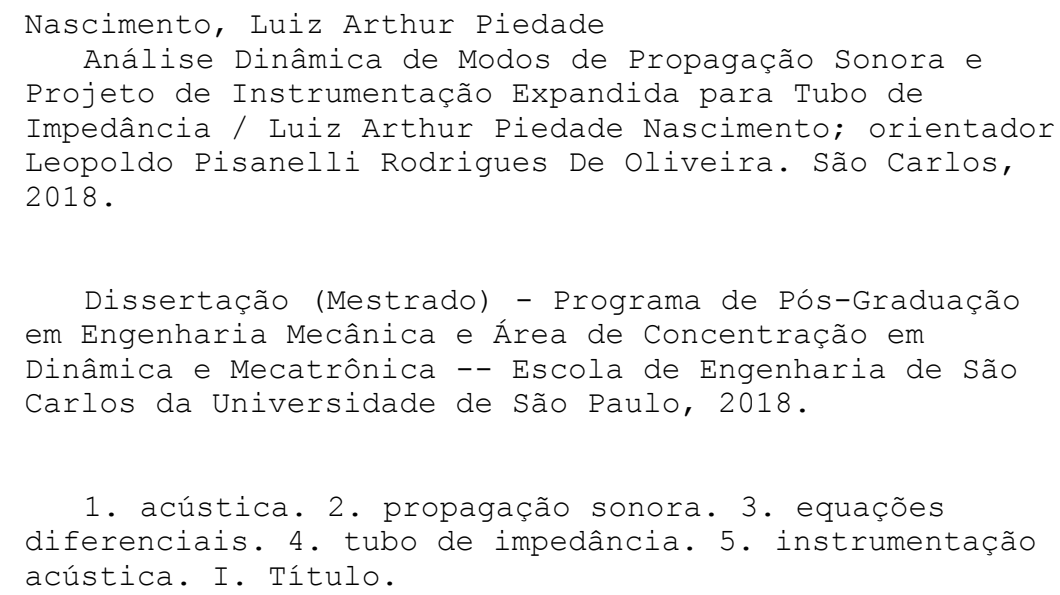

Eduardo Graziosi Silva - CRB - 8/8907 


\section{FOLHA DE JULGAMENTO}

Candidato: Engenheiro LUIZ ARTHUR PIEDADE NASCIMENTO.

Título da dissertação: "Análise dinâmica de modos de propagação sonora e projeto de instrumentação expandida para tubo de impedância".

Data da defesa: 05/11/2018.

Comissão Julgadora:

Prof. Dr. Leopoldo Pisanelli Rodrigus de Oliveira (Orientador)

(Escola de Engenharia de São Carlos/EESC)

Prof. Dr. Sidiney Bruce Shiki

(Universidade Federal de São Carlos/UFSCar)

Prof. Dr. Jaime Alberto Mosquera Sanchez

(Universidade Federal de Santa Maria/UFSM)
Resultado:

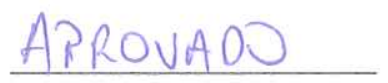

APROVADO

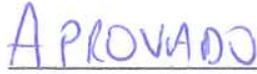

Coordenador do Programa de Pós-Graduação em Engenharia Mecânica: Prof. Associado Gherhardt Ribatski

Presidente da Comissão de Pós-Graduação:

Prof. Associado Luís Fernando Costa Alberto 



\section{Agradecimentos}

Essa dissertação simboliza um ciclo de quase dez anos aprendendo, ensinando e convivendo com muitas pessoas na Escola de Engenharia de São Carlos da Universidade de São Paulo, a que devo meu amadurecimento enquanto ser humano, profissional e cientista.

Agradeço aos meus pais, Rizete e Bosco, e ao meu irmão, Júnior, por terem investido suas confianças no meu potencial e, principalmente, por terem dado a oportunidade de me dedicar aos estudos e ao meu treinamento profissional. Infelizmente nem todas as pessoas têm as oportunidades que eu tive na vida. Por isso, sou eternamente grato.

Agradeço aos amigos e amigas que me acompanharam nessa jornada, pelo apoio, por acreditarem em mim, por me ouvirem desabafar angústias e incertezas. Àqueles da graduação e da escola que ainda estão comigo. Não conseguiria nomear todos que me foram valiosos nessa jornada, mas um agradecimento especial à Francine por ser minha companheira e por me dar forças. Fran, obrigado por estar aqui, mas sobretudo, obrigado por existir.

Aos meus companheiros e companheiras do Laboratório de Dinâmica, pela troca de conhecimento e experiência, também pelos cafés, conversas, cervejas e churrascos compartilhados. Espero também ter contribuído em suas trajetórias.

A todos os pós-graduandos e pós-graduandas do Brasil, brasileiros ou estrangeiros, que carregam o peso e a responsabilidade de desenvolver Ciência no nosso País, muitas vezes sem incentivo material ou afetivo, quase sempre sozinhos. Espero que meu trabalho esteja à altura da nossa classe. Obrigado por insistirem nos seus sonhos e no nosso futuro. A vocês, meu agradecimento, meu respeito e minha admiração.

Agradeço também ao Prof. Dr. Leopoldo Pisanelli Rodrigues de Oliveira não só pela orientação e pela confiança no meu trabalho, mas também - e principalmente - pela paciência e pela amizade. Tem sido um prazer e um grande aprendizado trabalhar com você nesses últimos anos. Obrigado também por ajudar a construir uma Universidade mais justa, inclusiva e humana para todos nós.

A todos os profissionais do Programa de Pós-Graduação de Engenharia Mecânica da EESC/USP, aos nossos profissionais de manutenção e limpeza; aos técnicos Diego, Sérgio e China, às secretárias Cris, Ana e Iara; por último, e não menos importante, a todo o corpo docente.

Por fim, agradeço à CAPES, pelo incentivo financeiro a esse projeto de pesquisa. 

"What I'm looking for is not out there, it is in me."

Hellen Keller 



\section{Resumo}

NASCIMENTO, L.A.P., Análise Dinâmica de Modos de Propagação Sonora e Projeto de Instrumentação Expandida para Tubo de Impedância. Dissertação de Mestrado- Escola de Engenharia de São Carlos, Universidade de São Paulo, São Carlos, 2018.

Aplicações para o sistema de tubo de impedância são amplamente utilizadas na indústria da engenharia acústica para fins de instrumentação acústica e visualização de campo acústico, principalmente no que tange a estimativa de coeficiente de absorção sonora em regimes de propagação sonora plana. A condição de propagação plana é, na verdade, uma simplificação teórica dos fenômenos acústicos no interior do tubo de impedância. Este trabalho busca estudar esses fenômenos acústicos internos a estruturas tubulares projetadas em uma bancada experimental. São demonstradas as equações que descrevem a operação normal do tubo de impedância segundo as normas internacionais ASTM E1050 e ISO 10534-2, em coordenadas cilíndricas. A partir disso, são identificadas as hipóteses simplificadores para a operação do tubo e são propostos dois sistemas de instrumentação expandida para o tubo de impedância, que contemplam a operação normal do tubo e que ampliam a banda de frequência de observação do campo acústico. Um sistema é caracterizado pela instalação de nove microfones, em grupos de três por seção; outro sistema é caracterizado pela instalação de cinco microfones ao longo do comprimento do cilindro. Inicialmente são testadas hipóteses de construção do sistema, que validam a existência da propagação de modos planos ao longo de uma faixa inicial de frequência e uma frequência de ativação para modos não-normais, superiores aos primeiros. Em seguida, a instrumentação expandida dos tubos é utilizada para estimar a localização de modos não-normais, em comparação com resultados obtidos de uma análise modal acústica feita no sistema. Esse método é capaz de identificar 10 das 14 primeiras frequências modais do sistema, acima da frequência de ativação azimutal. Também são discutidas limitações e implicações da instrumentação proposta. Por fim, são apontadas técnicas teóricas de expansão da frequência útil de operação do tubo de impedância por aproximação quadrática de combinações de funções de transferência dos pontos de medida, ainda utilizando a instrumentação expandida. Esse método é avaliado pela curva de fator de reflexão para terminações planas e é capaz de atenuar significativamente instabilidades na banda azimutal.

Palavras-chave: acústica; propagação sonora; equações diferenciais; tubo de impedância; instrumentação acústica. 


\begin{abstract}
NASCIMENTO, L.A.P., Dynamic Analysis of Sound Propagation Modes and Extended Instrumentation for Impedance Tubes. Master Thesis - São Carlos School of Engineering, University of São Paulo, São Carlos, 2018.
\end{abstract}

The impedance tube system is largely used in the acoustical engineering industry in order to provide acoustical instrumentation and field acoustics visualization, mostly by means of sound absorption coefficient in the plane-wave propagation frequency band. The plane-wave propagation is a theoretical simplification of the acoustic phenomena that occur inside the impedance tube. This work aims to study these phenomena in a generically tubular structure by designing an experimental workbench. The equations that describe the impedance tube's operation are derived as the international standards ASTM E1050 and ISO 10534-2, using cylindrical coordinates in order to identify its hypothesis. Two impedance tube systems are proposed in order to reproduce the normal operation and to visualize acoustical phenomena above the plane cut-off frequency. The systems differ from each other by the number and the distribution of microphones through their structures. Initially, the plane-wave propagation band is verified and then the azimuthal mode cut-on frequency is identified. It proposes expanded instrumentation methods that estimates azimuthal modes of propagation by comparing them to a modal analysis. This method is able to identify 10 out of the 14 former modal frequencies above the plane-wave cut-off frequency. The method's limitations and implications are also discussed. It discusses mathematical approaches for the expansion of the impedance tube's operation band using mathematical and computational techniques of quadratic approximation. The methods ids evaluated by the reflection factor curves, comparing different arrangement of measurement.

Keywords: acoustics; sound propagation; differential equations; impedance tube; acoustical instrumentation. 


\section{Lista de Símbolos}

\begin{tabular}{|c|c|}
\hline$p$ & Pressão sonora \\
\hline$\rho$ & Densidade do meio fluídico \\
\hline$T$ & Temperatura do meio fluídico \\
\hline$\vec{u}$ & Velocidade de volume da partícula acústica \\
\hline$\mu$ & Viscosidade do meio fluídico \\
\hline$t$ & Tempo \\
\hline$\gamma$ & Coeficiente de expansão adiabática \\
\hline$c$ & Velocidade do som \\
\hline$\Psi$ & Função de onda \\
\hline$\omega$ & Frequência angular \\
\hline$x$ & Coordenada longitudinal \\
\hline$\theta$ & Coordenada azimutal \\
\hline$r$ & Coordenada radial \\
\hline$k$ & Autovalor longitudinal \\
\hline$m$ & Autovalor azimutal \\
\hline$n$ & Autovalor radial \\
\hline$J_{m}$ & Função de Bessel de $1^{\circ}$ tipo com índice $m$ \\
\hline$Y_{m}$ & Função de Bessel de $2^{\circ}$ tipo com índice $m$ \\
\hline$a$ & Raio interno do sistema \\
\hline$L$ & Comprimento do sistema \\
\hline$P$ & Amplitude de pressão sonora \\
\hline$H_{12}$ & Função de transferência entre os pontos 1 e 2 \\
\hline$R$ & Fator de reflexão \\
\hline$s$ & Distância entre os microfones \\
\hline$\alpha$ & Coeficiente de absorção sonora \\
\hline$Z$ & Impedância acústica \\
\hline
\end{tabular}




\section{Lista de Figuras}

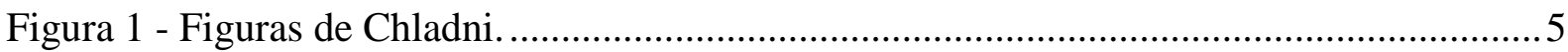

Figura 2 - Sistema de tubo proposto por Kundt............................................................... 7

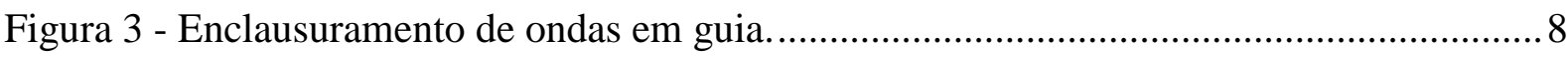

Figura 4 - Sistema de tubo de impedância utilizado em RUAN (2018). .................................

Figura 5 - Visualização simplificada de pressão e deslocamento de partículas em ondas

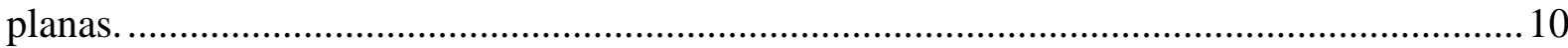

Figura 6 - Visualização de modos de propagação sonora para coordenadas cilíndricas .........20

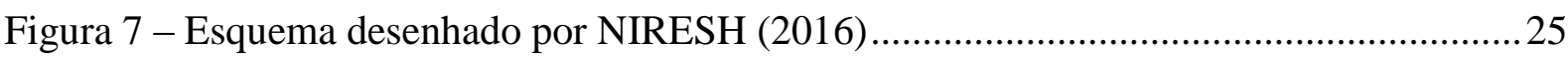

Figura 8 - Sistema clássico de tubo de impedância para o método de função de transferência.

Figura 9 - Ilustração esquemática utilizada no projeto do tubo de impedância.......................28

Figura 10 - Ilustração mostrando as regiões do tubo de impedância que estão em uma mesma fase considerando os modos azimutais.

Figura 11 - Visualização dos pontos de medida em uma mesma seção de tubo com modos azimutais ativados.

Figura 12 - Ilustração da disposição dos microfones instalados........................................... 32

Figura 13 - Ilustração esquemática de M microfones instalados em série em um tubo. ..........34

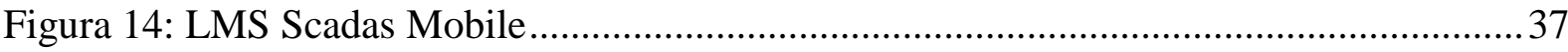

Figura 15 - Alto falante FRS 8-8 utilizado para excitar o sistema. ....................................... 38

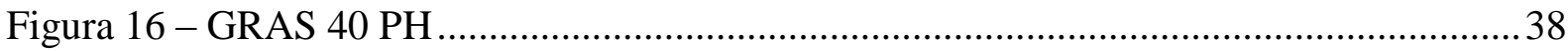

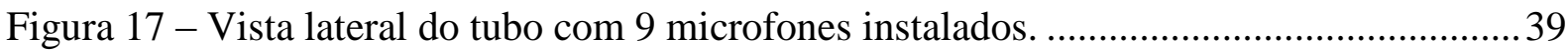

Figura 18 - Vista detalhada da instalação de microfones no tubo com 5 microfones. ............. 39

Figura 19 - Vista detalhada da instalação de microfones no tubo com 9 microfones. ............ 40

Figura 20 - Vista detalhada da instalação dos microfones nos tubos com suas respectivas

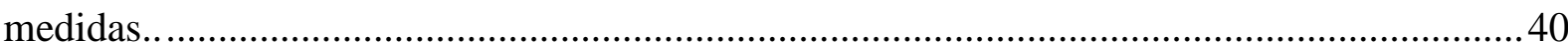

Figura 21 - Montagem do microfone no selim de derivação................................................ 41

Figura 22 - Montagem final do microfone no selim de derivação........................................ 41

Figura 23 - Fotografia do tubo construído com 9 microfones. ............................................... 42

Figura 24 - Fotografia em detalhe do tubo com 5 microfones instalados............................... 42

Figura 25 - Comparação entre curvas de coeficiente de absorção sonora para terminação plana, entre o LMS Scadas e o método utilizado. 
Figura 26 - Comparação das amplitudes de pressão sonora para os microfones instalados em uma mesma seção do tubo.

Figura 27 - Fotografia em detalhe do anteparo para provocar os modos azimutais.

Figura 28 - Comparação entre funções de transferência para entrada de pressão no sistema, com e sem anteparo.

Figura 29 - Visualização de modos normais e azimutais pela análise modal acústica 48

Figura 30 - Visualização de frequências modais azimutais para a seção A. .50

Figura 31 - Visualização de frequências modais azimutais para a seção B. 50

Figura 32 - Visualização de frequências modais azimutais para a seção C.

Figura 33 - Comparação entre curvas de fatores de reflexão para os três arranjos propostos e para a função de transferência entre um par de microfones.

Figura 34 - Detalhe da comparação de fatores de reflexão entre os arranjos propostos com detalhe na faixa plana de propagação sonora.

Figura 35 - Detalhe da comparação de fatores de reflexão entre os arranjos propostos com

detalhe na banda de frequência superior a primeira ativação azimutal. .54

Figura 36 - Funções de Bessel de primeiro tipo, para os 5 primeiros índices inteiros. 63

Figura 37 - Dimensões catalogadas do tubo.

Figura 38 - Dimensões catalogadas do selim de derivação

Figura 39 - Dimensões catalogadas do cap de terminação.

Figura 40 - Dimensões catalogadas da união parafusada.

Figura 41 - Propriedades físico-químicas do PPR Industrial. 68

Figura 43 - Modo 20 identificado pelo LMS Scadas. 69

Figura 44 - Modo 21 identificado pelo LMS Scadas

Figura 45 - Modo 22 identificado pelo LMS Scadas 70

Figura 46 - Modo 23 identificado pelo LMS Scadas. 70

Figura 47 - Modo 24 identificado pelo LMS Scadas 71

Figura 48 - Modo 25 identificado pelo LMS Scadas. .71

Figura 49 - Modo 26 identificado pelo LMS Scadas. .71

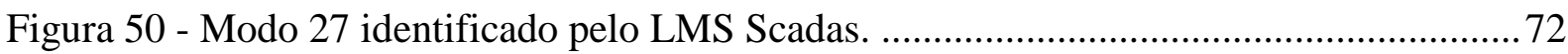

Figura 51 - Modo 28 identificado pelo LMS Scadas. ........................................................... 72

Figura 52 - Modo 29 identificado pelo LMS Scadas. ............................................................ 72

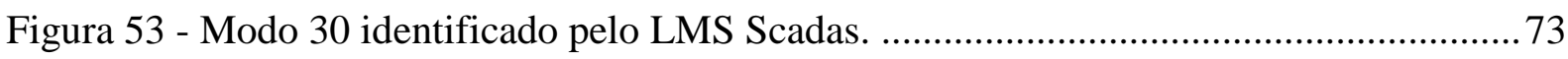

Figura 54 - Modo 31 identificado pelo LMS Scadas. ............................................................ 73 


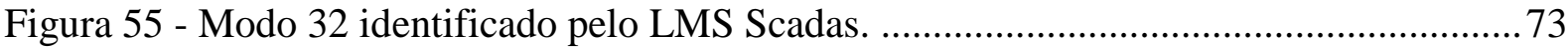




\section{Lista de Tabelas}

Tabela 1 - Comparação das médias quadráticas de coeficientes de absorção sonora nas oitavas

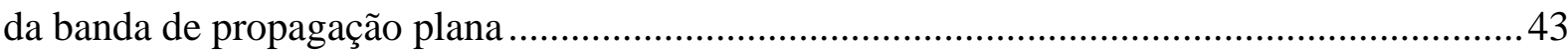

Tabela 2 - Ângulo de fase relativa entre os microfones do arranjo para modos acima do $1^{\circ}$

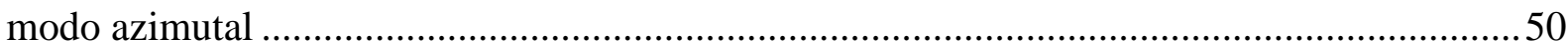

Tabela 3 - Frequências estimadas pelos métodos da soma e pela análise modal 52

Tabela 4 - Comparação de médias quadráticas de fatores de reflexão entre a banda plana e a banda de ativação. 


\section{Sumário}

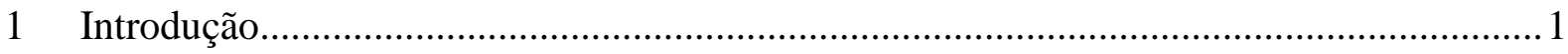

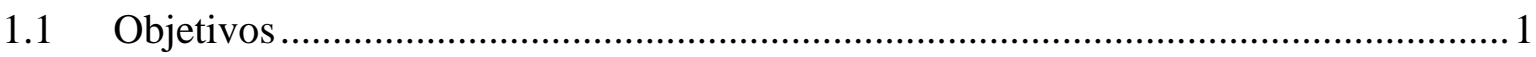

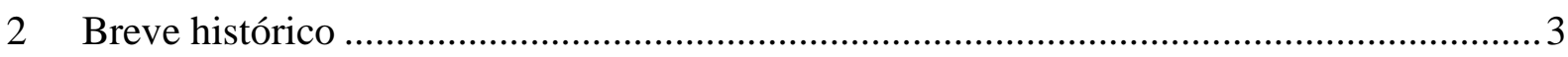

2.1 Vibrações e Acústica ............................................................................................

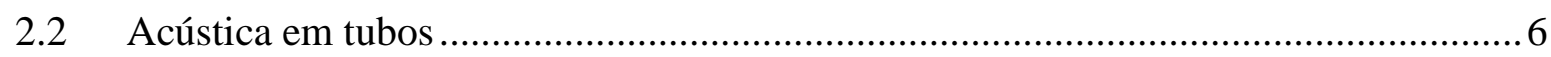

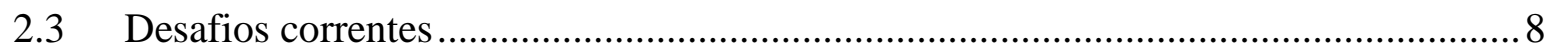

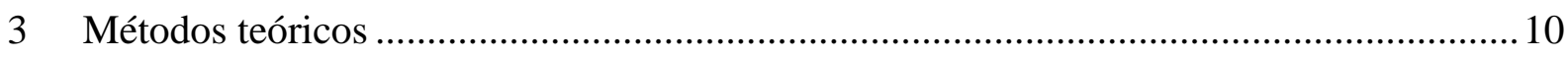

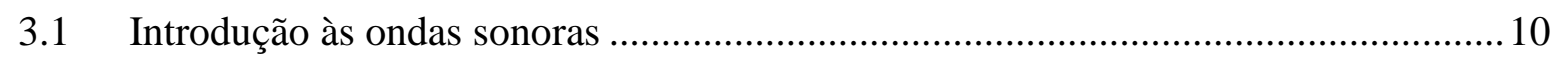

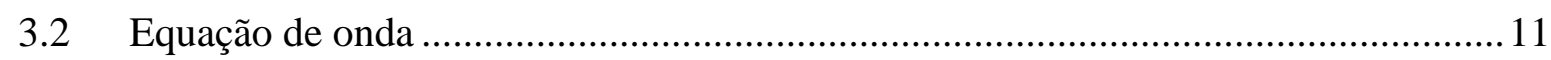

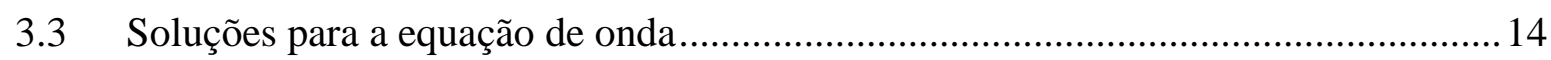

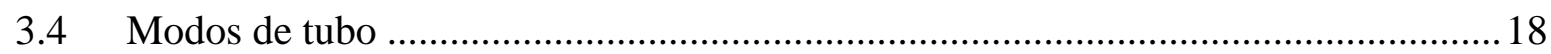

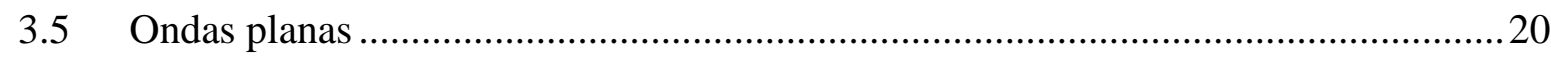

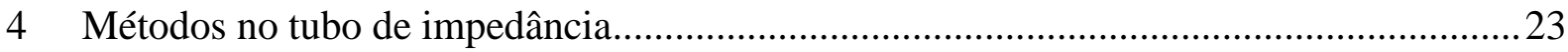

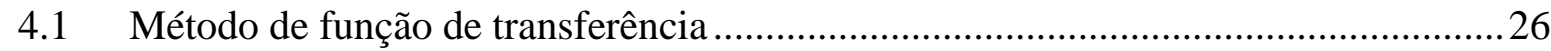

4.2 Identificação nodal do primeiro modo azimutal em tubo de impedância .....................30

4.3 Expansão da faixa útil de frequência para tubo de impedância ......................................34

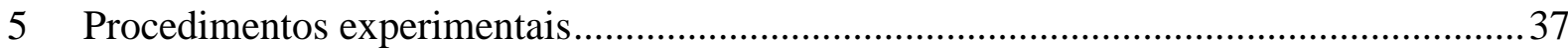

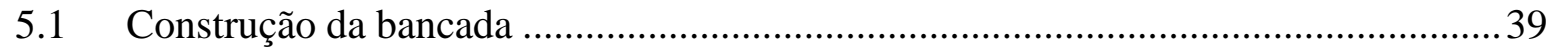

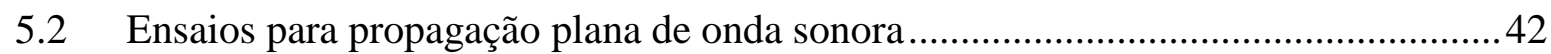

5.3 Identificação de modos de propagação azimutais........................................................ 44

5.4 Ensaios para extensão da frequência útil em tubo de impedância ...............................51

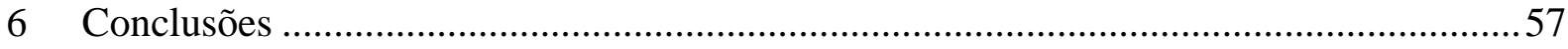

6.1 Trabalhos Futuros .................................................................................. 58

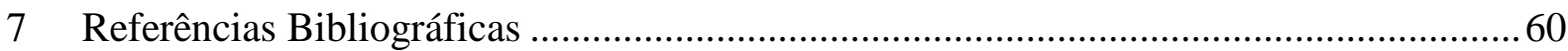




\section{Introdução}

Acústica é a física dos sons (NEPOMUCENO, 1968). Além de ser o estudo de geração, propagação e efeitos das ondas sonoras, a acústica é um tema multidisciplinar pelo fato de lidar, assim como a ótica, com uma função sensorial humana fundamental, no caso, a audição. Por conta disso, a acústica se torna objeto de diferentes áreas do conhecimento humano: desde a Física, para investigação sobre propriedades da matéria, passando pela arquitetura, o conforto acústico, a engenharia e a música, além da medicina e da psicologia (BERANEK, 1990).

Além dos conceitos empíricos de sons, também se pode falar em ultrassons, infrassons, acústica submarina, acústica em sólidos, sons estruturais e mais. A maioria dos casos de uso tecnológico da acústica explora a capacidade de transmissão de informações através das ondas sonoras. Essas informações estão associadas às ondas na energia de propagação, nas frequências de propagação ou até mesmo no formato das ondas (CHAIGNE, 2003).

Dada a importância da propagação sonora, é comum serem construídos sistemas chamados de guias de onda, que enclausuram o fenômeno ondulatório em um espaço delimitado, podendo assim controlar as perdas de energia, controlar o ambiente de propagação mais facilmente e projetar um sistema de instrumentação fixo e versátil.

Em Acústica, um dos mais famosos sistemas de guia de ondas é chamado de tubo de impedância, que enclausura ondas sonoras em uma estrutura de tubo, cilíndrico ou retangular, muito utilizado em turbinas, sistemas de ventilação, exautores e escapamentos automotivos.

Este trabalho tem como motivação principal estudar a propagação sonora em uma estrutura cilíndrica de tubo de impedância; projetar e construir duas versões diferentes de tubo de impedância, com instrumentações distintas, a fim de estudar esses fenômenos ondulatórios de transmissão de energia.

\subsection{Objetivos}

O trabalho teórico e experimental desta dissertação se ergue sobre o objetivo de projetar, construir e verificar um sistema acústico devidamente instrumentado, que seja capaz de suportar diferentes tipos de ensaios acústicos. Esse sistema acústico é inspirado em um sistema de tubo de impedância clássico e, por isso, deve reproduzir ensaios normalmente reproduzidos em tubos de impedância, como determinação de impedâncias acústicas e coeficientes de absorção de materiais. 
Contudo, entende-se que a estrutura e a instrumentação necessária para a construção de um tubo de impedância suscitam outros tipos de ensaio, como ensaios de transmissão acústica, de monitoramento de propagação de ondas, de visualização de modos superiores de onda, entre outros ensaios.

Para esse fim, se faz necessário um estudo teórico sobre a propagação de ondas sonoras em estruturas tubulares. Busca-se modelar analítica e numericamente os fenômenos ondulatórios enclausurados em tubos sem escoamento de fluidos. Esses modelos geram resultados parciais para os fenômenos e devem ser confrontados com os resultados experimentais, observados no sistema real.

A fim de atingirem-se estes objetivos, algumas metas intermediárias são necessárias, entre outras:

a) Estudar o estado da técnica de instrumentação e análise de fenômenos acústico em estruturas de tubo de impedância;

b) Projetar uma bancada experimental para verificar os métodos do estado da técnica;

c) Avaliar a consistência dos resultados observados na bancada para a propagação sonora em frentes planas de onda;

Desta forma, pretende-se alcançar como resultado desta pesquisa, a extensão da técnica de medida de frentes planas de onda para modos de propagação azimutais, acima da frequência de corte de propagação plana. A construção deste aparato, juntamente com a validação experimental desta técnica, representa um legado deste trabalho para futuras investigações deste grupo de pesquisa. 


\section{Breve histórico}

Neste capítulo, é feita uma breve descrição do que tem sido o desafio de se estudar os fenômenos acústico nos últimos séculos. Incialmente, a história dos fenômenos vibroacústicos desde a Grécia Antiga, quando os primeiros termos relacionados à Acústicas foram observados e forjados, até a expressão desses fenômenos em termos matemáticos, ainda no século XVIII, passando pela utilização do cálculo para descreves esses fenômenos até técnicas de visualização de ondas.

Em seguida, dá-se um destaque para a história dos estudos em Acústica de tubos, que contextualiza historicamente este trabalho. Descreve-se também as primeiras utilizações da estrutura de guia de ondas. Também é feita uma breve descrição dos desafios futuros que cientistas e pesquisadores do mundo inteiro vêm enfrentando para entender cada vez melhor como os fenômenos sonoros e como é possível desenvolver tecnologias que elevem cada vez mais o estado da técnica.

A contextualização histórica é feita baseada nos textos de LINDSAY (1966) e LINDSAY (1973).

\subsection{Vibrações e Acústica}

É aceito que os primeiros estudos que relacionam vibrações e acústica datam do século VI a.C., na Grécia, e são atribuídos a Pitágoras (570 a.C. - 495 a.C.), que relacionou pela primeira vez as frequências audíveis causadas por cordas vibrantes. Antes mesmo da matemática como se conhece hoje, assim como da física clássica, os gregos conseguiram observar que existem relações entre a estrutura vibrante, como comprimento da corda, e o som que se observa. Assim foram concebidos conceitos de frequência, harmonia, oitava, entre outros; conceitos esses que são amplamente utilizados ainda hoje.

Mesmo os primeiros instrumentos musicais sendo os de percussão e os que usam de estruturas tubulares, como as flautas paleolíticas mostrada em DIEDRICH (2007), os primeiros desenvolvimentos científicos da vibroacústica se deram a partir de cordas vibrantes.

Grandes nomes da Ciência contribuíram para o que hoje se chama Acústica. Galileu Galilei (1564 - 1642) discutiu a influência do comprimento, densidade e tensão em cordas vibrantes. Também observou que frequências múltiplas inteiras de uma frequência mais baixa soavam, conjuntamente, agradáveis aos ouvidos. 
Joseph Sauveur (1653 - 1716), considerado um dos "pais" da acústica, sugeriu essa terminologia pela primeira vez e contribuiu para sua epistemologia, procurando entender até onde a ciência da época poderia compreender os fenômenos sonoros e tentando determinar os limites da ciência acústica da arte musical. Sauveur também observou que cordas vibrantes apresentavam pontos estáticos, aos quais chamou "nós", e pontos de vibração máxima, os "antinós".

Enquanto alguns cientistas se preocupavam com a natureza e formação das ondas sonoras, outros se preocuparam com a sua propagação. É sabido que empiricamente não se verifica o movimento do ar enquanto se escuta um som, por isso, inicialmente acreditava-se que as fontes sonoras emitiam partículas que eram sensíveis pelos ouvidos. Robert Boyle (1627 1691) extraiu o ar de um vaso de vidro onde havia um despertador. Assim, conseguiu demonstrar experimentalmente que o som carece de um meio para se propagar.

Nos anos seguintes, a comunidade científica se lançou ao desafio de calcular com qual velocidade o som se propaga no ar, chegando a resultados satisfatórios bastante cedo. A maioria dos ensaios consistia em observar a diferença da velocidade entre o som e a luz, que já havia sido estimada em 1676, por Rømer (1644 - 1710). Esses ensaios calculavam a diferença de percepção entre o som e a luz emitidos pelo disparo de canhões ou outras armas de fogo.

Nas décadas seguintes, nomes como Taylor (1685 - 1731), Bernoulli (1700 - 1782), d'Alembert (1717 - 1783), Euler (1707 - 1783) desenvolveram as ferramentas matemáticas de equações diferenciais ordinárias e parciais, o que possibilitou um refinamento importante nas teorias de sistemas dinâmicos, como a propagação de ondas sonoras. Essas ferramentas ajudaram a entender fenômenos como a presença de diferentes harmônicos em cordas vibrantes. É atribuída a Bernoulli a ideia de que qualquer vibração poderia ser expressa como a superposição de modos mais simples de vibrar (DARRIGOL, 2007). Essa ideia é considerada o embrião para o desenvolvimento das séries de Fourier (1768 - 1830), que são amplamente utilizadas até hoje na geração e processamento de dados analógicos e digitais, especialmente em acústica.

Os desenvolvimentos matemáticos de vibrações extrapolaram a complexidade do estudo das cordas vibrantes e foram utilizados por Euler e Bernoulli, juntamente com a lei de elasticidade de Robert Hooke (1635 - 1703), para estudar o comportamento vibratório de vigas, desenvolvendo o que se conhece hoje pelo modelo de viga de Euler-Bernoulli. 
No início do século XIX, Ernst Chladni (1756 - 1824) publicou um tratado (CHLADNI, 2015) observando a presença de linhas nodais em pratos vibrantes, que seriam a equivalência bidimensional dos nós em cordas vibrantes. Considerado também um dos pais da acústica moderna, Chladni foi pioneiro em fazer observações de vibrações utilizando areia fina, a fim de visualizar essas linhas nodais, algumas ilustradas na Figura 1. Esse raciocínio é a base sobre a qual August Kundt (1839 - 1894) desenvolveu seu Tubo de Kundt, alguns anos mais tarde, e que está presente no âmago deste trabalho.

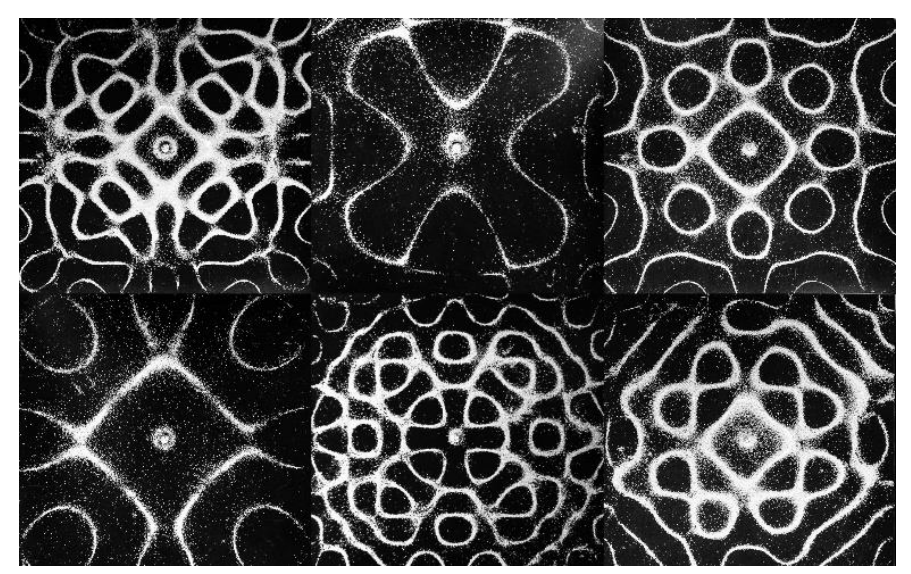

Figura 1 - Figuras de Chladni. Fonte: http://www.luteria.ufpr.br/portal/wp-content/uploads/2013/08/chladni.pdf (Acessado em 24/09/2018)

Na mesma época, foram realizados os primeiros experimentos de propagação sonora em sólidos e em líquidos, onde foram observadas velocidades de propagação maiores em líquidos e maiores ainda em sólidos, cerca de 10 vezes mais, segundo os ensaios de Biot (1774 - 1862).

Ainda no final do século XVIII, Lagrange (1736 - 1813), propôs um modelo para o ar, segundo a teoria cinética dos gases. Segundo esse modelo, baseado na hipótese isotérmica, poderia se calcular a velocidade de propagação sonora no ar, mas não obteve bons resultados. Em 1816, Laplace (1749 - 1827) propôs a hipótese adiabática para a propagação sonora, que obteve resultados mais verossímeis, além de demonstrar matematicamente como a velocidade de propagação depende da temperatura ambiente.

A acústica, como ciência, amadureceu drasticamente no século XIX. Cientistas como Helmholtz (1821 - 1894), Lord Rayleigh (1842 - 1919) e Stokes (1819 - 1903) fizeram contribuições fundamentais para o aprimoramento teórico e experimental dessa ciência. A aplicação desse aprimoramento em técnica foi garantida por nomes como Alexander Graham 
Bell (1847 - 1922) e Thomas Edison (1847 - 1931). Bell foi considerado por muitos anos o inventor do aparelho de telefone e dedicou boa parte do seu trabalho à educação de pessoas com deficiências auditivas. Fundou um dos maiores laboratórios de telefonia do mundo, Bell Telephone Laboratories, que possui no portfólio invenções como o fax, a televisão, as células fotovoltaicas, o LED entre outras tecnologias. Edison inventou o ditafone, o mimeógrafo e o fonógrafo. Demonstrou que a voz humana poderia ser gravada e, por isso, foi nomeado membro honorário da ASA, Acoustical Society of America, em seu ano de fundação, 1929.

O século XX aprimorou a técnica e as tecnologias voltadas ao som. Nesse século viu-se o amadurecimento do capitalismo e, com ele, o amadurecimento da indústria cultural e científica; demandou-se, assim, uma tecnologia de comunicação de alta fidelidade e a nível global, seja para fins de guerra ou de entretenimento.

Nesse século, foram desenvolvidas as áreas de acústica arquitetônica, com Wallace Sabine (1868 - 1919), Vern Knudsen (1893 - 1974), Leo Beranek (1914 - 2016) e outros; o ultrassom, com Francis Galton (1922 - 1911); o sonar, com Paul Langevin (1972 - 1946); a aeroacústica, com James Lighthill (1924 - 1998); a termoacústica, com Nicolas Rott (1917 2006); entre outras áreas, sendo cada uma um campo vasto de pesquisa e tecnologia.

Além disso, foram somente nos últimos 100 anos que foram inventadas tecnologias como o do microfone condensador, em 1917, por Edward Wente (1889 - 1972); e dos princípios básicos do alto falante eletrodinâmico, como se conhece hoje, em 1925, por Chester Rice (1988 - 1951) e Edward Kellogg (1882 - 1960). Na década de 1940 foi popularizado o uso das caixas acústicas seladas ou com refletores de graves, contudo, somente em 1951 os parâmetros eletromecânicos de alto falantes, microfones e caixas acústicas foram apropriadamente estabelecidos com os trabalhos de Neville Thiele (1920 - 2012) e Richard Small (1945 - 2014), responsáveis pelos parâmetros Thiele-Small, ainda amplamente utilizados.

Vale observar que boa parte da tecnologia acústica desenvolvida nos últimos 100 anos pouco mudou, a não ser pela inserção de novos materiais, métodos de fabricação e processamento de dados. Sistemas de captação e reprodução de som permanecem essencialmente os mesmo há décadas.

\subsection{Acústica em tubos}

O comportamento acústico em estruturas tubulares vem sendo estudado desde a segunda metade do século XIX. Os primeiros desenvolvimentos teóricos são atribuídos a Poisson (1781 
-1840), que conseguiu derivar expressões de propagação em tubos e também estudou casos de mudança abrupta de seção transversal, assim como o de reflexão normal entre dois fluidos diferentes.

O primeiro desenvolvimento experimental foi documentado por August Kundt (18391894), na Alemanha (KUNDT, 1866). Um setup experimental foi descrito para visualizar a formação de ondas estacionárias em um tubo preenchido de materiais como serragem. Algumas formas regulares foram observadas nos materiais e, a partir delas, demonstrou-se possível de calcular grandezas como a velocidade de propagação do som. Essas formas regulares, podem ser entendidas como a equivalência tridimensional dos pontos nodais em cordas vibrantes. Devido a esse desenvolvimento, também se conhece o tubo de impedância como tubo de Kundt, embora se observe diferenças significativas em seus usos. Uma visualização do sistema proposto por Kundt é ilustrado na Figura 2.

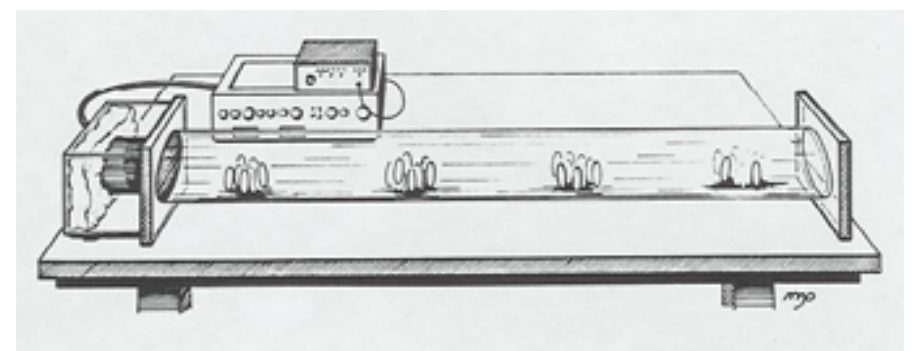

Figura 2 - Sistema de tubo proposto por Kundt. Fonte: demoweb.physics.ucla.edu/content/100-kundts-tube (Acessado em 24/09/2018)

Alguns anos depois, Rayleigh dedicou um capítulo inteiro da sua célebre série de livros (RAYLEIGH, 1969) à fenomenologia das vibrações em tubos, tentando sumarizar os resultados obtidos nos anos anteriores. O desenvolvimento parte dos experimentos de Kundt a fim de desenvolver matematicamente a propagação de vibrações unidimensionais em tubos. Essa publicação foi uma das primeiras que mostra o desenvolvimento matemático da equação de onda, mostrando que o campo acústico plano é composto por ondas progressivas e regressivas, tal qual D’Alembert sugeria um século antes. Nessa publicação também são escrutinados casos de tubos curvos, com bifurcações etc. Esses desenvolvimentos matemáticos se tornaram umas das principais bases teóricas sobre as quais a acústica se ergueu no século XX e XXI.

Tubos e dutos são elementos frequentes em plantas e processos de engenharia, para geração de potência, transporte de gás, óleo e de água, assim como redes de ventilação. Esses elementos são projetados de modo que a energia sonora se propague segundo uma rota planejada. FAHY (2005) pontua que a grande vantagem da estrutura tubular, seja ela circular 
ou não, é que a propagação de energia sonora é guiada em uma única direção, de modo a ter um melhor controle sobre sons gerado e, principalmente, ruídos. Assim, o estudo, análise e modelagem da propagação sonora em estruturas tubulares de fazem de grande importância para a engenharia acústica.

As ondas sonoras que se propagam através de um tubo são continuamente refletidas pelas paredes do tubo, o que garante que essa energia flua em uma única direção (não necessariamente em um único sentido), por isso essa estrutura também é conhecida como guia de ondas. Uma visualização do fenômeno é mostrada na Figura 3. Além disso, esse confinamento garante uma diminuição do grau de atenuação da energia acústica quando comparada à propagação em campo livre. Na guia de onda, essa atenuação ocorre principalmente por efeitos de camada limite e pela existência de não-uniformidades na estrutura, como válvulas, difusores ou outros acoplamentos.

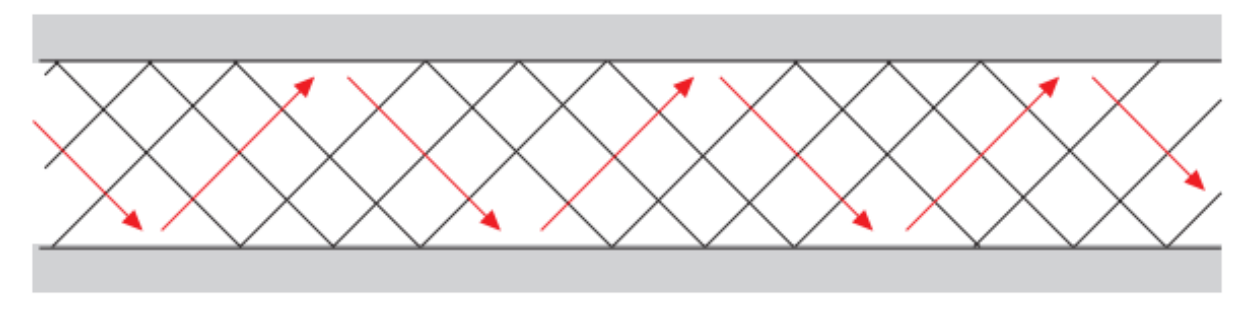

Figura 3 - Enclausuramento de ondas em guia. Fonte:

http://www.flowairs.eu/_resources/Documents/Training\%2520october/Cours/Rientra_Duct_FlowAirS2012slides .pdf (Acessado em: 24/09/2018)

\subsection{Desafios correntes}

Nos últimos anos, com o desenvolvimento de técnicas computacionais é possível que se visualize o campo acústico que se propaga em uma guia de ondas em mais detalhes. As medidas de pressão sonora feitas em sistemas cilíndricos fechados, ou parcialmente fechados, estão sempre sujeitas a erros. Ainda é um desafio levar em consideração uma quantidade de variáveis no problema de construção de um modelo de propagação. Muitas vezes, são desconsiderados efeitos de dispersão, de posicionamento e dimensão dos microfones, rugosidade e assimetrias nas superfícies da guia, entre outros. Para realizar ensaios controlados, tem se usado sistemas com redes neurais para ajustar esse tipo de erro (NIRESH, 2016).

Ainda disso, tem sido explorada a utilização de instrumentos menores e mais precisos para tentar minimizar a propagação desses erros. Alguns trabalhos recentes relacionam diferentes tipos de medida de pressão do campo acústico para calcular resultados mais precisos. 
Seja explorando variáveis adicionais do sistema ou minimizando erros aleatórios e sistemáticos (RUAN, 2018). Esses estudos buscam, assim como neste trabalho, explorar analiticamente o modelo de propagação de ondas mecânicas e serão mais detalhados nos próximos capítulos.

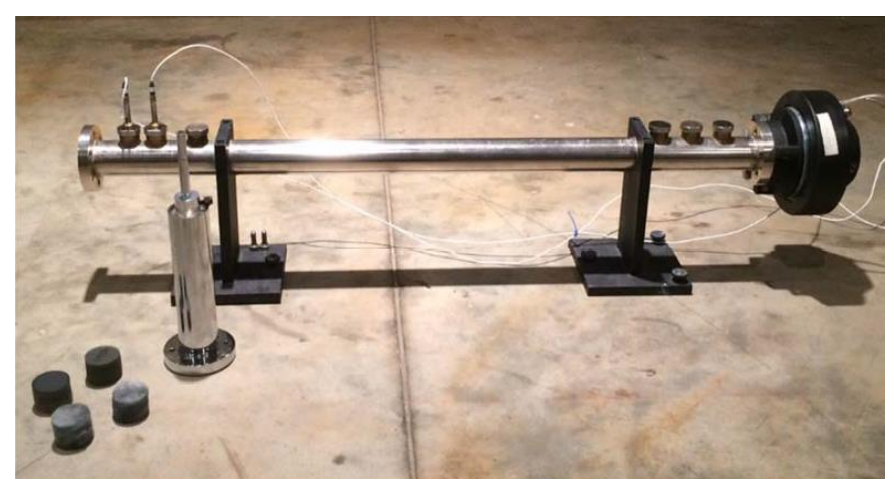

Figura 4 - Sistema de tubo de impedância utilizado em RUAN (2018).

Com o crescimento de grandes centros urbanos, muito tem se discutido acerca do conforto acústico dos ambientes. Tem-se buscado conhecer e utilizar em construção civil materiais que tenham características acústica e calculáveis. Estudos mais recentes têm observado o comportamento acústicos de materiais não-convencionais, muitas vezes buscando a reutilização, a sustentabilidade e a redução de custos (FOROUHARMAJD, 2018; (GOMEZ ESCOBAR e MADERUELO-SANZ, 2017). Esses estudos também serão melhor detalhados afrente. 


\section{Métodos teóricos}

Neste capítulo, será feito um apanhado geral acerca dos métodos e conceitos utilizados para o desenvolvimento deste trabalho. Aqui, são feitas as introduções físicas e matemática para a definição do problema de propagação de onda em um meio contínuo unidimensional.

Inicialmente é feita a demonstração da equação de onda para um sistema de coordenadas genérico a partir da equação de continuidade de gases perfeitos, a equação de Euler e a equação de Navier-Stokes. Com a equação de onda generalizada, são estudados seus resultados para um sistema se coordenada cilíndrica, de onde são derivadas as expressões para o tubo de impedância trabalhado nos capítulos seguintes.

\subsection{Introdução às ondas sonoras}

Ondas sonoras são distúrbios oscilatórios que se propagam em um meio elástico. As ondas consistem no movimento das moléculas do fluido na direção de propagação, comprimindo-se uma contra as outras ou afastando-se. Essa movimentação faz parte de uma cadeia de efeitos no fluido que inclui mudanças nos valores de pressão, densidade e temperatura locais no meio. Em acústica, essas variáveis do campo são medidas para cada partícula de fluido. Esse termo é adotado em dinâmica dos fluidos para descrever o estado cinemático de um fluido. FAHY (2005) explica que essa é uma entidade fictícia que permite expressar uma média dos vetores de posição, velocidade e aceleração das moléculas do fluido em uma região pequena ao redor do ponto de interesse.

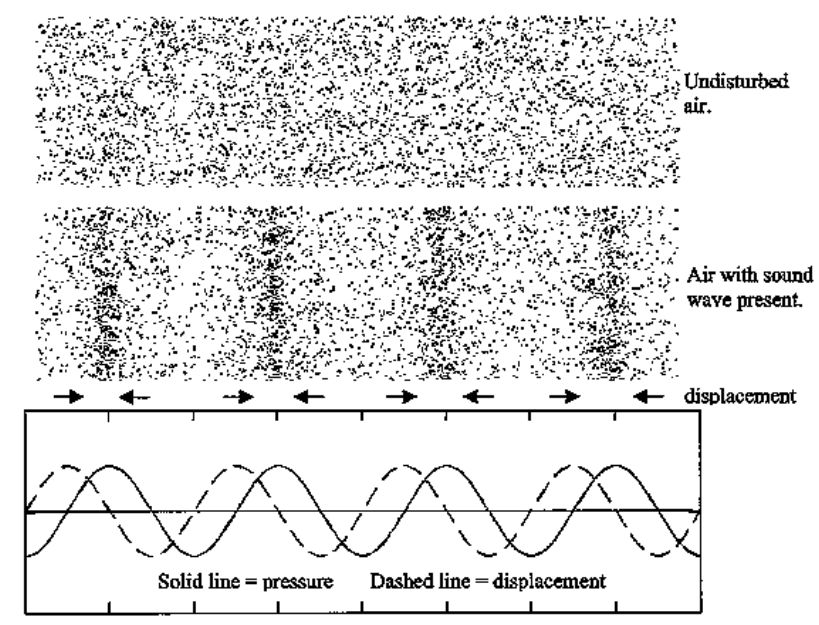

Figura 5 - Visualização simplificada de pressão e deslocamento de partículas em ondas planas. Fonte: http://www.colorado.edu (Acessado em 01/05/2017) 
A pressão sonora é a diferença instantânea entre o valor de pressão total no tempo e o valor estático de pressão, essa diferença significa o som que se escuta. Na maioria dos casos, essa diferença de pressão corresponde a valores muito pequenos à percepção visual e tátil humana. Em um ambiente comum, a $20^{\circ} \mathrm{C}$ e a $101,3 \mathrm{kPa}$, a densidade do ar é de $1,204 \mathrm{~kg} / \mathrm{m}^{3}$. Nesse ambiente, a variação de pressão entre partículas fluidas causada por um campo sonoro correspondente a $120 \mathrm{~dB}$, valor próximo ao limiar da dor, é cerca de $2 \cdot 10^{-4} \mathrm{~Pa}$. Para esse mesmo campo, a diferença de temperatura é menor que $0,02^{\circ} \mathrm{C}$ e a velocidade da partícula fluida chega a $50 \mathrm{~mm} / \mathrm{s}$.

A fim de deixar o problema de propagação matematicamente palpável, a próxima seção desenvolve as equações de estado de gases perfeitos para derivar uma função de pressão sonora no tempo e no espaço.

\subsection{Equação de onda}

A dedução matemática para a equação de onda se baseia em três hipóteses básicas para meios elásticos. Admite-se que:

a) a massa é conservada dentro de um volume de controle diferencial;

b) o momento das forças agentes é conservado, ou seja, a força longitudinal causada pela diferença de pressão em um volume de controle diferencial é equilibrada pela inércia do meio;

c) o fenômeno energético é adiabático, ou seja, que não há troca de energia térmica.

Além disso, neste estudo, considera-se um meio fluídico estacionário, ou seja, sem escoamento, que é caracterizado por uma pressão estática de equilíbrio $p_{0}$, assim como uma densidade de equilíbrio $\rho_{0}$. Nesse caso, as variáveis associadas ao campo acústico são pequenas variações ao redor desses valores de equilíbrio. Nota-se que essas variáveis são funções do tempo e do espaço.

$$
\begin{aligned}
& p_{\text {total }}=p_{0}+p \\
& \rho_{\text {total }}=\rho_{0}+\rho \\
& T_{\text {total }}=T_{0}+T
\end{aligned}
$$

Nas Equações (3.1) a (3.3), as variáveis com subscrito 0 representam o valor central em torno do qual flutuam as grandezas do campo acústico. 
O objetivo central desse modelo é representar como as variações acontecem espacialmente e temporalmente. Para isso, recorre-se a algumas equações da mecânica dos fluidos. Em primeiro lugar, seja a equação de conservação de massa para um volume de controle diferencial de fluido, definida por:

$$
\frac{\partial \rho}{\partial t}+\nabla \cdot(\rho \cdot \vec{u})=q
$$

onde $\vec{u}$ representa o vetor velocidade do volume de controle e $q$ representa uma entrada do sistema.

Considerando também o meio de propagação como um meio contínuo, isto é, que não haja descontinuidade nas suas propriedades, como bolhas ou vazios, e que as variáveis de interesse são diferenciáveis no tempo, a equação de Navier-Stokes, sobre o escoamento de fluidos é:

$$
\rho\left(\frac{\partial u}{\partial t}+u \cdot \nabla u\right)=-\nabla p+\mu\left(\nabla^{2} u+\frac{1}{3} \nabla \cdot(\nabla \cdot u)\right)+\rho \cdot f+\rho \cdot q \cdot u
$$

onde $f$ é uma parcela de força externa no sistema e $\mu$ a viscosidade do fluido. Aqui, negligencia-se o termo de força externa e as parcelas que contém a viscosidade do fluido. Para a equação de continuidade, também se negligencia o termo de entrada. Assim, obtém-se as equações (3.6) e (3.7):

$$
\begin{gathered}
\frac{\partial \rho}{\partial t}+\nabla \cdot(\rho \cdot u)=0 \\
\rho\left(\frac{\partial u}{\partial t}+u \cdot \nabla u\right)=-\nabla p
\end{gathered}
$$

De modo a obter uma única equação a partir das Equações (3.6) e (3.7), opera-se o divergente de (3.7):

$$
\begin{gathered}
\nabla \cdot\left(\rho\left(\frac{\partial u}{\partial t}+u \cdot \nabla u\right)\right)=-\nabla^{2} p \\
\nabla \cdot\left(\frac{\partial}{\partial t}(\rho u)-u \frac{\partial \rho}{\partial t}\right)+\nabla \cdot \rho(u \cdot \nabla u)=-\nabla^{2} p
\end{gathered}
$$

Ainda com o mesmo propósito, diferencia-se a Equação (3.6) em relação ao tempo: 


$$
\frac{\partial^{2} \rho}{\partial t^{2}}+\frac{\partial}{\partial t} \nabla \cdot(\rho u)=0
$$

Substituindo um resultado no outro, obtém-se uma única equação, seja:

$$
\frac{\partial^{2} \rho}{\partial t^{2}}-\nabla^{2} p=-\nabla \cdot\left(u \frac{\partial \rho}{\partial t}\right)+\nabla \cdot \rho(u \cdot \nabla u)
$$

Antes de prosseguir, é importante que se observe que essa equação busca modelar a situação em que há um escoamento presente no meio, representado pela variável de velocidade, ao mesmo tempo, a viscosidade do meio, as forças e entradas externas são negligenciadas. Dito isto, substitui-se as equações de (3.1) a (3.3), na equação (3.11), obtendo:

$$
\frac{\partial^{2} \rho_{0}}{\partial t^{2}}+\frac{\partial^{2} \rho}{\partial t^{2}}-\nabla^{2} p_{0}-\nabla^{2} p=-\nabla \cdot\left(u \frac{\partial \rho_{0}}{\partial t}+u \frac{\partial \rho}{\partial t}\right)+\nabla \cdot\left(\left(\rho_{0}+\rho\right)(u \cdot \nabla u)\right)
$$

Observando que as parcelas constituídas da diferenciação dos valores centrais das variáveis $p_{0}$ e $\rho_{0}$ no tempo são nulas. Pode-se simplificar e expandir a equação, negligenciando também os termos em segunda ordem, obtendo-se:

$$
\frac{\partial^{2} \rho}{\partial t^{2}}-\nabla^{2} p_{0}-\nabla^{2} p=0
$$

A simplificação dos termos em segunda ordem é dada pelo fato de que a variação de pressão e velocidade do fluido é muito pequena em relação aos termos de estado permanente. Isto é, a pressão sonora é uma pequena perturbação em um estado permanente do meio de propagação.

Admitindo também que o termo médio de pressão respeita, no mínimo, a equação de Laplace, isto é, que seu valor médio seja igual a pressão manométrica medida em qualquer direção do sistema de coordenadas adotado, ou que varie linearmente de acordo com cada um deles, obtém-se:

$$
\nabla^{2} p_{0}=0
$$

Aqui, deve-se considerar também que as expansões e contrações no volume de controle acontecem de tal modo rápido que não há tempo suficiente para que haja troca de energia térmica com o meio. Chama-se adiabático o caso em que há variação de pressão, densidade e temperatura de um gás, mas não trocas de calor pela superfície de controle. Para um processo adiabático, sabe-se: 


$$
p=\left(\frac{\gamma p_{0}}{\rho_{0}}\right) \rho
$$

Substituindo na Equação (3.13), encontramos a equação de onda, onde c é relacionado a velocidade de propagação da onda no meio.

$$
\begin{gathered}
\left(\frac{\gamma p_{0}}{\rho_{0}}\right) \nabla^{2} p=\frac{\partial^{2} p}{\partial t^{2}} \\
\nabla^{2} p=\frac{1}{c^{2}} \frac{\partial^{2} p}{\partial t^{2}}
\end{gathered}
$$

A Equação (3.17) tem a mesma forma das equações de propagação de ondas transversais em cordas, ondas longitudinais em barras, ondas transversais em discos e em pratos, como se pode observar amplamente na literatura (SETO, 1971; MORSE, 1948; BERANEK, 1990); assim, boa parte das propriedades e dos cálculos observados nesses casos mais simples podem ser generalizados para se entender o comportamento dinâmico das ondas sonoras em muitas situações.

É importante também que se observe que, diferentemente da demonstração clássica realizada em MORSE (1948), aqui não foi levado em consideração nenhum sistema de coordenadas generalizado. Em geral, essa demonstração é feita utilizando o sistema de coordenadas retangulares, o que não é o caso deste trabalho, onde será utilizado o sistema de coordenadas cilíndricas, embora haja como intercambiar esses sistemas de coordenadas facilmente.

\subsection{Soluções para a equação de onda}

Para entender como a equação de onda generalizada se comporta, considere um tubo circular de raio constante a e comprimento $L$. Tomando-se o sistema de coordenadas cilíndricas $\{x, r, \theta\}$, onde $x$ é a coordenada longitudinal ao tubo, $r$ a coordenada radial de cada superfície perpendicular ao eixo e $\theta$ a coordenada azimutal. Um campo acústico que se propaga no interior desse tubo é governado pela Equação (3.18).

$$
\nabla^{2} p=\frac{1}{c^{2}} \frac{\partial^{2} p}{\partial t^{2}}
$$

Pelas transformadas de Fourier, sabe-se possível representar uma função como uma soma de funções harmônicas. Por isso, sem perda de generalidade, seja a função $p$ uma função 
harmônica do tipo $p=p(x, r, \theta) e^{i \omega t}=\Psi e^{i \omega t}$, o que significa transformar a Equação (3.18) em uma equação de Helmholtz.

$$
\begin{gathered}
\nabla^{2}\left(\Psi e^{i \omega t}\right)=\frac{1}{c^{2}} \frac{\partial^{2}}{\partial t^{2}}\left(\Psi e^{i \omega t}\right) \\
\nabla^{2} \Psi+\left(\frac{\omega}{c}\right)^{2} \Psi=0
\end{gathered}
$$

Onde a função de onda é do tipo $\Psi=\Psi(x, r, \theta)$. Além disso, seja conhecida a função de onda para os pontos de uma coordenada $x=x_{0}$ do tubo e para os pontos que contenham a coordenada $r=a$, na parede do tubo. Essas condições descrevem um problema de Dirichlet.

Para resolver esse problema, seja que a função $\Psi$ se expresse em termos de variáveis separadas, ou seja, $\Psi=\Psi(x, r, \theta)=X(x) \cdot R(r) \cdot \Theta(\theta)$. Substituindo na Equação (3.20), temse:

$$
\frac{1}{X} \frac{\partial^{2} X}{\partial x^{2}}+\frac{1}{R}\left(\frac{\partial^{2} R}{\partial r^{2}}+\frac{1}{r} \frac{\partial R}{\partial r}\right)+\frac{1}{r^{2}} \frac{1}{\Theta} \frac{\partial^{2} \Theta}{\partial \theta^{2}}+\left(\frac{\omega}{c}\right)^{2}=0
$$

Com o mesmo argumento de Fourier acima, sejam também as funções $X(x)$ e $\Theta(\theta)$ representadas como funções harmônicas em suas coordenadas, de modo que:

$$
\begin{aligned}
& \frac{1}{X} \frac{\partial^{2} X}{\partial x^{2}}=-k^{2} \\
& \frac{1}{\Theta} \frac{\partial^{2} \Theta}{\partial \theta^{2}}=m^{2}
\end{aligned}
$$

Substituindo na Equação (3.21):

$$
\begin{gathered}
-k^{2}+\frac{1}{R}\left(\frac{\partial^{2} R}{\partial r^{2}}+\frac{1}{r} \frac{\partial R}{\partial r}\right)+\frac{m^{2}}{r^{2}}+\left(\frac{\omega}{c}\right)^{2}=0 \\
r^{2} \frac{\partial^{2} R}{\partial r^{2}}+r \frac{\partial R}{\partial r}+\left(\mathrm{M}^{2} r^{2}-m^{2}\right) R=0
\end{gathered}
$$

onde $\mathrm{M}^{2}=\left(\frac{\omega}{c}\right)^{2}-k^{2}$

Substituindo a variável adimensional $\hat{r}=\mathrm{Mr}$ na Equação (3.25), obtém-se: 


$$
\hat{r}^{2} \frac{\partial^{2} R}{\partial \hat{r}^{2}}+\hat{r} \frac{\partial R}{\partial \hat{r}}+\left(\hat{r}^{2}-m^{2}\right) R=0
$$

A Equação (3.26) é reconhecida como equação de Bessel, e tem como solução a combinação linear das funções de Bessel de primeiro e segundo tipo, com índice $m$. O Anexo A traz uma descrição mais detalhada sobre as funções de Bessel.

$$
R_{m}(r)=A J_{m}(\mathrm{Mr})+B Y_{m}(\mathrm{Mr} r)
$$

Para garantir que a função $R_{m}(r)$ seja contínua para $r=0$, isto é, no centro do tubo, deve-se ter $B=0$.

Ainda no problema de Dirichlet, deve-se levar em consideração que se conhece a função para as condições de contorno do problema. Aqui, considera-se que o tubo possui paredes internas rígidas. Essa condição garante que:

$$
\begin{aligned}
& \left.\frac{\partial \Psi(x, r, \theta)}{\partial r}\right|_{r=a}=0 \\
& \left.\frac{\partial \Psi(x, r, \theta)}{\partial x}\right|_{x=0, L}=0
\end{aligned}
$$

Combinando a função da Equação (3.25) e a condição de fronteira da Equação (3.28), chega-se à seguinte condição de contorno para o tubo de paredes rígidas:

$$
J_{m}^{\prime}(\mathrm{M} a)=0
$$

As Equação (3.25) e (3.28) compõem um problema de Sturm-Liouville, cujas soluções são uma sequência conhecida. As derivadas da função de Bessel de ordem m possui infinitos zeros, cuja sequência de abcissas denotamos por uma sequência cujo n-ésimo elemento é dado por $j_{m n}$. Então:

$$
\begin{gathered}
J_{m}^{\prime}\left(j_{m n}\right)=0, n=0,1,2, \ldots \\
\mu_{m n}=\frac{j_{m n}}{a}
\end{gathered}
$$

Onde $\mu_{m n}$ é o autovalor da (3.30). E, da Equação (3.25), o número de onda da equação de Helmholtz original:

$$
\left(\frac{\omega}{c}\right)^{2}=k^{2}+\left(\frac{j_{m n}}{a}\right)^{2}
$$


Na Equação (3.33), os índices $k, m$ e $n$ são correspondentes a um modo de propagação em cada uma das coordenadas do sistema de coordenadas cilíndrico adotado. O índice $k$ é denominado número de onda longitudinal, enquanto os outros dois são chamados número de onda azimutal e radial, respectivamente. Observando que a mesma análise pode ser feita para quaisquer outras bases ortogonais desejada.

Ainda é possível que se suponha que as paredes das terminações longitudinais do tubo também são rígidas, segundo a Equação (3.29), $\partial X / \partial x(x=0, L)=0$. Para essa condição de contorno, é possível demonstrar uma solução geral e particular para o problema diferencial da Equação (3.22), que também é um problema de Dirichlet:

$$
\begin{gathered}
\frac{1}{X} \frac{\partial^{2} X}{\partial x^{2}}=-k^{2}, \frac{\partial X}{\partial x}(x=0)=0, \frac{\partial X}{\partial x}(x=L)=0 \\
X(x)=X_{0} \cos (k x) \\
\sin (k L)=0 \\
k=0, \frac{\pi}{L}, \frac{2 \pi}{L}, \frac{3 \pi}{L}, \ldots
\end{gathered}
$$

Os valores que $k$ pode assumir são chamados os números de onda longitudinais para o tubo em questão, que dependem inversamente do comprimento do tubo.

Apesar de não existir uma condição de contorno para a função $\Theta(\theta)$, sabe-se que ela deve ser uma função $2 \pi$-cíclica .

$$
\begin{gathered}
\frac{1}{\Theta} \frac{\partial^{2} \Theta}{\partial \theta^{2}}=-m^{2}, \frac{\partial \Theta}{\partial \theta}(x=0)=\frac{\partial \Theta}{\partial \theta}(x=2 \pi) \\
\Theta(\theta)=\Theta_{0} \cos (m \theta+\phi) \\
\Theta(\theta)=\Theta_{0} e^{i m \theta} \\
m \in \mathbb{N}, \phi \in \mathbb{R}
\end{gathered}
$$

A (3.33) traz que, para diferentes valores de frequência que se propaga dentro do tubo circular de paredes rígidas existe uma função de onda diferente. Isso significa dizer que há infinitos valores de frequências que esse tubo tem para vibrar o ar em seu interior. 
Por fim, pode-se representar a função de onda como uma soma de autofunções. Cada autofunção é determinada pela combinação dos autovalores $k, m$ e $n$. Seja então a função de pressão sonora:

$$
\begin{gathered}
p(\omega, t)=\sum_{m=-\infty}^{+\infty} \sum_{n=0}^{+\infty} c_{m n} \Psi_{m n} e^{-i \omega t} \\
\Psi_{k m n}(x, r, \theta)=\Psi_{0} J_{m}\left(\frac{\alpha_{m n} r}{a}\right) \sin (k x) e^{i m \theta}
\end{gathered}
$$

A (3.43), representa a função de onda para um campo acústico em um tubo de paredes e terminações rígidas. Caso a condição de terminações rígidas não possa ser aplicada ao modelo, seja por ter uma entrada acústica ou uma abertura ao meio externo, a Equação (3.42) pode ser reescrita como:

$$
\Psi_{k m n}(x, r, \theta)=\left(X^{+} e^{-i k x}+X^{-} e^{i k x}\right) J_{m}\left(\frac{j_{m n} r}{a}\right) e^{i m \theta}
$$

Assim, considerando uma propagação unidimensional na coordenada longitudinal da propagação no tubo, tem-se uma função geral para o campo acústico:

$$
p_{k m n}(t)=\sum_{m=-\infty}^{+\infty} \sum_{n=0}^{+\infty}\left(p_{m n}^{+} e^{-i k_{m n} x}+p_{m n}^{-} e^{i k_{m n} x}\right) J_{m}\left(\frac{j_{m n} r}{a}\right) e^{i m \theta} e^{-i \omega t}
$$

Observando que os valores de $p_{m n}^{+}$e $p_{m n}^{-}$ditam a amplitude da função de pressão sonora para cada modo associado a uma dupla $(m, n)$. Os termos exponenciais contendo $e^{ \pm k_{m n} x}$ estão relacionados à propagação longitudinal da onda. Ainda a solução da Equação (3.45) leva em consideração que o tubo tem uma terminação e que, nela, há uma parcela de onda refletida.

Os fatores que compõem a função de pressão sonora no tubo estão relacionados a uma variável espacial diferente: longitudinal, azimutal e radial. Assim, eles se relacionam com modos diferentes de vibração do ar enclausurado na guia de ondas. Esse tema será abordado na próxima seção.

\subsection{Modos de tubo}

Os valores que a função de pressão sonora dentro de um tubo de paredes rígidas assume depende das frequências das ondas que se propagam no tubo e possuem uma função de onda respectiva, que compõem o campo acústico. Como apontado, esses valores estão relacionados 
com a coordenada longitudinal através do fator $e^{ \pm i_{m n} x}$, que decai de acordo com $k_{m n}$, definido pela Equação (3.46).

$$
k_{m n}=\sqrt{\frac{\omega^{2}}{c_{0}{ }^{2}}-\frac{j_{m n}{ }^{2}}{R^{2}}}
$$

Sendo $k_{m n} \in \mathbb{R}$, ele pode ser representado por $k_{m n}=a+i b, a \in \mathbb{R}, b \in \mathbb{R}$. Assim o fator de decaimento longitudinal do modo:

$$
e^{i k_{m n} x}=e^{i(a+i b) x}=e^{(-a+i b) x}=e^{-a x} e^{i b x}
$$

Isso significa que um modo que possui $k_{m n}$ complexo é um modo que decai exponencialmente em $e^{-a x}$ na coordenada longitudinal, por isso é chamado de modo evanescente. Observando a Equação (3.46), sabe-se que esses modos evanescentes possuem frequências de ativação, isto é, uma frequência a partir da qual esse modo deixa de ser evanescente e se torna um modo que se propaga, com $k_{m n}$ real e positivo. Essa frequência de ativação vem da Equação (3.33). Observando também que a sequência $\left\{j_{m n}\right\}$ é crescente: quanto maior o modo, maior sua frequência de ativação.

$$
\omega_{\text {ativaça } 0}=\frac{c_{0} j_{m n}}{R}
$$

O Anexo A mostra que o primeiro valor que $j_{m n}$ assume é o zero. Isso significa que existe um modo de propagação que tem sua frequência de ativação em $0 \mathrm{~Hz}$. Esse modo significa o que se conhece por propagação de frentes planas de onda, ou ondas planas. A propagação sonora segundo frentes planas de onda é melhor estudada na Seção 3.6 deste trabalho.

Para avaliar como os modos não planos aparecem na banda de frequência, deve-se entender o papel de cada autovalor $k, m$ e $n$ utilizados no método de solução por separação de variáveis da seção anterior. $\mathrm{O}$ autovalor $k$ está diretamente relacionado com a propagação longitudinal de ondas sonoras, contudo, a Equação (3.48) garante que cada combinação de autovalores $m$ e $n$ gera um valor de $k$, e que estão relacionados a autofunções ortogonais entre si (RIENSTRA e HIRSCHBERG, 2016).

Como descrito na seção anterior, o autovalor $m$ está relacionado à coordenada azimutal do sistema, ou seja, ele descreve e caracteriza as frequências de ativação para modos azimutais de propagar. Esse caso é explorado na Seção 4.2 deste trabalho. Por sua vez, o autovalor $n$ está 
relacionado com a coordenada radial do sistema. A implicação modal desses valores está ilustrada na Figura 7.

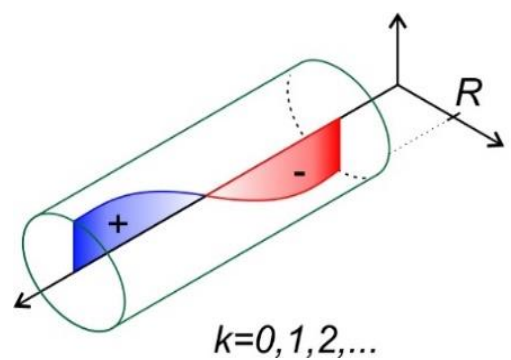

$k=0,1,2, \ldots$

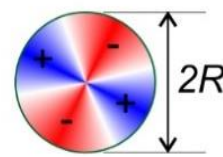

$m=0,1,2, \ldots$

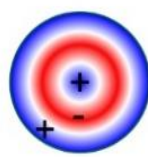

$n=0,1,2, \ldots$

Figura 6 - Visualização de modos de propagação sonora para coordenadas cilíndricas

\subsection{Ondas planas}

As ondas planas são o tipo mais simples que podem se propagar em um meio fluido (KINSLER, 1962). A principal característica desse tipo de onda é que a pressão acústica, o deslocamento das partículas fluidas, mudanças de densidade, entre outras grandezas, têm a mesma amplitude para todos os pontos de um plano genérico que seja perpendicular a direção de propagação de onda. Essas amplitudes também variam temporalmente de modo síncrono entre si. Esse fenômeno acontece graças à hipótese de fluido invíscido, ou muito pouco viscoso, feita na Seção 3.2, que diminui significativamente os efeitos da camada limite viscosa na cinemática do fluido, pois garante-se que as únicas forças que agem sobre as partículas fluidas são as forças causadas pelas diferenças de pressão no meio.

Para descrever matematicamente a propagação sonora por ondas planas, seja a Equação (3.17) com o operador laplaciano descrito em coordenadas cilíndricas:

$$
\frac{\partial^{2} p}{\partial x^{2}}+\frac{\partial^{2} p}{\partial r^{2}}+\frac{1}{r} \frac{\partial p}{\partial r}+\frac{1}{r^{2}} \frac{\partial^{2} p}{\partial \theta^{2}}=\frac{1}{c^{2}} \frac{\partial^{2} p}{\partial t^{2}}
$$

Assumindo que, no regime de propagação plano não há variações de pressão para as coordenadas radial e azimutal, a Equação (3.49) se reduz a:

$$
\frac{\partial^{2} p}{\partial x^{2}}-\frac{1}{c^{2}} \frac{\partial^{2} p}{\partial t^{2}}=\left(\frac{\partial}{\partial x}+\frac{1}{c} \frac{\partial}{\partial t}\right)\left(\frac{\partial}{\partial x}-\frac{1}{c} \frac{\partial}{\partial t}\right) p=0
$$

A solução para essa equação é a soma de duas funções arbitrárias em relação às coordenadas espacial e temporal: 


$$
p(x, t)=f(x-c t)+g(x+c t)
$$

$\mathrm{O}$ argumento $x-c t$ da primeira função representa uma frente plana de onda se propagando no sentido positivo da coordenada $x$ a uma velocidade $c$. Analogamente, o argumento $x+c t$ representa uma frente plana de onda se propagando no sentido negativo da coordenada $x$. Essa solução geral é chamada de solução de ondas progressivas e foi desenvolvida por D’Alembert, em 1747 (MAGALHÃES, 2013).

Assumindo, sem perda de generalidade, a função de pressão sonora como harmônica (CHAIGNE, 2003), tem-se $p(x, t)=P(x) e^{i \omega t}$. Substituindo na Equação (3.50), tem-se:

$$
\begin{gathered}
\frac{d^{2}}{d x^{2}} P(x)+\frac{\omega^{2}}{c^{2}} P(x)=0 \\
P(x)=P_{+} e^{-i \beta x}+P_{-} e^{i \beta x} \\
p(x, t)=\left(P^{+} e^{-i k x}+P^{-} e^{i k x}\right) e^{-i \omega t}
\end{gathered}
$$

Onde $\beta=\omega / c$, dado da Equação (3.46), para quando $j_{m n}=0$, é o número de onda para a propagação plana em coordenada longitudinal ao tubo. 



\section{Métodos no tubo de impedância}

No desenvolvimento das equações que descrevem a propagação da onda sonora em um meio fluido, não é considerada nenhuma direção específica em que essa propagação acontece, isto é, trata-se da propagação sem limites ou contornos. Em seguida, foi desenhada uma solução analítica para a equação de onda considerando um sistema de coordenadas cilíndricas. As coordenadas cilíndricas são importantes para a solução dessa equação porque representam a estrutura tubular, que é muito presente na manufatura de estruturas complexas que envolvem propagação sonora, como escapamento de veículos, encanamento de ventilação e de aquecimento, compressores, turbinas, entre outras estruturas.

Este capítulo trata de como a soluções analíticas da equação de onda são abordadas em um contexto prático. Para isso, propõe-se e projeta-se uma bancada experimental no Laboratório de Dinâmica da EESC, a partir da estrutura clássica de um tubo de impedância, com uma instrumentação estendida.

Essa bancada é composta por dois tubos de material polímero instrumentados com 9 e 5 microfones, respectivamente. Cada um dos tubos, assim como suas dimensões e materiais serão descritos no próximo capítulo.

O objetivo dessa bancada, além de conseguir reproduzir ensaios clássicos no tubo de impedância, é de conseguir gerar diferentes campos acústica no interior do tubo, também de projetar uma instrumentação capaz de gerar e identificar esses campos acústicos, assim como suas implicações físicas.

Apesar de ser uma estrutura conhecida há décadas, os tubos de impedância ainda hoje são amplamente produzidos e estudados, tanto em âmbito comercial quanto em âmbito acadêmico.

Desde o início do século XX, após o desenvolvimento do protótipo do tubo de Kundt, já se faziam trabalhos com esse aparato, como o estudo feito por KENNELLY e KUROKAWA(1921). Esse trabalho foi um dos pioneiros em trazer o termo impedância para a acústica. Experimentalmente, foi utilizado um tubo de comprimento variável instrumentado com transdutores telefônicos, já que a tecnologia de alto falantes eletrodinâmicos como conhecemos hoje ainda não havia sido desenvolvida. 
Na década de 70 e início da década de 80 muito se avançou no estudo de propagação sonora em tubo, em ondas planas ou em ordens superiores. DOAK (1973a, 1973b) estudou a distribuição de fontes sonoras ao longo de tubos, os efeitos da seção transversa e da geometria dos tubos para a propagação sonora. Além disso, foram demonstrados os efeitos da impedância das paredes do tubo, assim como das terminações, nos cálculos de pressão sonora; também foi observada a relação entre a potência sonora gerada por modos mais altos de propagação em comparação com a propagação plana no tubo.

DOAK (1973a) também destaca que o domínio dos fenômenos acústicos em um tubo de comprimento finito e sem escoamento é fundamental para o entendimento de fenômenos mais complexos, como quando há presença de escoamento, temperatura não-homogênea e seção transversal variável. Experimentalmente, DOAK $\left(1973^{\mathrm{a}}\right)$ utilizou o método de ondas estacionárias (SWM, standing wave method), em que o comprimento variável do tubo permite localizar pontos nodais ao longo do comprimento e, a partir disso, calcular as frequências modais da estrutura.

Alguns anos depois, SEYBERT e ROSS (1977) inauguraram a abordagem de decomposição normal do campo acústico em tubo, com ou sem escoamento. Esse método consiste na observação da pressão sonora em dois pontos distintos ao longo do comprimento do tubo gerada a partir de uma entrada de ruído branco em uma das extremidades do tubo. As frentes de onda incidente e reflexiva, decompostas do campo acústico, são calculadas a partir do auto espectro e do espectro cruzado observado pelos microfones. Com esse método, foi capaz de se mensurar o coeficiente de absorção sonora de materiais instalados na terminação do tubo com maior rapidez e sem a necessidade de se construir uma bancada com microfone itinerante dentro tubo.

Em seguida, CHUNG e BLASER (1980a, 1980b) utilizaram a ideia de decomposição normal do campo acústico para desenvolver o método de função de transferência para determinar as componentes incidente e reflexiva do campo. Essa decomposição, assim como antes, leva à determinação do coeficiente complexo de reflexão na extremidade do tubo, assim como a perda de transmissão e o coeficiente de absorção sonora. Esse trabalho significou um grande avanço experimental à prática de acústica de tubos. A partir dele, pode-se desenvolver as normas internacionais até hoje utilizadas para cálculo de coeficiente de absorção sonora, a ASTM E1050 e a ISO 10534-2. 
Mesmo depois dessas décadas de estudo sobre os fenômenos acústicos associados ao tubo de impedância, ainda nos dias de hoje são levantadas questões e propostos métodos acerca dessa temática, muitos desses trabalhos estão relacionados à avaliação de materiais e estruturas para o controle de ruído e também à visualização de modos não-normais no tubo.

NIRESH et al (2016), por exemplo, utiliza técnicas matemáticas de otimização para minimizar os erros de medida no tubo de impedância. Foram listados alguns tipos de erros associados à operação do tubo, sejam eles intrínsecos (erros de montagem, distorção no falante, ressonância no tubo etc) ou extrínsecos (erro de sinal, distorções nos circuitos eletrônicos, diferenças de temperatura etc) e a partir desses, foram utilizados algoritmos de otimização por enxame de partículas (PSO, particle swarm optimization) e redes neurais para comparar os resultados de um tubo de impedância construído com um tubo de impedância comercial. É importante que se destaque que, mesmo abrindo precedentes para uma abordagem mais contemporânea do tubo de impedância, os conceitos e desenvolvimentos teóricos de NIRESH ainda se baseiam naqueles de décadas atrás, citados acima.

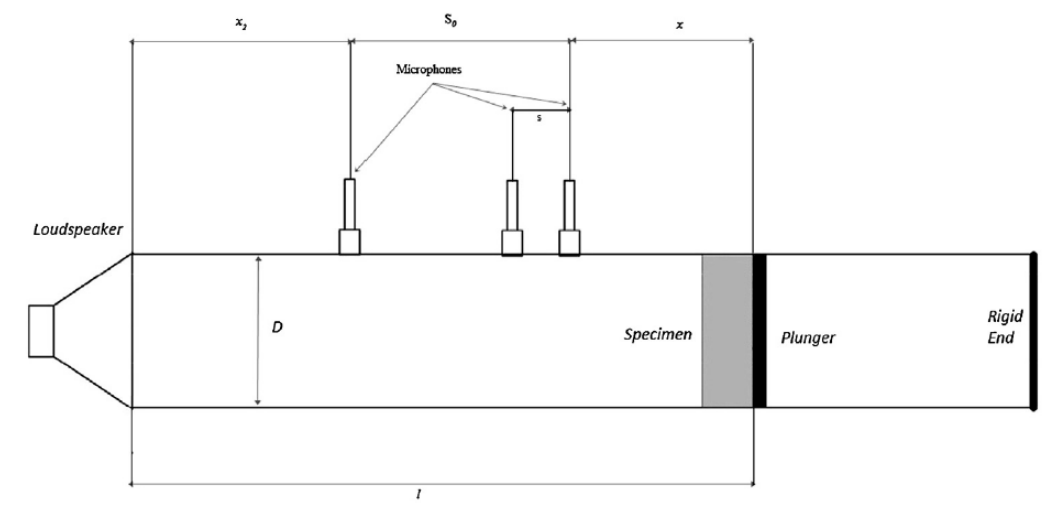

Figura 7 - Esquema desenhado por NIRESH (2016)

Ainda, devidos aos altíssimos custos de um tubo impedância comercializado, várias são as publicações de projetos próprios de tubos de impedância, seja para instrumentação acústica como para fins didáticos. Muitos desses trabalhos utilizam materiais alternativos e de baixo custo para reproduzir esses fenômenos acústicos (MAREZE, 2016; LINSCHEID e PAPACOSTA, 2016). É exatamente nesse sentido que este trabalho também foi construído.

Além das questões relativas à propagação sonora e seus modos de propagação dentro do tubo, a principal utilização comercial desse aparato é para fazer a caracterização de materiais para projetos acústicos, seja como um objeto da arquitetura, da engenharia civil ou da engenharia de materiais. JIANG et al 2017), por exemplo, estuda as características acústica de 
amostras de materiais impressos por manufatura aditiva, relacionando-as com características físicas dos materiais, como geometria e porosidade. As relações entre propriedades acústicas de materiais impressos têm sido bastante discutidas nos últimos anos (NASCIMENTO, RODRIGUES e DE OLIVEIRA, 2018), uma vez que essa tecnologia aumenta as possibilidades de estudos e experimentações com conceitos de metamateriais em engenharia.

Também têm sido feitos muitos trabalhos que utilizam o tubo de impedância para avaliar o desempenho acústico de diferentes tipos de materiais alternativos, desde a lã de ovelha (DEL REY, 2017), passando por podas de oliva (MARTELLOTTA, 2018) até bitucas de cigarro (GOMEZ ESCOBAR e MADERUELO-SANZ, 2017), que são geradas ao bilhões por dia no mundo.

A relevância do tubo de impedância se manteve durante todas essas décadas, dentre outros motivos, pela facilidade e acessibilidade de reprodução e análise do método de função de transferência, que atribuiu grande agilidade ao trabalho experimental. Neste trabalho, utilizase os conceitos desse método para estudar a propagação sonora unidimensional em tubos.

Neste capítulo, estão descritos alguns métodos de avaliação de propagação sonora em uma estrutura de tubo de impedância. Na primeira seção, o método clássico normatizado é descrito segundo as equações já demonstradas aqui. Na seção seguinte, são descritos alguns métodos de análise do tubo de impedância com instrumentação expandida a fim de observar o primeiro modo azimutal no tubo de impedância, acima da frequência de corte de propagação plana.

\subsection{Método de função de transferência}

Para a operação do tubo de impedância, as normas internacionais levam em consideração a instrumentação por ondas estacionárias e a instrumentação por função de transferência. O primeiro método, um microfone móvel é usado para identificar os pontos de máxima e mínima pressão sonora dentro do tubo de impedância enquanto ondas sonoras são geradas por um alto falante na extremidade. Da razão entre essas pressões, calcula-se o coeficiente de reflexão da extremidade oposta e, a partir dele, a impedância normal e o coeficiente de absorção sonora da mesma extremidade. $\mathrm{O}$ segundo método, descrito neste trabalho, a fonte sonora emite um sinal distribuído em uma faixa de frequência a passo que se calcula a função de transferência entre dois microfones localizados em pontos diferentes ao longo do tubo, o que leva ao cálculo dos mesmos parâmetros anteriores, mas na dimensão da frequência. 
Essa última tem algumas vantagens sobre a primeira (SETAKI, 2016) e a principal delas é a possibilidade de se calcular o coeficiente de reflexão para uma banda de frequência, ao invés de para uma frequência única. Além dessa vantagem, a instrumentação é mais robusta porque não possui elementos móveis, que são mais suscetíveis a erros de medida. Ao invés disso, montam-se microfones nas paredes internas do tubo. A Figura 8 mostra um esquema de instrumentação clássica de um tubo de impedância por função de transferência.

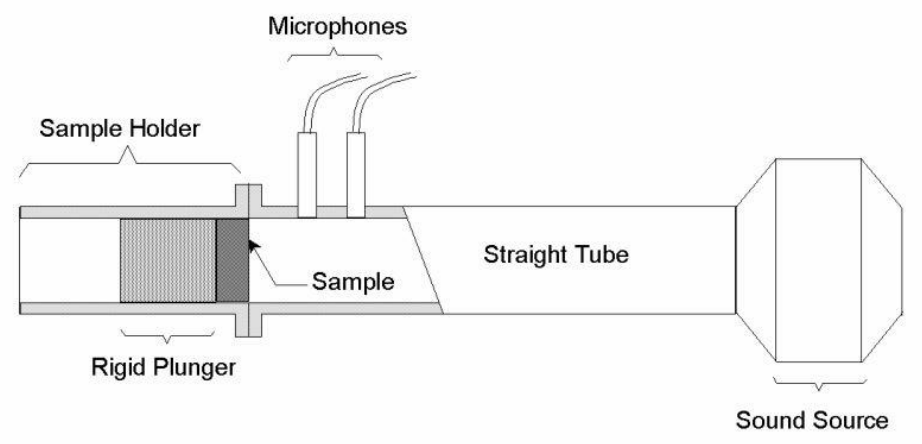

Figura 8 - Sistema clássico de tubo de impedância para o método de função de transferência.

Mesmo com tantas reproduções do modelo de tubo de impedância por função de transferências, esse sistema conta com algumas dificuldades que limitam a abrangência do seu uso, tanto para avaliação acústica de materiais, quanto para o estudo da propagação sonora. A principal dificuldade está na faixa de frequência útil de operação.

Como foi apontado na Seção 3.6, um campo acústico em um tubo, circular ou não, pode ser de duas categorias:

a) Para frequências em que o comprimento de onda seja maior que o diâmetro (ou o maior comprimento) da seção transversal do tubo, a única forma em que o som se propaga e carrega energia acústica é através de ondas planas, axiais ao tubo, as chamadas frentes de onda. Para essas frequências, mesmo que haja não-uniformidades ou acoplamentos ao longo do comprimento do tubo, essas não-uniformidades rapidamente se atenuam;

b) Para frequências em que o comprimento de onda é menor que o maior comprimento da seção transversal do tubo, a interferência entre as reflexões nas paredes do tubo gera uma propagação não-plana, que dependem fortemente da geometria do tubo (DOAK, 1973b). Esse cenário forma o que se chama de modos não-planos de propagação. Quanto maior a frequência, maior o número de modos em que o som pode se propagar. Nesses casos, a energia acústica transportada é distribuída entre esses modos. 
Assim, o método de função de transferência se faz válido quando a propagação sonora no tubo pode ser descrita como uma propagação plana. De fato, isso é verdade caso se considere um tubo de paredes rígidas internas e para frequências abaixo da frequência de ativação do primeiro modo não-normal, como discutido na Seção 3.4. Na verdade, a norma ISO 105342:1998 admite a frequência máxima de operação para um tubo de impedância de diâmetro interno $d$, em um ambiente onde a velocidade de propagação do som seja de $c_{0}$, como:

$$
f_{\text {máxima }}<0,58 \frac{c_{0}}{d}
$$

A norma também indica um limite inferior para a frequência de operação do tubo de impedância. Esse valor depende da distância entre os pontos de medida da pressão sonora, $\underline{s}$. Se a frequência de propagação for muito pequena, o comprimento de onda é muito maior em relação a distância entre os pontos de observação. Esse valor é indicado como:

$$
f_{\text {mínima }}>0,05 \frac{c_{0 .}}{s}
$$

Como foi estudado na Seção 3.6, a pressão sonora para a propagação plana unidimensional a uma frequência $\omega$, para as coordenadas longitudinal e temporal é:

$$
p(x, t)=\left(P^{+} e^{-i k x}+P^{-} e^{i k x}\right) e^{-i \omega t}
$$

Na Equação (4.3), $P^{+}$e $P^{-}$são as magnitudes de pressão das frentes de onda que se propagam no sentido positivo e negativo na coordenada longitudinal. A Figura 9 esquematiza um tubo de impedância, de comprimento $L$, de terminação plana qualquer de impedância acústica superficial $Z$, sendo excitado acusticamente por um alto falante instalado em uma extremidade, gerando um campo acústico plano observado por dois microfones, instalados nas coordenadas $x_{1}$ e $x_{2}$ do tubo.

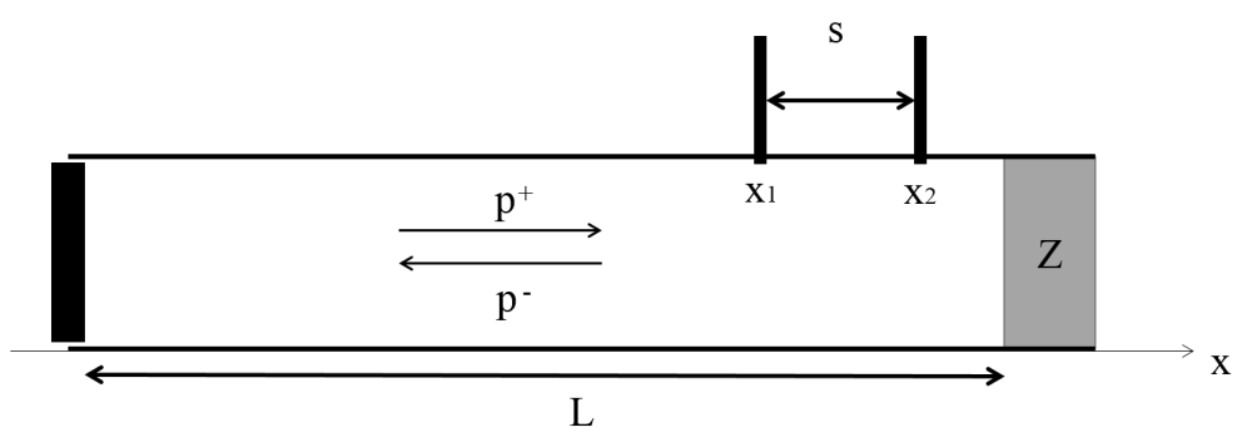

Figura 9 - Ilustração esquemática utilizada no projeto do tubo de impedância. 
A pressão sonora nos microfones 1 e 2, respectivamente, pela Equação (4.4) e (4.5):

$$
\begin{aligned}
& p_{1}(t)=\left(P^{+} e^{-i k x_{1}}+P^{-} e^{i k x_{1}}\right) e^{-i \omega t} \\
& p_{2}(t)=\left(P^{+} e^{-i k x_{2}}+P^{-} e^{i k x_{2}}\right) e^{-i \omega t}
\end{aligned}
$$

Seja $H_{12}$ a função de transferência para as funções de pressão estimadas pelos microfones 1 e 2, para uma propagação à frequência $\omega$ definida como:

$$
\begin{gathered}
H_{12}=\frac{p_{2}}{p_{1}}=\frac{P^{+} e^{-i k x_{2}}+P^{-} e^{i k x_{2}}}{P^{+} e^{-i k x_{1}}+P^{-} e^{i k x_{1}}} \\
H_{12}=\frac{e^{-i k x_{2}}+R \cdot e^{i k x_{2}}}{e^{-i k x_{1}}+R \cdot e^{i k x_{1}}}
\end{gathered}
$$

sendo $R$ definido como fator de reflexão, razão entre as magnitudes de pressão no sentido positivo e negativo de propagação. Observando que $R$ é uma função da frequência. Assim, tem-se:

$$
R=\frac{H_{12}-e^{-i k s}}{e^{i k s}-H_{12}} e^{2 i k x_{1}}
$$

Sendo um tubo de paredes rígidas, o fator de reflexão dependerá somente da terminação do tubo, de impedância acústica superficial $Z$. A impedância da terminação se relaciona com o fator de reflexão através do coeficiente de absorção sonora $\alpha$, definido como a fração de energia incidente sobre uma superfície que é absorvida e passa a se propagar no material da terminação. Na verdade, uma parte dessa energia absorvida também se dissipa em forma de calor. Assim, o coeficiente de absorção é definido como:

$$
\alpha=1-|R|^{2}
$$

Além disso, a impedância acústica superficial do material se relaciona com o fator de reflexão por:

$$
Z_{s}=Z_{0} \frac{1+R}{1-R}
$$

sendo $Z_{0}$ a impedância característica do meio de propagação.

Chama-se atenção a que $R$ é um número complexo. A sua parte real descreve a energia perdida pela onda, enquanto a sua parte imaginária descreve a mudança de fase causada pelo material. 


\subsection{Identificação nodal do primeiro modo azimutal em tubo de impedância}

O método de função de transferência parte da simplificação da equação de propagação de onda para um tubo de paredes rígidas, onde se propagam ondas de frentes planas. Como discutido na Seção 3.6, essa simplificação só se faz válida até uma frequência máxima, que depende do diâmetro interno do tubo. Acima dessa frequência máxima, modos superiores ao modo plano têm suas respectivas frequências de ativação alcançadas. Nesse caso, já não se pode garantir que a pressão medida por um microfone faceado à parede tem a mesma magnitude em todos os pontos daquela seção transversal. Na verdade, pela Seção 3.6, sabe-se que acima da frequência máxima do modo plano, os modos azimutais começam a existir e a se propagar no campo acústico.

Para se incluir os modos azimutais na análise, seja a pressão sonora no tubo de paredes rígidas, seja a equação:

$$
p_{k m n}(t)=\sum_{m=-\infty}^{+\infty} \sum_{n=0}^{+\infty}\left(P_{m n}^{+} e^{-i k_{m n} x}+p_{m n}^{-} e^{i k_{m n} x}\right) J_{m}\left(\frac{\alpha_{m n} r}{a}\right) e^{i m \theta} e^{-i \omega t}
$$

A simplificação dos fatores que representam os modos radiais e azimutais reduz o campo acústica em duas propagações planas, uma em cada sentido da direção longitudinal. Com o método de função de transferência, bastam duas medidas diferentes no campo para determinar a função de pressão. Para expandir essa análise, é necessário que se façam outras medidas ao longo do tubo, de modo a determinar as variáveis dos outros modos.

Neste trabalho, além do caso plano clássico, aborda-se os modos azimutais. Os modos radiais não serão abordados experimentalmente devida a dificuldade prática de fazer medidas em pontos internos ao tubo sem influenciar o campo acústico. Assim, para o caso azimutal, são propostos outros pontos de instrumentação na parede do tubo.

A Figura 10 mostra uma superfície interna ao tubo em que a coordena azimutal é constante $m \theta+\operatorname{Re}\left(k_{m n}\right) x$, e leva em consideração também a posição longitudinal da medida. 


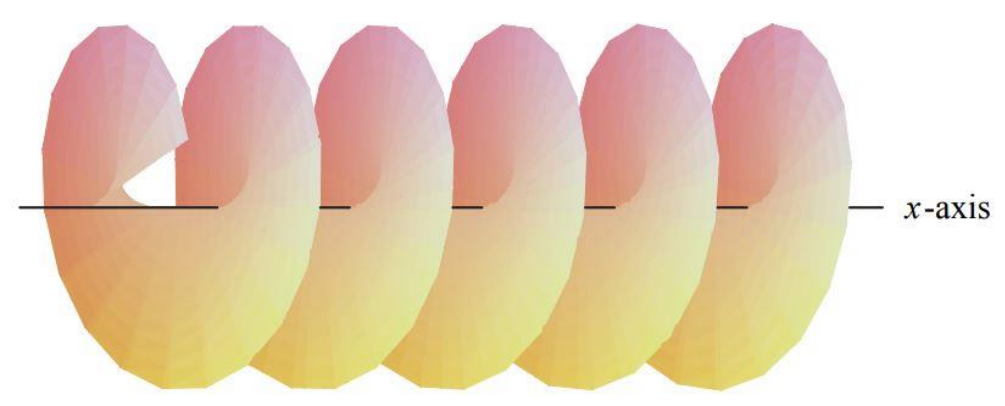

Figura 10 - Ilustração mostrando as regiões do tubo de impedância que estão em uma mesma fase considerando os modos azimutais. Fonte:

flowairs.eu/_resources/Documents/Training\%2520october/Cours/Rientra_Duct_FlowAirS2012slides.pdf

(Acessado em: 24/09/2018)

Devido a isso, para se avaliar a variação da pressão acústica para a coordenada azimutal, é necessário que se instrumente o tubo em outros pontos numa mesma superfície. Para avaliar os modos radiais, deve-se observar os valores de pressão em distâncias do centro do tubo diferentes. Esse caso não está sendo tratado neste trabalho por dificuldades técnicas de instalação, já que um microfone interno ao tubo adicionaria variações muito complexas à análise.

Já para o caso dos modos azimutais, ainda dentro do primeiro modo azimutal, propõese observar os valores de pressão em diferentes pontos da parede do tubo, de modo a entender o comportamento da função de pressão quando os microfones de uma mesma seção não observam os mesmos valores de pressão sonora. Isso indica a presença de um modo azimutal em determinada frequência.

Essa situação é ilustrada na Figura 11, onde dois microfones instalados em uma seção qualquer do tubo, para dois modos de propagação azimutais, para $m=2$ e $m=3$, respectivamente, sem perda de generalidade. Os microfones percebem valores diferentes em suas posições, desde que a pressão azimutal se distribui harmonicamente pela seção de acordo $\operatorname{com} e^{i m \theta}$.

Analogamente à seção anterior, expressa-se o valor de pressão observado por cada microfone em uma mesma seção segundo a função da Equação (4.11). Dessa vez, no entanto, não se ignora o fator relativo à coordenada azimutal. 

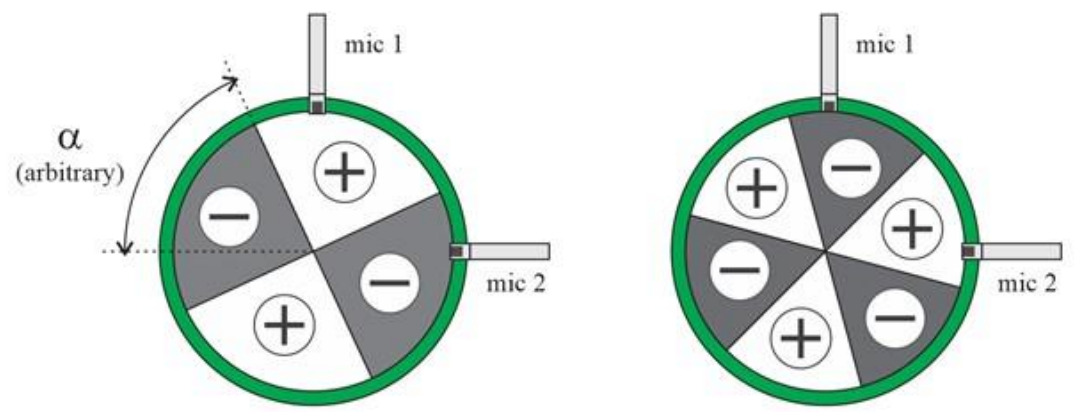

Figura 11 - Visualização dos pontos de medida em uma mesma seção de tubo com modos azimutais ativados.

Para o fator radial na função, considera-se ainda o primeiro modo radial, ou seja, $n=1$. O que garante que o fator $J_{m}\left(\frac{j_{m n} r}{a}\right)$ é igual à unidade, para todo $-\infty<m<\infty$.

Seja então uma seção A do dado tubo, como ilustrado na Figura 12, onde se observa a variação dos valores de pressão em três pontos distintos da mesma seção. A pressão para o microfone A1:

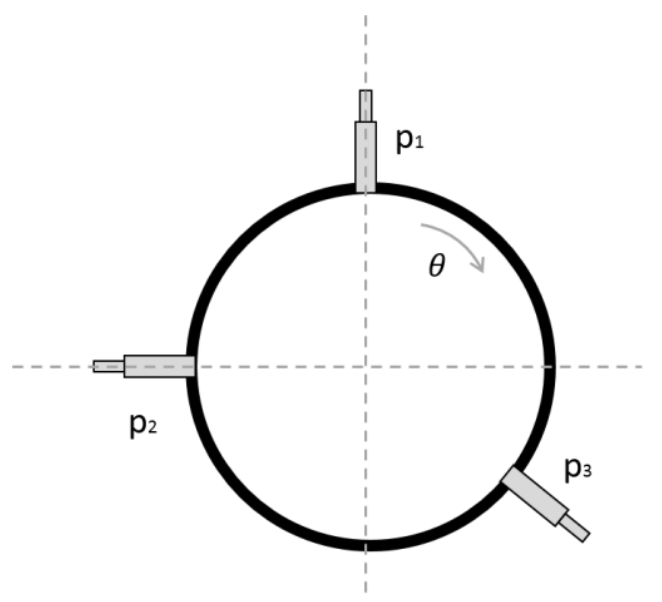

Figura 12 - Ilustração da disposição dos microfones instalados.

$$
\begin{aligned}
p_{A 1}(\omega, t) & =\left(P_{-1,0}^{+} e^{-i k_{-1,0} x_{1}}+P_{-1,0}^{-} e^{i k_{-1,0} x_{1}}\right) J_{-1}\left(\frac{j_{-1,0} r}{a}\right) e^{-i \theta_{1}} e^{i \omega t}+ \\
& +\left(P_{0,0}^{+} e^{-i k_{0,0} x_{1}}+P_{0,0}^{-} e^{i k_{0,0} x_{1}}\right) J_{0}\left(\frac{j_{0,0} r}{a}\right) e^{i \omega t}+ \\
& +\left(P_{1,0}^{+} e^{-i k_{1,0} x_{1}}+P_{1,0}^{-} e^{i k_{1,0} x_{1}}\right) J_{1}\left(\frac{j_{1,0} r}{a}\right) e^{i \theta_{1}} e^{i \omega t}
\end{aligned}
$$

Na Equação (4.12), os valores para $P_{-1,0}^{ \pm}, P_{0,0}^{ \pm}, P_{1,0}^{ \pm}$constituem 6 incógnitas desse sistema. Ao contrário da Seção 4.1, aqui não será abordado o sentido de se ter um fator de 
reflexão azimutal, que levaria em consideração os valores das pressões medidas em cada seção do tubo.

Em vez disso, os valores de pressão de cada microfone da seção podem ser combinados algebricamente entre si. Seja então, o valor complexo de pressão observada pelos microfones $p_{A 1}, p_{A 2}$ e $p_{A 3}$. Além disso, para o primeiro modo radial, os fatores que multiplicam os fatores exponencial dependem somente da coordenada longitudinal, da coordenada radial e da frequência de operação, assim, são iguais para uma mesma seção.

$$
\begin{aligned}
& p_{A 1}=P\left(x_{A}, r, \omega\right) e^{i m \theta_{1}} \\
& p_{A 2}=P\left(x_{A}, r, \omega\right) e^{i m \theta_{2}} \\
& p_{A 3}=P\left(x_{A}, r, \omega\right) e^{i m \theta_{3}}
\end{aligned}
$$

A estratégia algébrica adotada consiste em somar os valores complexos de pressão doía a dois observados e observar o comportamento dessa soma ao longo do eixo de frequência. Enquanto o módulo do resultado for maior que o módulo de cada uma das parcelas, significa que esses microfones estão em pontos do plano em que a pressão acústica oscila em uma mesma fase. Esses pontos da seção têm, aproximadamente, a mesma amplitude, assim, a estratégia consiste em identificar para quais frequências o resultado dessa soma se torna menor que ambas as parcelas. Nesses casos, deve existir uma linha nodal azimutal entre esses dois microfones, ou um número ímpar de linhas nodais.

Caso a pressão acústica nesses dois pontos tomados esteja em fase, isto é, $m \theta_{1}=m \theta_{2}=m \theta$, a soma resulta em $p_{A 1}+p_{A 2}=2 P\left(x_{A}, r, \omega\right) e^{i m \theta}$, que é um valor maior que cada uma das parcelas, em módulo.

Supondo, então, que há uma diferença de fase $\Delta(m \theta)=m \Delta \theta$ entre esses dois pontos, a nova soma resultaria em $p_{A 1}+p_{A 2}=P\left(x_{A}, r, \omega\right)\left(1+e^{i m \Delta \theta}\right)$. Esse novo valor só se torna menor que cada uma das parcelas quando:

$$
\frac{\pi}{2}<\Delta(m \theta)<\frac{3 \pi}{2}
$$

Tomando o primeiro modo azimutal, $m= \pm 1$, a defasagem deve estar entre $\frac{\pi}{2}$ e $\frac{3 \pi}{2}$. 
Sabendo que a linha nodal se localiza entre dois pontos defasados de $\pi$, para o primeiro modo azimutal, pode-se garantir que há uma linha nodal desde que:

$$
\left|p_{1}+p_{2}\right|<\left|p_{1}\right|+\left|p_{2}\right|
$$

O procedimento descrito foi chamado de método da soma, para identificação de nós azimutais na faixa de frequência correspondente ao primeiro modo azimutal de propagação em tubo de impedância. No capítulo seguinte, esse método é posto em prática e seus resultados discutidos.

\subsection{Expansão da faixa útil de frequência para tubo de impedância}

Mesmo sendo teoricamente possível de se identificar alguns modos azimutais acima da frequência de corte de propagação plana, a análise de absorção acústica de materiais acima dessa frequência, mesmo para incidência normal é comprometida.

SANADA (2017) trabalha a questão da expansão da faixa útil de observação para um tubo de impedância. Assim como descrito na seção anterior, SANADA (2017) trabalha com a combinação de um conjunto de medidas na mesma seção transversal do tubo. Assumindo que medidas diametralmente opostas causariam uma anulação dos modos azimutais, o que é comprovado pelos seus experimentos. Essa técnica permite que se avalie a incidência normal para frequências acima da frequência de corte indicada pela norma.

Mesmo com resultados inéditos, SANADA (2017) indicou diferenças para os resultados dependendo da amostra, das distâncias entre os microfones e da quantidade de microfones de cada ensaio. Para avaliar essa questão, propõe-se aqui uma combinação das medidas de diferentes microfones, em diferentes seções do tubo, a partir de uma aproximação quadrática.

CHO (2005) demonstra que, para um conjunto de $M$ medidas de pressão acústica, em seções diferentes do tubo, como indicado na Figura 13, há $M(M-1) / 2$ arranjos de funções de transferência possíveis de serem calculados.

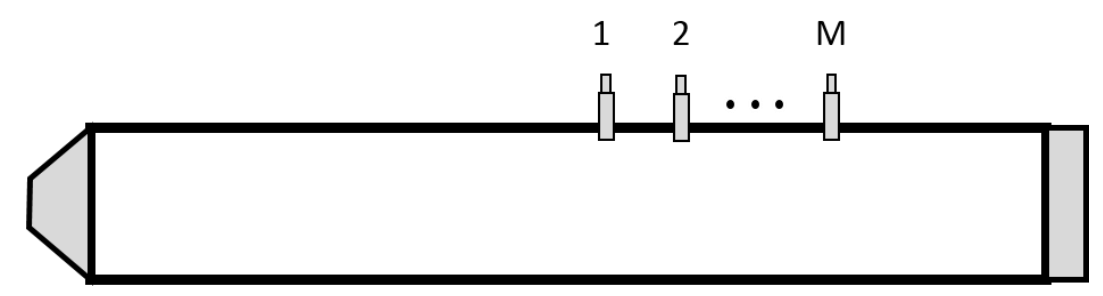

Figura 13 - Ilustração esquemática de M microfones instalados em série em um tubo. 
Sejam $n$ e $m$ duas medidas quaisquer desse conjunto, CHO (2005) mostra que é possível combinar os resultados de cada um desses arranjos de funções em uma única curva de fator de reflexão na faixa completa de frequência como:

$$
R=-\frac{\sum_{n=1}^{M-1} \sum_{m=n+1}^{M}\left[e^{-i k\left(L-x_{n}\right)} H_{n m}-e^{-i k\left(L-x_{m}\right)}\right]\left[e^{-i k\left(L+x_{n}\right)} H_{n m}-e^{i k\left(L+x_{m}\right)}\right] *}{\sum_{n=1}^{M-1} \sum_{m=n+1}^{M}\left|e^{-i k\left(L+x_{n}\right)} H_{n m}-e^{-i k\left(L+x_{m}\right)}\right|^{2}}
$$

Onde $H_{n m}$ é a função de transferência entre as medidas $n$ e $m, x_{m}$ e $x_{n}$ a coordenada longitudinal das seções correspondentes a cada medida e $L$ o comprimento do tubo.

Para este ensaio, busca-se combinar as diferentes medidas feitas nas seções do tubo. Dadas 3 medidas diferentes por seção, em 3 seções, há 18 possíveis combinações de medidas para se calcular função de transferência. Em tese, essas funções de transferência são iguais para o regime de propagação plana. No entanto, ao redor da frequência de corte, essas funções se diferenciam devido à ativação do primeiro modo azimutal. Assim, são avaliados os efeitos de soma de medidas de seção na curva de coeficiente de absorção sonora, uma vez que se espera uma curva plana nula, mesmo depois da ativação do primeiro modo azimutal. 



\section{Procedimentos experimentais}

Nas próximas seções, serão descritos os ensaios experimentais desenvolvidos neste trabalho, assim como suas respectivas viabilizações instrumentais. Foram construídas duas bancadas experimentais expandidas de tubo de impedância, uma com 5 microfones instalados e outra com 9 microfones instalados.

A sequência de experimentos desenvolvidos busca trazer 4 resultados principais ao trabalho:

a) Validar a estrutura tubular construída, assim como os materiais e os métodos de fabricação, como viável para serem reproduzidos os ensaios de avaliação de fator de reflexão e coeficiente de absorção sonora à incidência normal;

b) Reproduzir, de fato, os testes de avaliação de coeficiente de absorção sonora para incidência normal, tanto para o método clássico descrito pelas normas, quanto para comparação de pares de microfones entre medidas;

c) Reproduzir e medir os cenários de propagação não-normal para frequências acima das frequências de corte utilizando a instrumentação expandida, a fim de avaliar o método descrito para identificação de modos azimutais;

d) Reproduzir e a validar o método de expansão da frequência útil de medida de coeficiente de absorção sonora para incidência plana, para cima da frequência de corte de propagação plana.

Todos os ensaios experimentais foram realizados no Laboratório de Dinâmica da EESCUSP. Para construção do tubo, foram utilizando materiais de baixo custo, sempre que possível. Em todos os ensaios foi utilizado o sistema de aquisição de dados LMS Scadas Mobile, da Siemens Industry Software, ilustrado na Figura 14, que também funcionou como gerador de sinal para o alto falante instalado na primeira terminação do tubo.

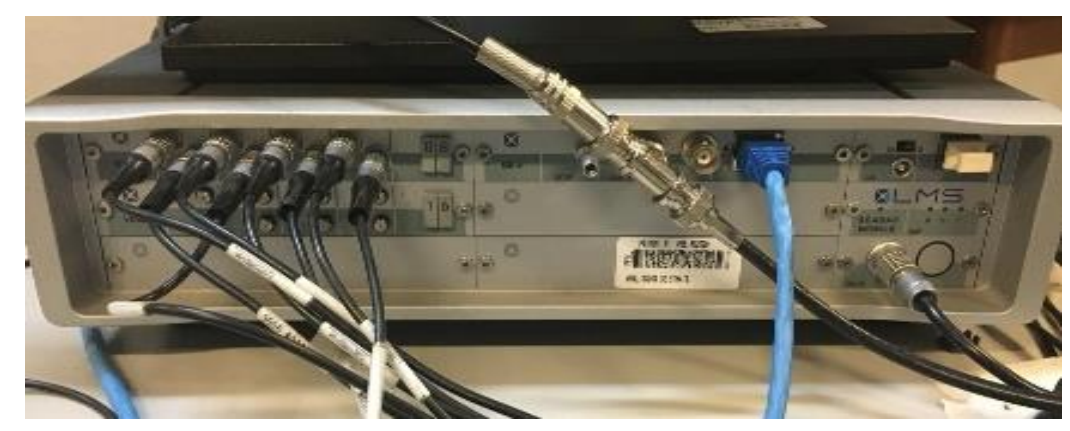

Figura 14: LMS Scadas Mobile 
Para excitar o sistema, o alto falante utilizado é do modelo FRS 8-8, ilustrado na Figura 14. Esse modelo possui $8 \mathrm{~cm}$ de diâmetro externo e 8 ohms de impedância nominal, com resposta plana em frequência entre $100 \mathrm{~Hz}$ e $20 \mathrm{kHz}$. Devido ao seu tamanho e resposta em frequência, é comumente utilizado em modelos e em dispositivos eletrônicos. O FRS 8-8 possui diafragma de formato cônico e frequência de ressonância a $120 \mathrm{~Hz}$.

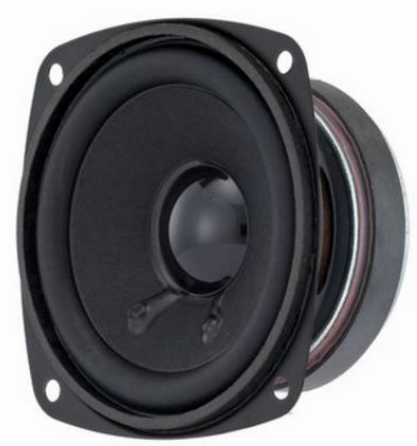

Figura 15 - Alto falante FRS 8-8 utilizado para excitar o sistema.

Em todos os ensaios do trabalho, o alto-falante foi excitado com um sinal elétrico do tipo chirp, de 0 a $4 \mathrm{KHz}$, a uma resolução de $0,125 \mathrm{~Hz}$.

Por fim, para instrumentar o campo acústico, foram utilizados microfones do modelo GRAS 40 PH, cuja curva de resposta em frequência é plana, com variação de no máximo $1 \mathrm{~dB}$, de $50 \mathrm{~Hz}$ a $5 \mathrm{kHz}$. Os microfones possuem um diâmetro de $7 \mathrm{~mm}$ e foram todos calibrados em relação a uma mesma referência a $1 \mathrm{kHz}$. Para a estimativa de coeficiente de reflexão sonora, os microfones também tiveram as fases calibradas entre si, conforme descreve a norma ISO 10534-2.

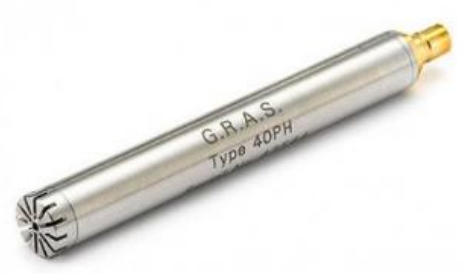

Figura 16 - GRAS $40 \mathrm{PH}$

Neste capítulo, são descritos os procedimentos experimentais desenvolvidos. Inicialmente, descreve-se o projeto dos tubos de impedâncias construídos, desde o material escolhido, os processos de fabricação e seus desenhos em CAD. Em seguida, avalia-se o desempenho dos tubos de impedância para a propagação sonora plana com terminação rígida. 
Com a mesma montagem, avalia-se as medidas de coeficiente de absorção sonora para um material de coeficientes conhecidos.

Os procedimentos finais exploram a instrumentação estendida dos tubos de impedância, primeiro para identificar os modos azimutais e, em seguida, para verificar a extensão da faixa útil de frequência do tubo, segundo a aproximação quadrática de CHO (2005).

\subsection{Construção da bancada}

Propõe-se uma bancada experimental que consiste em um tubo hidráulico de polipropileno copolímero random (PPR Industrial) com selins de derivação instalados nas laterais do tubo. Essa estrutura é fixada a duas terminações. A primeira terminação consiste de um alto falante instalado a um compartimento vedado, enquanto a segunda terminação consiste em um pistão ajustável de nylon faceado ao fim do tubo. O pistão é instalado em um tubo similar ao tubo principal que é fixado por união flangeada.

São propostos dois modelos de tubo principal: um para observar modos de propagação plana e outro para observar modos de propagação azimutais. O primeiro tubo possui 5 microfones instalados no seu corpo, enquanto o segundo possui 9 microfones instalados. A Figura 17 mostra a estrutura total, em CAD, do sistema. As Figuras 18 e 19 mostram os detalhes do modelo com 5 microfones e com 9 microfones, respectivamente.

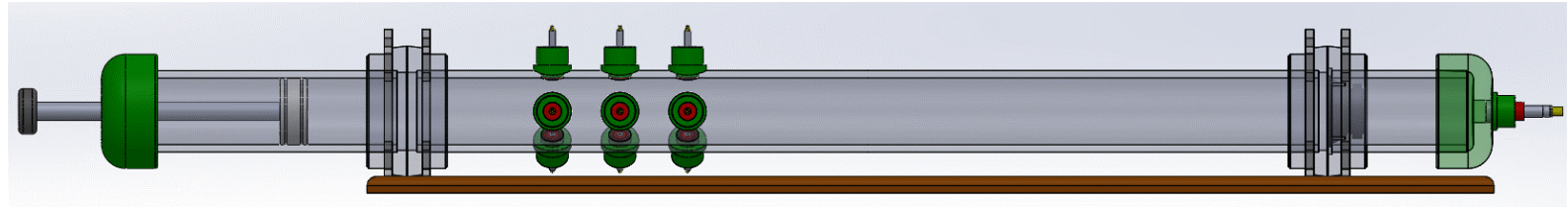

Figura 17 - Vista lateral do tubo com 9 microfones instalados.

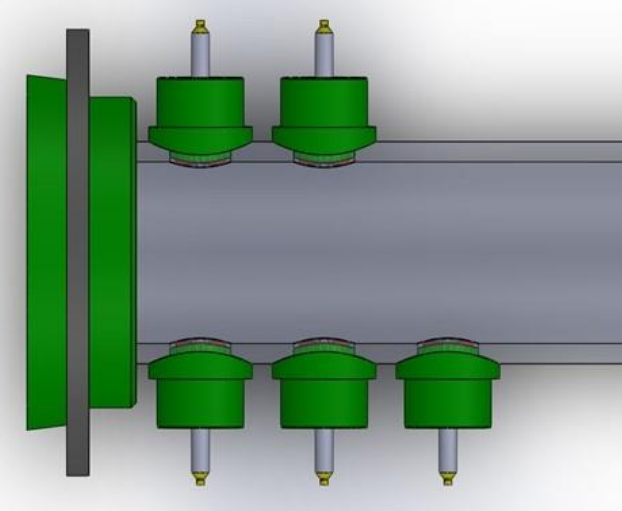

Figura 18 - Vista detalhada da instalação de microfones no tubo com 5 microfones. 


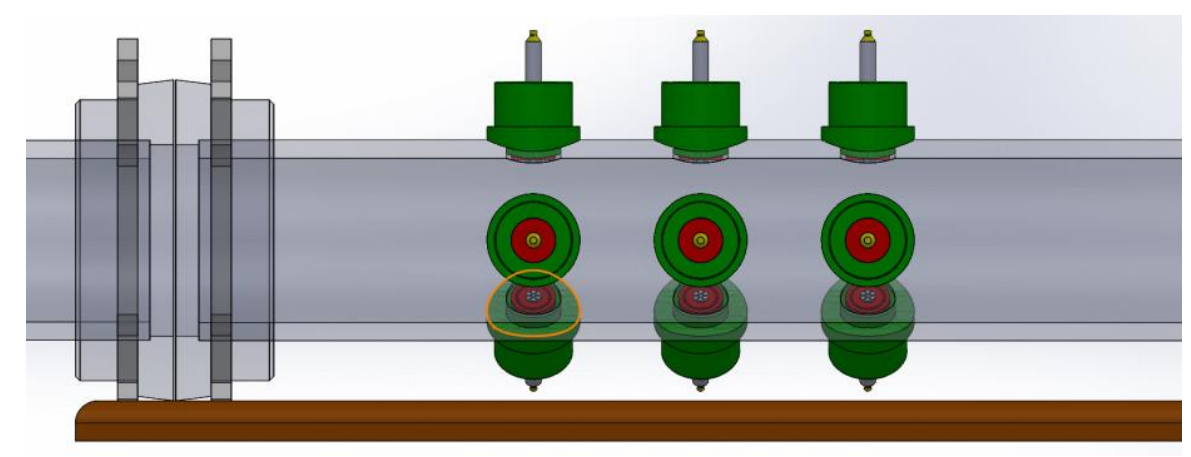

Figura 19 - Vista detalhada da instalação de microfones no tubo com 9 microfones.

As dimensões do tubo e o espaçamento entre microfones estão ilustradas no esquema da Figura 20.

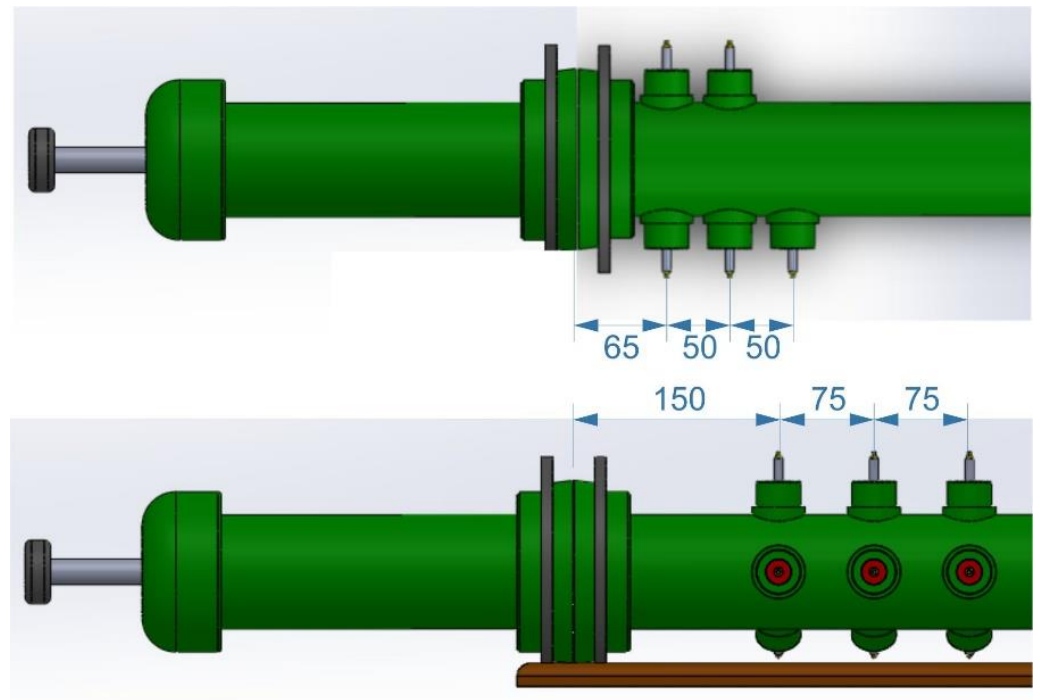

(b)

Figura 20 - Vista detalhada da instalação dos microfones nos tubos com suas respectivas medidas (a) montagem com 5 microfones e (b) montagem com 9 microfones..

A linha de produtos de tubulação escolhida para compor o sistema atende alguns requisitos práticos básicos ao sistema, descritos pelas normas ASTM E1050 e a ISO 10534-2, são esses:

a) O sistema é constituído por dois tubos, que são montados e desmontados com robustez. Entre a montagem dos dois tubos, há um compartimento para uma amostra de material, sustentada por um pistão feito de material rígido. Esse compartimento deve ser de maneira que a amostra de material também se ajuste com robustez.

b) $\mathrm{O}$ material que constitui o sistema deve ser maciço, com paredes de acabamento superficial liso e rígido. Além disso, as reentrâncias causadas pelas conexões instaladas para os microfones na parede devem ser mínimas; 
c) O tubo principal deve suportar conexões de modo a poder-se instrumentar seu interior. Essa conexão deve suportar a instalação e desinstalação fácil dos microfones, de movo a facilitar a calibração do sistema.

Essa linha de tubulação hidráulica foi projetada para transportar água quente com um nível considerável de carga, que é muito superior ao nível de pressão trabalhado para acústica. A nível de comparação, esse valor de pressão corresponde a $215 \mathrm{~dB}$ em relação ao limiar audível a $1 \mathrm{kHz}$.

O Anexo B descreve e mostrar cada um dos componentes utilizados para a montagem do sistema, assim como duas dimensões específicas e seus desenhos técnicos mecânicos.

Para instalar os microfones no sistema, foram utilizados selins de derivação da mesma linha do tubo. Os selins foram conectados a bocais de alumínio, onde os microfones são encaixados utilizando anéis elásticos. Os selins também foram colados à superfície do tubo, de modo a ter a parede interna do tubo o mais faceada possível com a terminação do selim. A montagem dos microfones aos selins está ilustrada nas Figuras 21 e 22.

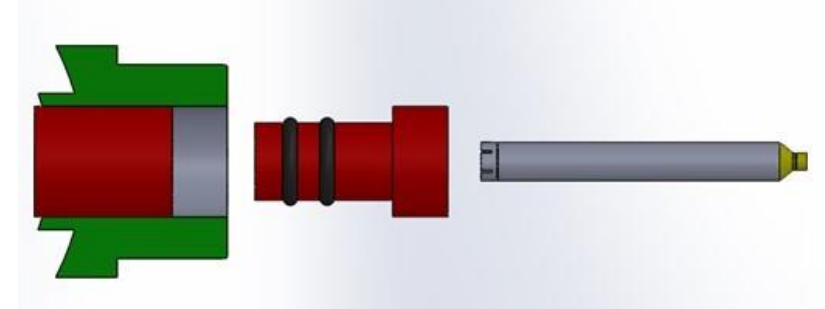

Figura 21 - Montagem do microfone no selim de derivação.

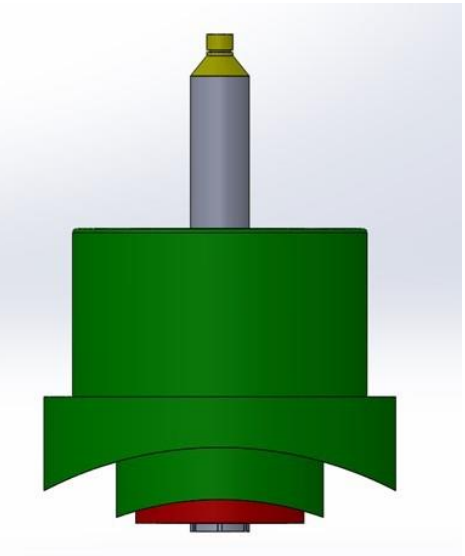

Figura 22 - Montagem final do microfone no selim de derivação. 
A Figura 23 mostra uma imagem da montagem final do sistema com 9 microfones, enquanto a Figura 24 mostra a montagem final do sistema com 5 microfones.

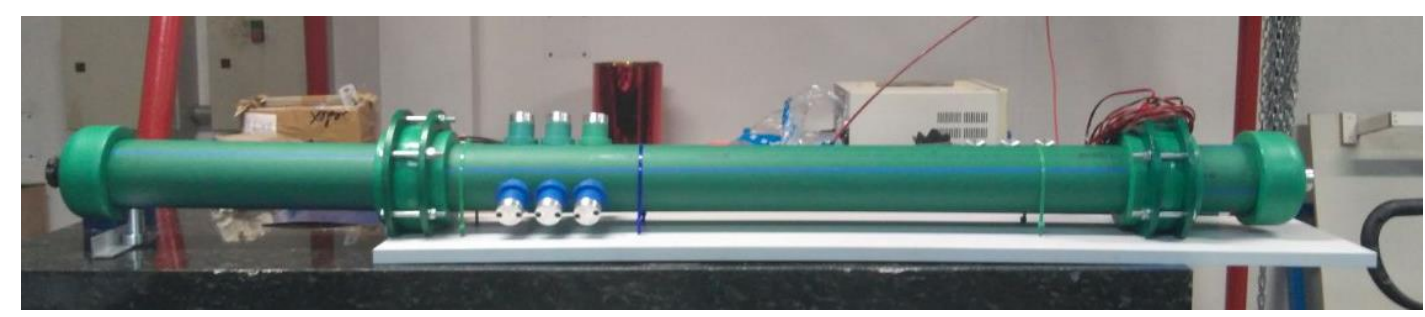

Figura 23 - Fotografia do tubo construído com 9 microfones.

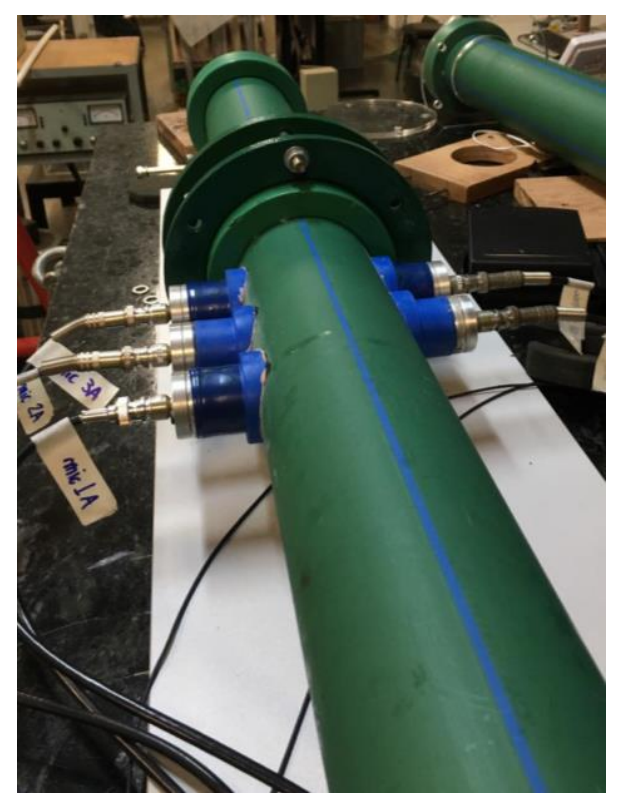

Figura 24 - Fotografia em detalhe do tubo com 5 microfones instalados.

\subsection{Ensaios para propagação plana de onda sonora}

O primeiro passo para a validação das bancadas construídas é observar o comportamento em vazio, isto é, sem amostras fixadas na terminação do tubo. Para esta seção, comparou-se o resultado de coeficiente de absorção sonora estimado pelo software LMS Scadas e o coeficiente calculado pelo código construído em MATLAB, mostrado em detalhes no Anexo D. Na Figura 25, essa comparação é mostrada, onde se pode observar uma boa consistência entre as curvas, apesar de o coeficiente calculado estar ligeiramente superior ao coeficiente estimado pelo software. 
Sendo uma terminação rígida, espera-se que o coeficiente de absorção sonora da terminação seja nulo, o que não acontece em nenhuma das curvas. Isso aponta que a terminação usada, e o material utilizado no sistema, não é exatamente rígida.

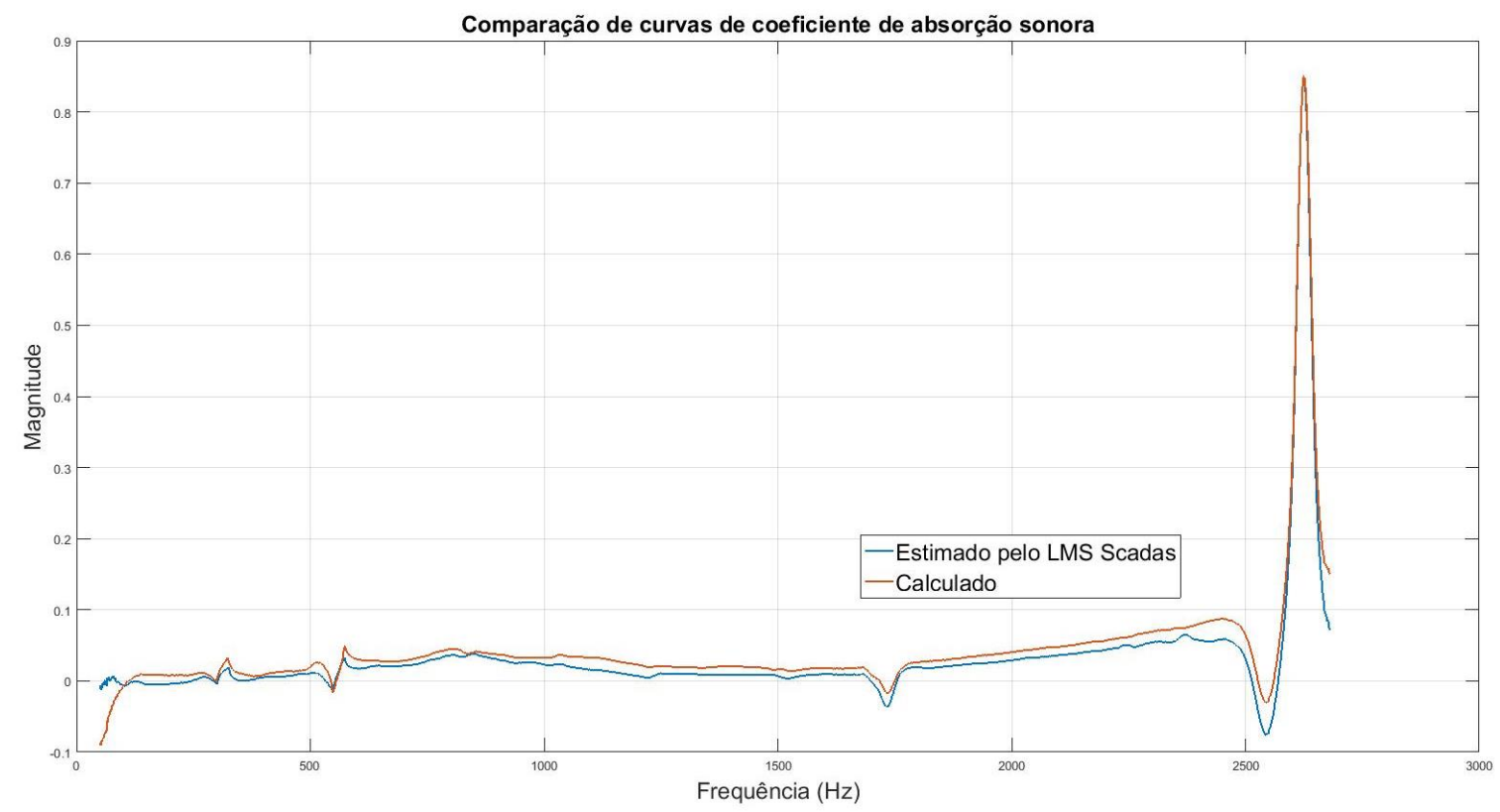

Figura 25 - Comparação entre curvas de coeficiente de absorção sonora para terminação plana, entre o LMS Scadas e o método utilizado.

A Tabela 1 compara os valores de coeficiente de absorção sonora, em RMS, para a terminação de PPR Industrial nas 15 primeiras frequências centrais de oitavas na banda plana.

Ainda, a fim de observar o comportamento dos sistemas na banda de frequência em que se espera propagação plana de ondas, comparou-se os valores de pressão sonora medidos em uma mesma seção na bancada com 9 microfones instalados, onde se mede em 3 pontos distintos numa mesma seção. A Figura 26 mostra a comparação das relações de magnitudes entre as medidas feitas na seção A do tubo.

Observa-se que todas as curvas estão uniformes entre si e majoritariamente coincidentes com a unidade, que é o esperado para uma terminação rígida. Ainda, percebe-se que essas curvas se distanciam com a aproximação da frequência de corte para o regime plano, que ocorre por volta de $2700 \mathrm{~Hz}$. Os efeitos desse comportamento também podem ser observados nos números da Tabela 1, em que o coeficiente de absorção sonora para o PPR industrial não é completamente nulo na banda de frequência. Para as frequências abaixo do corte, as razões entre as amplitudes das relações têm uma diferença de $1 \%$ entre si, exceto em 3 regiões, que correspondem às frequências de ressonância da colune de ar no tubo. 
Tabela 1 - Comparação das médias quadráticas de coeficientes de absorção sonora nas oitavas da banda de propagação plana. Valores em RMS por oitava.

\begin{tabular}{|c|c|c|}
\hline Freq. $[\mathbf{H z}]$ & $\begin{array}{c}\text { Estimado pelo } \\
\text { LMS Scadas }\end{array}$ & Calculado \\
$\mathbf{1 0 0}$ & 0 & 0 \\
$\mathbf{1 2 5}$ & 0 & 0 \\
$\mathbf{1 6 0}$ & 0 & 0 \\
$\mathbf{2 0 0}$ & 0 & 0 \\
$\mathbf{2 5 0}$ & 0,01 & 0,01 \\
\hline $\mathbf{3 1 5}$ & 0 & 0,02 \\
$\mathbf{4 0 0}$ & 0,01 & 0,01 \\
\hline $\mathbf{5 0 0}$ & 0,02 & 0,02 \\
$\mathbf{6 3 0}$ & 0,03 & 0,03 \\
\hline $\mathbf{8 0 0}$ & 0,02 & 0,04 \\
\hline $\mathbf{1 0 0 0}$ & 0,02 & 0,03 \\
\hline $\mathbf{1 2 5 0}$ & 0,01 & 0,02 \\
$\mathbf{1 6 0 0}$ & 0,03 & 0,02 \\
\hline $\mathbf{2 0 0 0}$ & 0,03 & 0,04 \\
$\mathbf{2 5 0 0}$ & & 0,06 \\
\hline
\end{tabular}

Com esses resultados, já é possível afirmar a consistência dos resultados observados nos tubos de impedância. Além disso, percebe-se que o material utilizado não é exatamente rígido, o que compromete a exatidão dos resultados, mesmo sem comprometer sua precisão.

\subsection{Identificação de modos de propagação azimutais}

O objetivo desta seção é reproduzir o método descrito na Seção 4.2. A título de referência, foi realizada uma análise modal experimental no tubo de impedância com 9 microfones utilizando os valores de pressão observados e o software LMS Scadas, rodando no Test.Lab. Na sequência, foram traçadas as curvas das somas das amplitudes de pressão, duas a duas por seção, a fim de identificar os modos não-normais superiores à frequência de corte para o diâmetro dado. Por fim, as frequências identificadas pela análise modal foram usadas de referência para avaliar as frequências de modos azimutais identificados nas curvas de amplitudes somadas. 


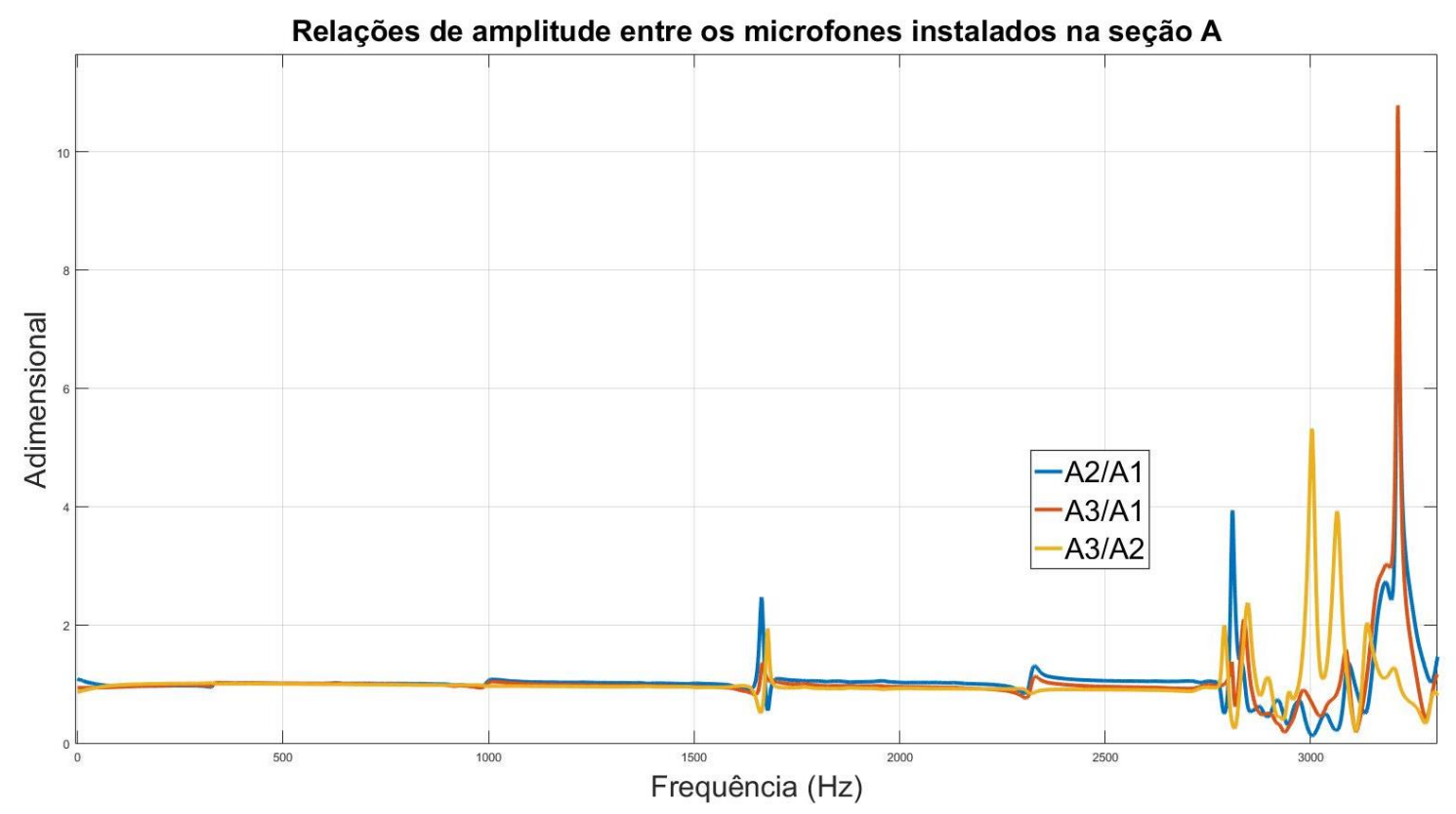

Figura 26 - Comparação das amplitudes de pressão sonora para os microfones instalados em uma mesma seção do tubo.

Aqui, levanta-se mais uma hipótese: supõe-se que os modos não-normais não são favorecidos na operação comum de tubo de impedância devido a que o deslocamento da membrana do alto falante se dá na direção axial do tubo. Para contornar esse problema, foi adicionado um anteparo na extremidade do falante, que desequilibra a emissão sonora plana do alto falante, favorecendo o aparecimento de modos não-normais no tubo. Esse anteparo é mostrado na Figura 27. Além disso, esses ensaios foram feitos utilizando a terminação rígida do tubo.

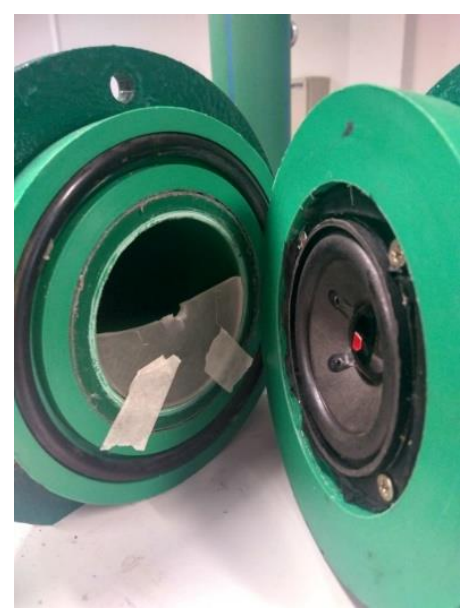

Figura 27 - Fotografia em detalhe do anteparo para provocar os modos azimutais. 
Para sustentar a hipótese de desequilíbrio levantada, a Figura 28 compara os resultados de coeficiente de absorção sonora para a terminação rígida, para esse sistema sem e com o anteparo da entrada do sistema. Observa-se que, com o anteparo, existem mais regiões de instabilidade acima da frequência de corte de propagação plana, sem diminuir as coerências da medida, o que indica regime permanente para esse ensaio.

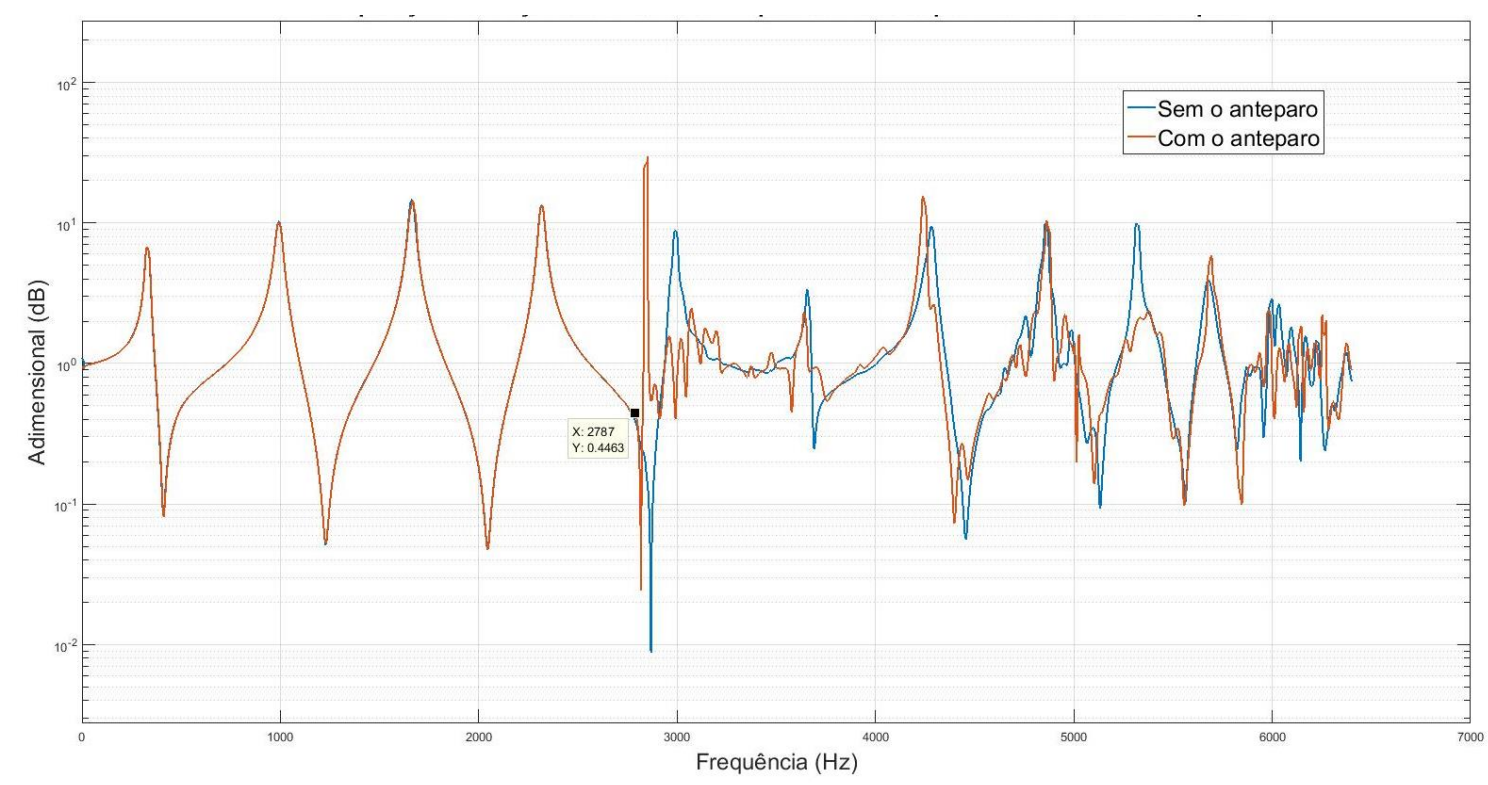

Figura 28 - Comparação entre funções de transferência para entrada de pressão no sistema, com e sem anteparo.

Para o processo de análise modal experimental, o sinal elétrico enviado aos terminais do alto falante foi adotado como referência enquanto considera-se como saída os valores de pressão medidos em cada um dos 9 microfones instalados no sistema. Sobre cada uma dessas curvas, realiza-se um ajuste de curva polinomial a fim de estimar os parâmetros modais do sistema. Por fim, baseado nos parâmetros modais estimados, é possível indicar alguns dos modos de vibrar do sistema, que devem evidenciar a característica plana ou azimutal de cada um. Esta análise pode ser feita tanto observando-se a fase relativa entre cada ponto de resposta (pressão acústica) ou graficamente, plotando os referidos modos.

A análise modal experimental gerou 14 visualizações de modos azimutais, que estão dispostas no Anexo C. Para visualizar esses modos, foi gerada uma projeção do corte do tubo pela sua geratriz. Por essa projeção é possível observar o comportamento da pressão sonora observada em cada ponto, através de uma relação de deslocamento e pressão. A Figura 29(a) mostra como essa projeção foi criada. Onde uma projeção gerada por um corte em geratriz ao 
cilindro, é associada com o deslocamento de um conjunto de pontos alinhados entre si em paralelogramos.

A Figura 29 também ilustra duas visualizações modais, para um modo plano e para um modo azimutal.

Com o auxílio da atribuição espacial à pressão sonora, pode-se gerar a visualização desses modos, que pode ser vista na Figura 29.

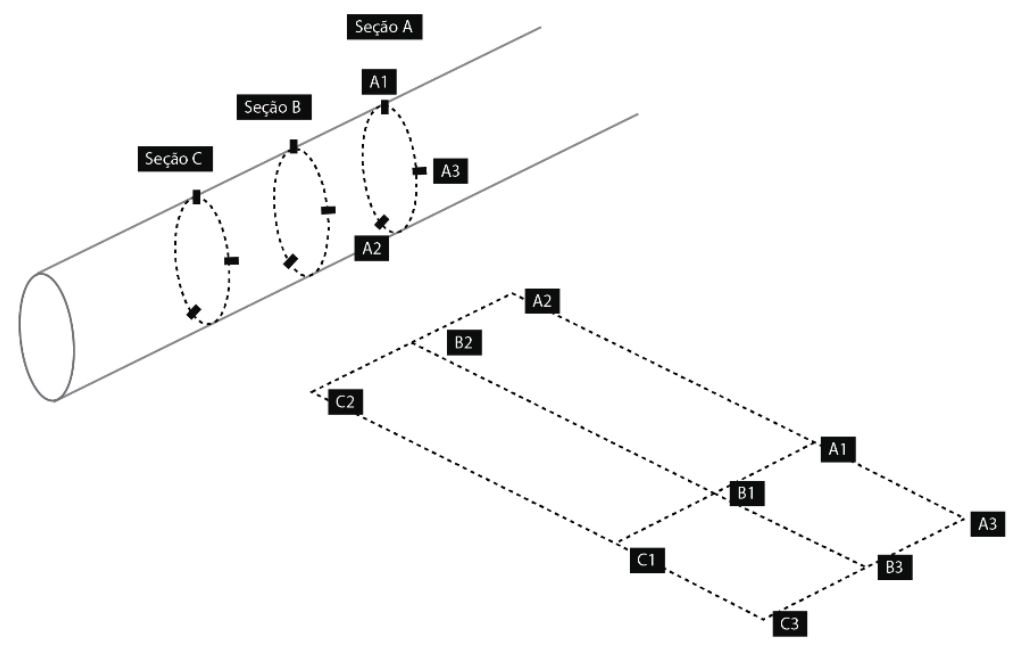

Figura 29(a)

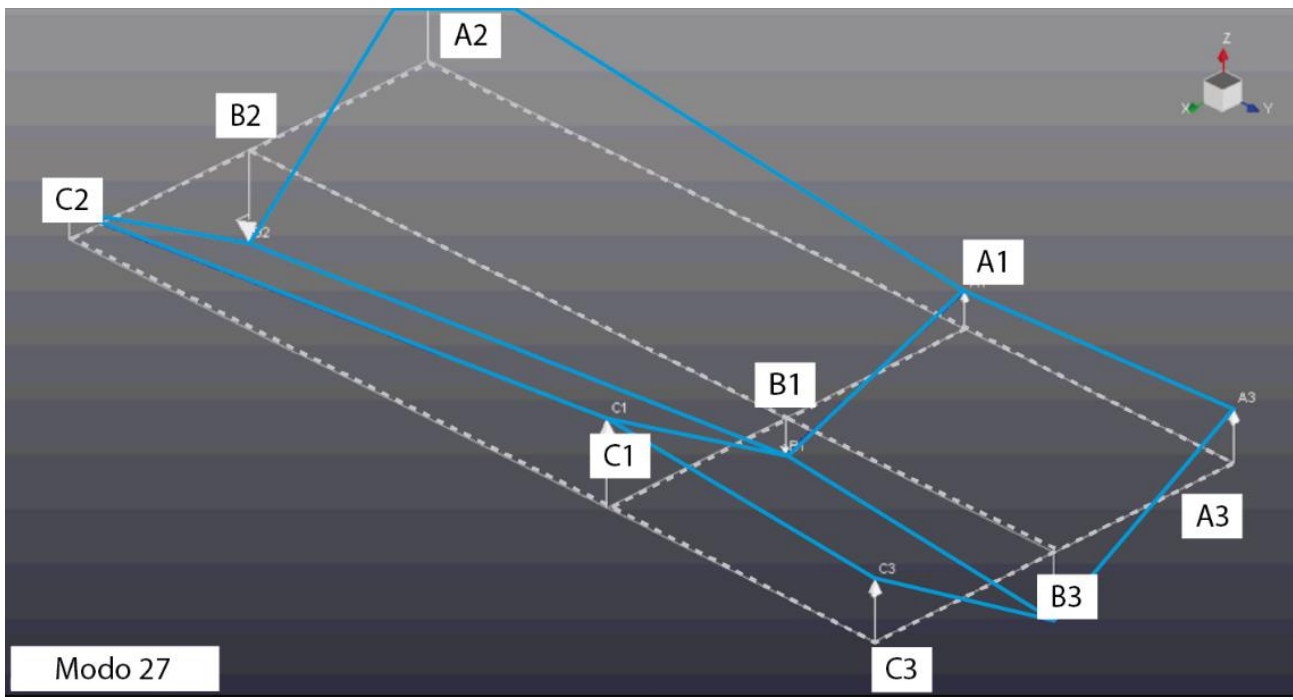

Figura 29(b) 


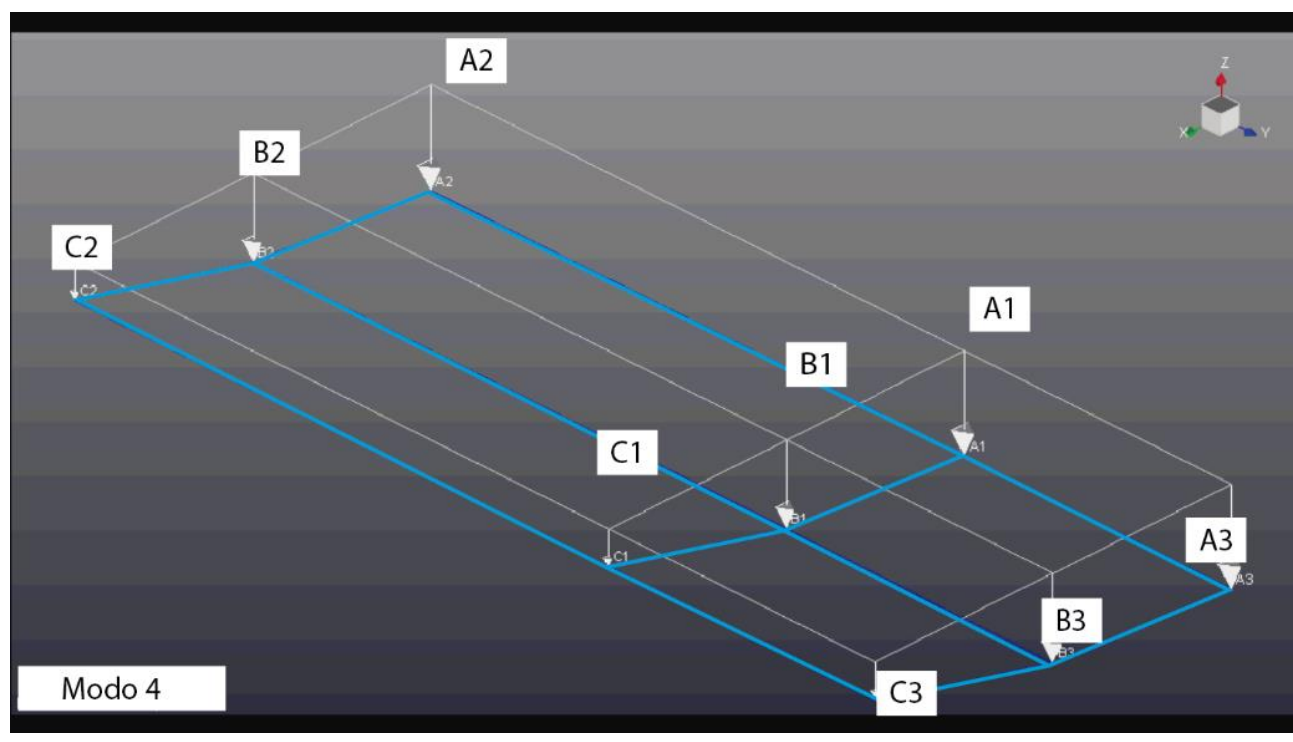

Figura 29(c)

Figura 29 - Visualização de modos normais e azimutais pela análise modal acústica. (a) Esquema de projeção da visualização; (b) Visualização espacial de um dos modos azimutais em projeção identificado pelo LMS Scadas;

(c) Visualização espacial de um dos modos planos em projeção identificados pelo LMS Scadas

Por este método, foram identificados 32 modos acústicos, numa faixa de frequência de $100 \mathrm{~Hz}$ a $4000 \mathrm{~Hz}$. Desses 32 modos, os 18 primeiros correspondem aos modos planos de propagação, sendo o $18^{\circ}$ modo correspondente à frequência de $2780 \mathrm{~Hz}$. Nesses 18 primeiros modos identificados, todos os microfones de uma mesma seção possuem amplitudes e fases equivalentes, enquanto há diferenças de amplitude e de fase entre os microfones de seções diferentes, segundo os modos longitudinais de propagação.

Os 14 últimos modos identificados são, em sua maioria, modos não-normais azimutais. Nesses modos, há diferenças de amplitude e de fase em, pelo menos, dois dos três microfones de cada seção. A Tabela 2 mostra os valores de frequência para os 14 primeiros modos acima da frequência de corte encontrados na análise modal. Cada modo é relacionado coma fase da função de pressão considerando somente a sua parte real, aproximada para 0 ou $\pi$, já que são considerados apenas os modos reais. Por fim, como observado na Seção 3.5, vale ressaltar que os modos radiais para a estrutura cilíndrica dada, tem sua frequência de ativação perto de 5400 $\mathrm{Hz}$ de frequência, aproximadamente. Ainda, a instrumentação proposta permite somente a identificação destes modos, uma vez que só há pontos de pressão tomados próximos ao diâmetro do tubo. 
Tabela 2 - Ângulos de fase relativa entre os microfones do arranjo para modos acima do $1^{\circ}$ modo azimutal.

\begin{tabular}{|c|c|c|c|c|c|c|c|c|c|}
\cline { 2 - 9 } & $\begin{array}{c}\text { Seção A } \\
\text { Mic \# }\end{array}$ & \multicolumn{3}{c|}{$\begin{array}{c}\text { Seção B } \\
\text { Mic \# }\end{array}$} & \multicolumn{2}{c|}{$\begin{array}{c}\text { Seção C } \\
\text { Mic \# }\end{array}$} \\
\hline $\begin{array}{c}\text { \# Modo - Frequência } \\
\text { (Hz) }\end{array}$ & $\mathbf{1}$ & $\mathbf{2}$ & $\mathbf{3}$ & $\mathbf{1}$ & $\mathbf{2}$ & $\mathbf{3}$ & $\mathbf{1}$ & $\mathbf{2}$ & $\mathbf{3}$ \\
\hline $\mathbf{1 9}-2821,3 \mathrm{~Hz}$ & 0 & 0 & $\pi$ & 0 & 0 & $\pi$ & 0 & 0 & $\pi$ \\
\hline $\mathbf{2 0}-2829,1 \mathrm{~Hz}$ & 0 & 0 & $\pi$ & 0 & 0 & $\pi$ & 0 & 0 & $\pi$ \\
\hline $\mathbf{2 1}-2870,9 \mathrm{~Hz}$ & 0 & 0 & $\pi$ & $\pi$ & 0 & $\pi$ & $\pi$ & 0 & $\pi$ \\
\hline $\mathbf{2 2}-2980,8 \mathrm{~Hz}$ & 0 & $\pi$ & $\pi$ & 0 & $\pi$ & $\pi$ & $\pi$ & $\pi$ & 0 \\
\hline $\mathbf{2 3}-3057,8 \mathrm{~Hz}$ & 0 & $\pi$ & $\pi$ & 0 & 0 & 0 & $\pi$ & 0 & $\pi$ \\
\hline $\mathbf{2 4}-3071,9 \mathrm{~Hz}$ & 0 & 0 & $\pi$ & 0 & 0 & 0 & 0 & $\pi$ & 0 \\
\hline $\mathbf{2 5}-3137,7 \mathrm{~Hz}$ & 0 & $\pi$ & $\pi$ & 0 & $\pi$ & $\pi$ & $\pi$ & $\pi$ & $\pi$ \\
\hline $\mathbf{2 6}-3190,7 \mathrm{~Hz}$ & 0 & 0 & 0 & 0 & $\pi$ & $\pi$ & 0 & $\pi$ & $\pi$ \\
$* \mathbf{2 7}-3268,5 \mathrm{~Hz}$ & 0 & 0 & 0 & 0 & 0 & 0 & 0 & 0 & 0 \\
\hline $\mathbf{2 8}-3366,2 \mathrm{~Hz}$ & 0 & $\pi$ & 0 & 0 & $\pi$ & $\pi$ & $\pi$ & 0 & 0 \\
$* \mathbf{2 9}-3448,7 \mathrm{~Hz}$ & 0 & 0 & 0 & 0 & 0 & 0 & 0 & 0 & 0 \\
\hline $\mathbf{3 0}-3589,5 \mathrm{~Hz}$ & 0 & $\pi$ & $\pi$ & $\pi$ & 0 & $\pi$ & 0 & $\pi$ & 0 \\
\hline $\mathbf{3 1}-3654,1 \mathrm{~Hz}$ & 0 & $\pi$ & 0 & $\pi$ & 0 & $\pi$ & 0 & $\pi$ & 0 \\
\hline $\mathbf{3 2}-3803,2 \mathrm{~Hz}$ & 0 & 0 & 0 & $\pi$ & 0 & 0 & 0 & 0 & 0 \\
\hline
\end{tabular}

Agora, é esperado que se encontre os mesmos modos não-normais identificados na Tabela 3 apenas com a observação dos dados de pressão aquisitados pelos microfones durante o ensaio descrito. Como apontado na Seção 4.2, assume-se que quando a soma algébrica simples das amplitudes de pressão entre dois microfones de uma mesma seção resulta em m valor menor que as parcelas individualmente, há uma diferença de fase entre essas funções de pressão, o que indica a existência de um número ímpar de linhas nodais entre os pontos de medida e, possivelmente, um modo azimutal. Com base nisto, um código em MATLAB foi escrito com o objetivo de comparar todas as curvas traçadas e identificar esses pontos, ou regiões, de soma destrutiva. Este código gera curvas que são nulas quando a soma das amplitudes é maior que pelo menos uma das parcelas, e iguais a 1 quando a soma das amplitudes é menor que as parcelas. Nessas frequências, há um indicativo de modo azimutal. As Figuras 30, 31 e 32 mostram os gráficos de comparação. 

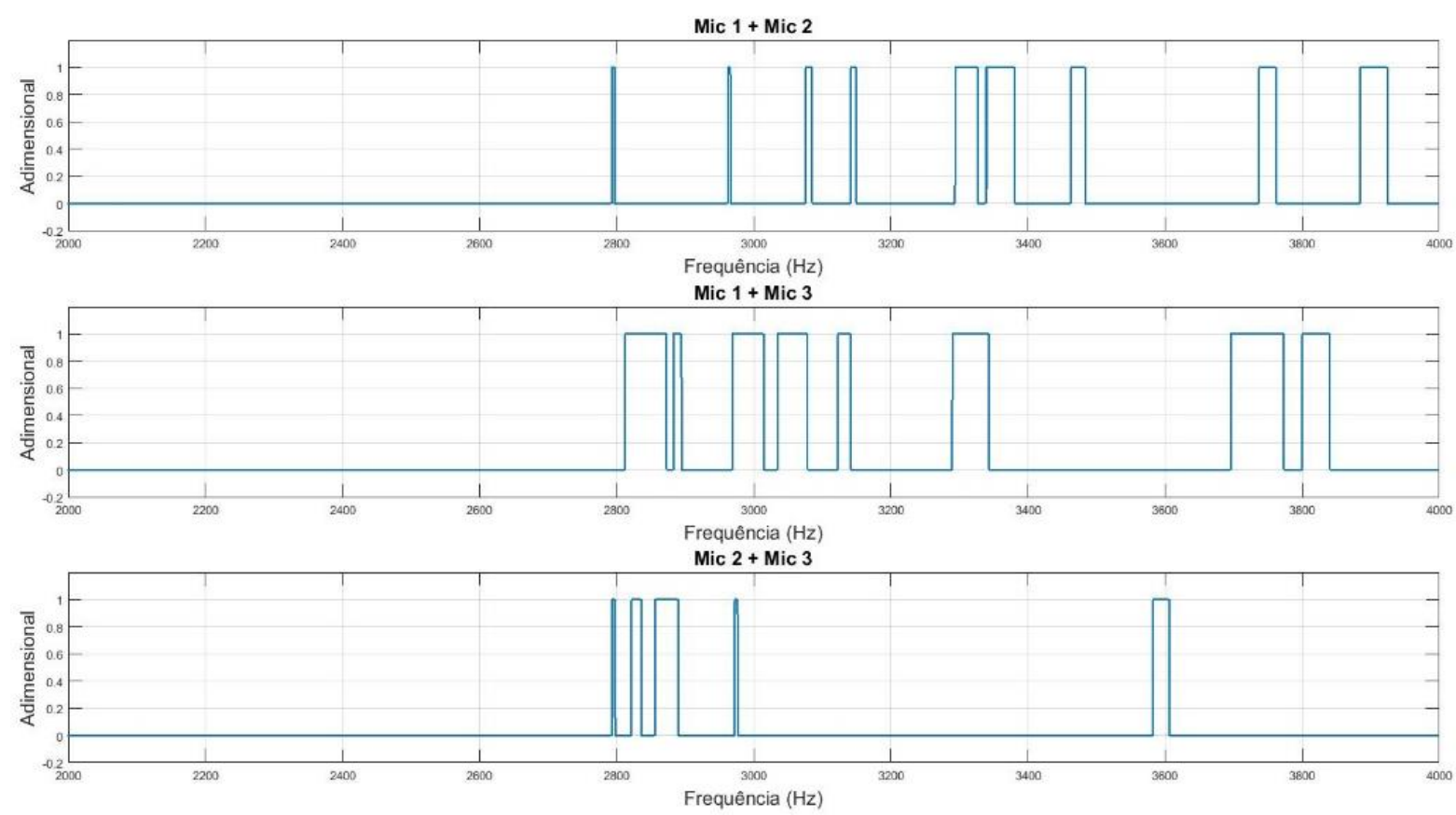

Figura 30 - Visualização de frequências modais azimutais para a seção A.
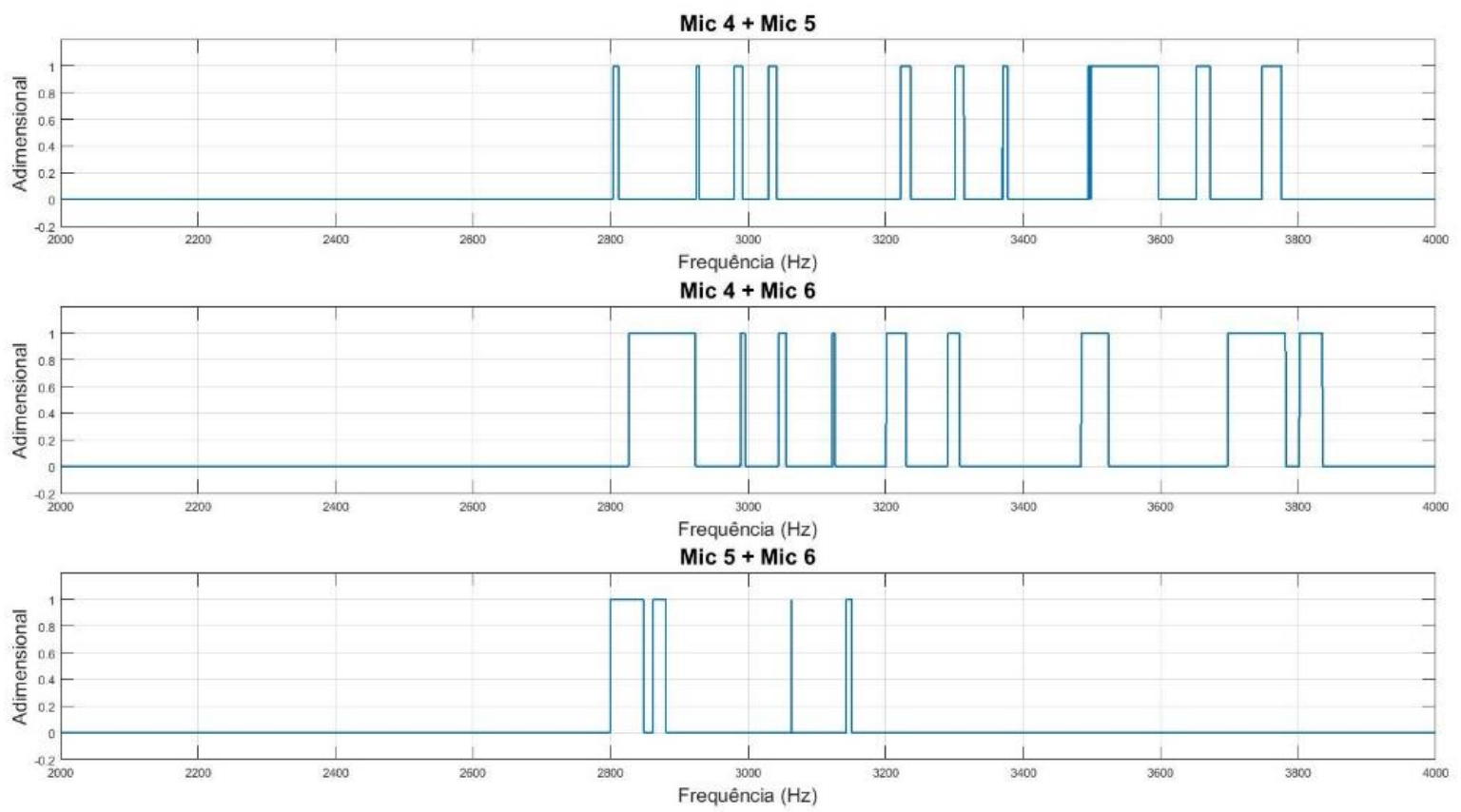

Figura 31 - Visualização de frequências modais azimutais para a seção B. 


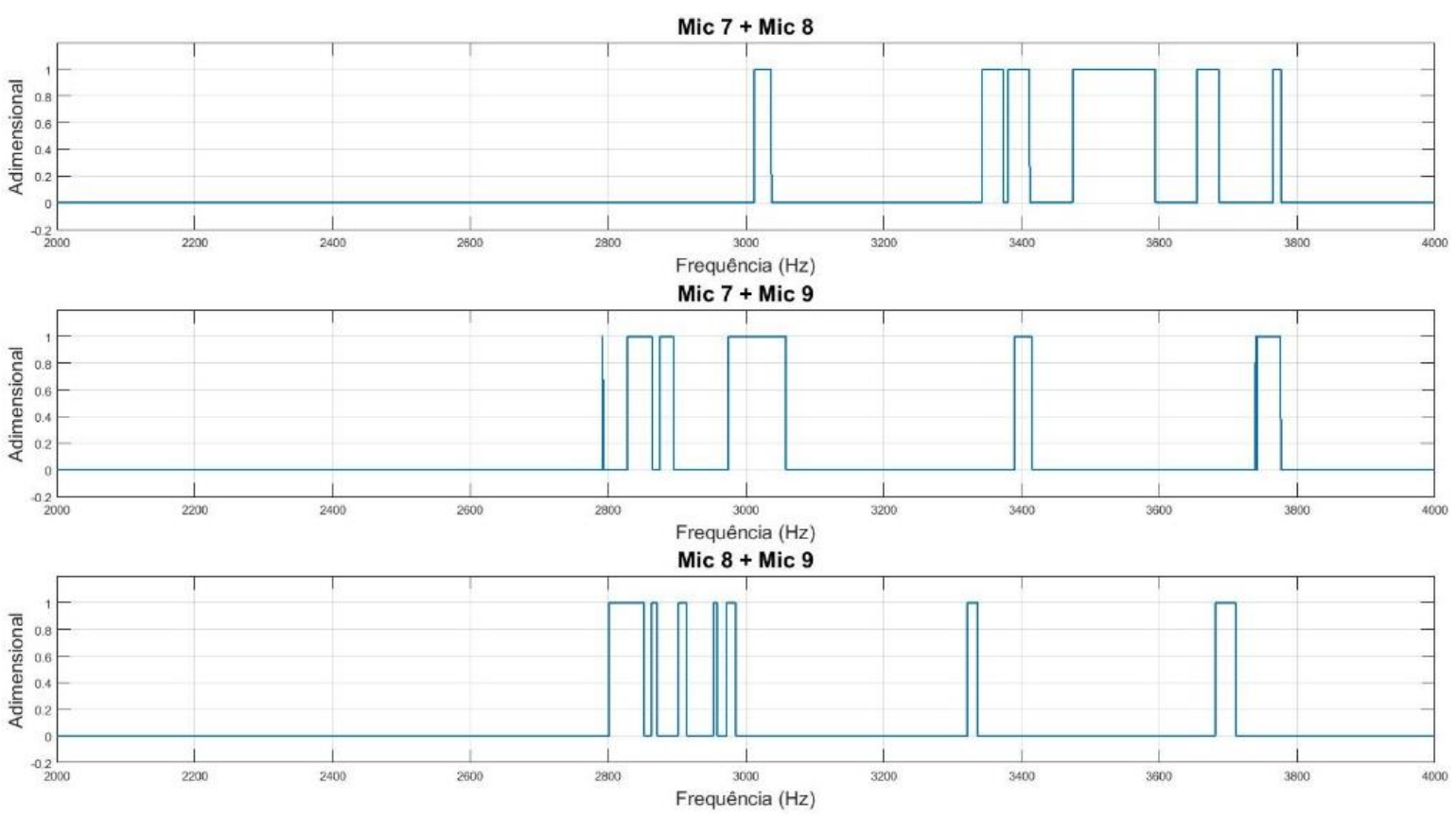

Figura 32 - Visualização de frequências modais azimutais para a seção C.

Verifica-se que as frequências dos modos indicadas pelo método ainda possuem uma baixa precisão, caso se leve em consideração as frequências modais indicadas pela análise modal. Ao todo, considerando-se as outras seções, o método desenvolvido consegue identificar 10 dos 14 modos não normais encontrados pela análise modal. Contudo, é possível verificar padrões claros entre alguns dos valores, principalmente aqueles ligeiramente acima da frequência de corte para ondas planas, onde ocorrem os primeiros modos azimutais. A Tabela 3 destaca a proximidade de alguns valores próximos obtidos pelos dois métodos.

A consistência de resultados nas frequências ligeiramente superiores ao corte indica um melhor desempenho do método para o primeiro modo de propagação azimutal do sistema. Isso ocorre porque, acima dessa região, já é possível que se formem modos de propagação e que há mais de uma linha nodal azimutal entre dois pontos de medida. Nesse caso, para uma quantidade par de linhas nodais, a soma entre duas medidas é, de fato, superior às suas parcelas, entretanto, o método desenvolvido não contempla essa situação.

\subsection{Ensaios para extensão da frequência útil em tubo de impedância}

Para este ensaio, busca-se estudar os efeitos de combinação das medias em uma mesma seção na avaliação de coeficiente de absorção sonora para incidência normal em frequências acima da frequência de ativação do primeiro modo azimutal em tubo de impedância. 
Tabela 3 - Frequências estimadas pelos métodos da soma e pela análise modal.

\begin{tabular}{|c|c|c|c|c|c|}
\hline \multicolumn{2}{|c|}{$\begin{array}{c}\text { Mic. 1 + Mic. 2 } \\
\text { Freq. (Hz) }\end{array}$} & \multicolumn{2}{c|}{$\begin{array}{c}\text { Mic. 1 + Mic. 3 } \\
\text { Freq. (Hz) }\end{array}$} & \multicolumn{2}{c|}{$\begin{array}{c}\text { Mic. 2 + Mic. 3 } \\
\text { Freq. (Hz) }\end{array}$} \\
\hline $\begin{array}{c}\text { Experi } \\
\text { mental }\end{array}$ & $\begin{array}{c}\text { Modal } \\
\text { acústic } \\
\text { a }\end{array}$ & $\begin{array}{c}\text { Experi } \\
\text { mental }\end{array}$ & $\begin{array}{c}\text { Modal } \\
\text { acústic } \\
\text { a }\end{array}$ & $\begin{array}{c}\text { Experi } \\
\text { mental }\end{array}$ & Modal \\
2793 & & & 2821 & 2795 & 2821 \\
2963 & 2980 & 2841 & 2829 & 2830 & 2829 \\
3085 & 3058 & 2891 & 2871 & 2876 & 2871 \\
3144 & 3138 & 2989 & 2981 & 2974 & 3071 \\
3310 & & 3061 & 3058 & & 3366 \\
3373 & 3366 & & 3072 & 3595 & \\
3481 & & 3138 & 3138 & & 3654 \\
3745 & & 3312 & & & \\
3915 & & 3729 & 3590 & & \\
\hline
\end{tabular}

Com 9 microfones instalados no sistema, 3 em cada seção, foram feitos 3 códigos em MATLAB para se traçar a curva de fator de reflexão para 3 diferentes tipos de arranjos de medidas. Esses códigos são mostrados no Anexo E.

O primeiro arranjo leva em consideração a soma das três medidas feitas em cada seção, de modo a gerar apenas uma função de transferência para cada seção. Além disso, foram consideradas apenas as funções transferência entra seção adjacentes.

O segundo arranjo levou em consideração a somatória dos microfones de cada seção tomados dois a dois, o que gera 9 combinações de funções de transferência para duas seções adjacentes. No total, foram consideradas 19 funções de transferência para esse arranjo.

O terceiro arranjo leva em consideração as medidas individualmente de cada seção, combinada com outra medida de uma seção adjacente. Para esse caso, não se considera os efeitos de soma, já que as medidas de cada seção são tomadas individualmente. Aqui, também foram formadas 19 funções de transferência.

As curvas de fator de reflexão para os 3 casos descritos estão ilustradas na Figura 33, comparados para o fator de reflexão tomado individualmente, sem o método de aproximação quadrática. Para melhor discussão, as Figuras 34 e 35 trazem os detalhes das curvas para o regime de propagação plana e para valores de frequência acima da primeira ativação azimutal. 
A Figura 34 traz o detalhe de propagação plana. Apesar de as curvas geradas com os arranjos estarem próximas entre sim, diferem da curva de fator de reflexão original. Isso acontece porque, para essa banda de frequência, os valores de fator de reflexão são muito parecidos entre si, para qualquer combinação de duas medidas aleatórias em seções adjacentes, já que o valor de pressão sonora em cada seção é uniforme nessa banda. Além disso, tem-se mais uma indicação de que a terminação utilizada no sistema não é exatamente rígida, já que idealmente a curva de fator de reflexão deve ser unitária para a banda de propagação plana.

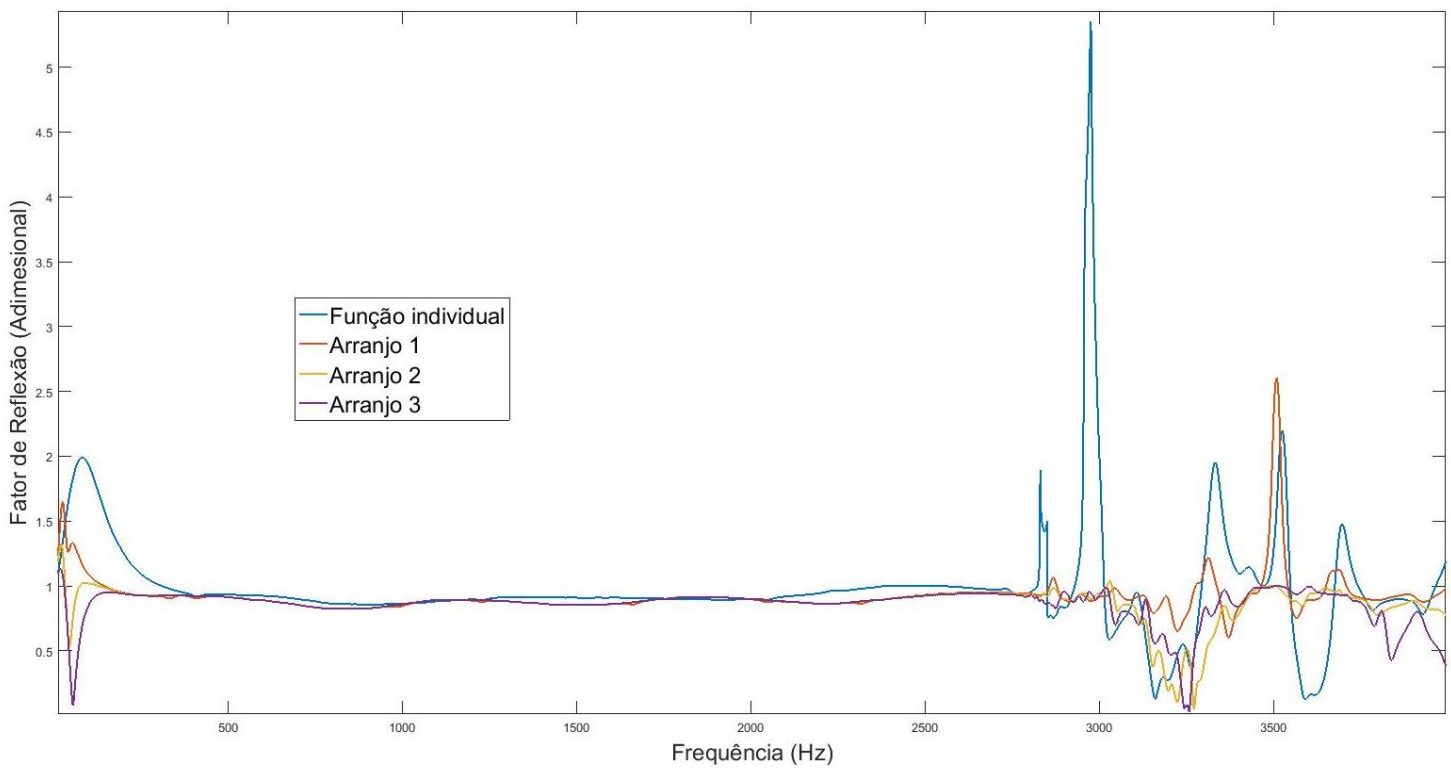

Figura 33 - Comparação entre curvas de fatores de reflexão para os três arranjos propostos e para a função de transferência entre um par de microfones.

Já a Figura 35 traz o detalhe da banda de frequência próxima a ativação dos modos azimutais. Para essa banda, percebe-se que a estimativa de fator de reflexão para uma função de transferência individual do tubo não é boa porque apresenta picos de valores muito maiores que 1, o que não é satisfatório conceitualmente. Como observado anteriormente, isso acontece devido a diferença de fase entre as medidas tomadas. Para as curvas geradas pela aproximação quadrática, esses picos de valores são atenuados, como esperado, até $3100 \mathrm{~Hz}$, aproximadamente, a partir de onde esses valores também divergem da unidade para mais de $15 \%$. 


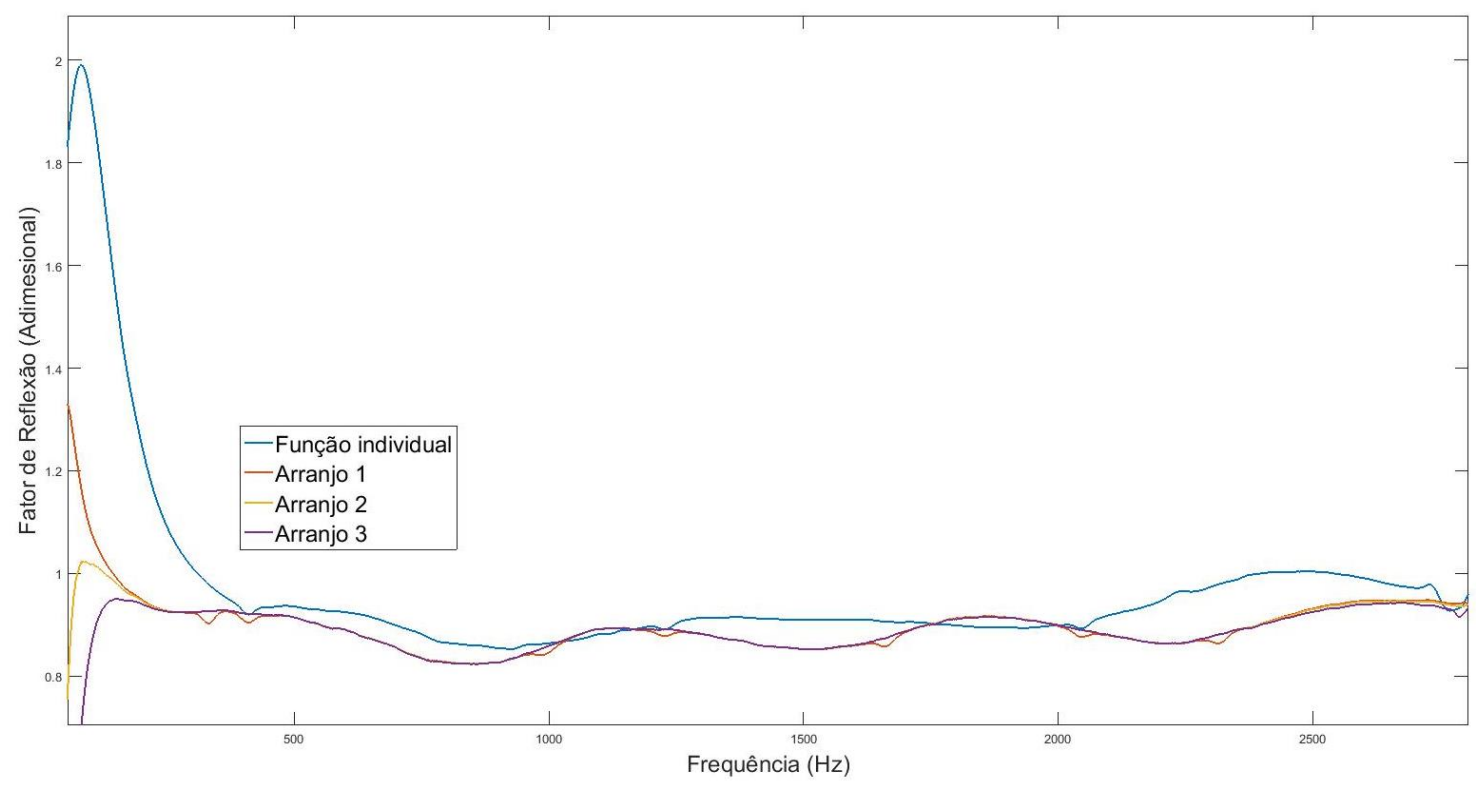

Figura 34 - Detalhe da comparação de fatores de reflexão entre os arranjos propostos com detalhe na faixa plana de propagação sonora.

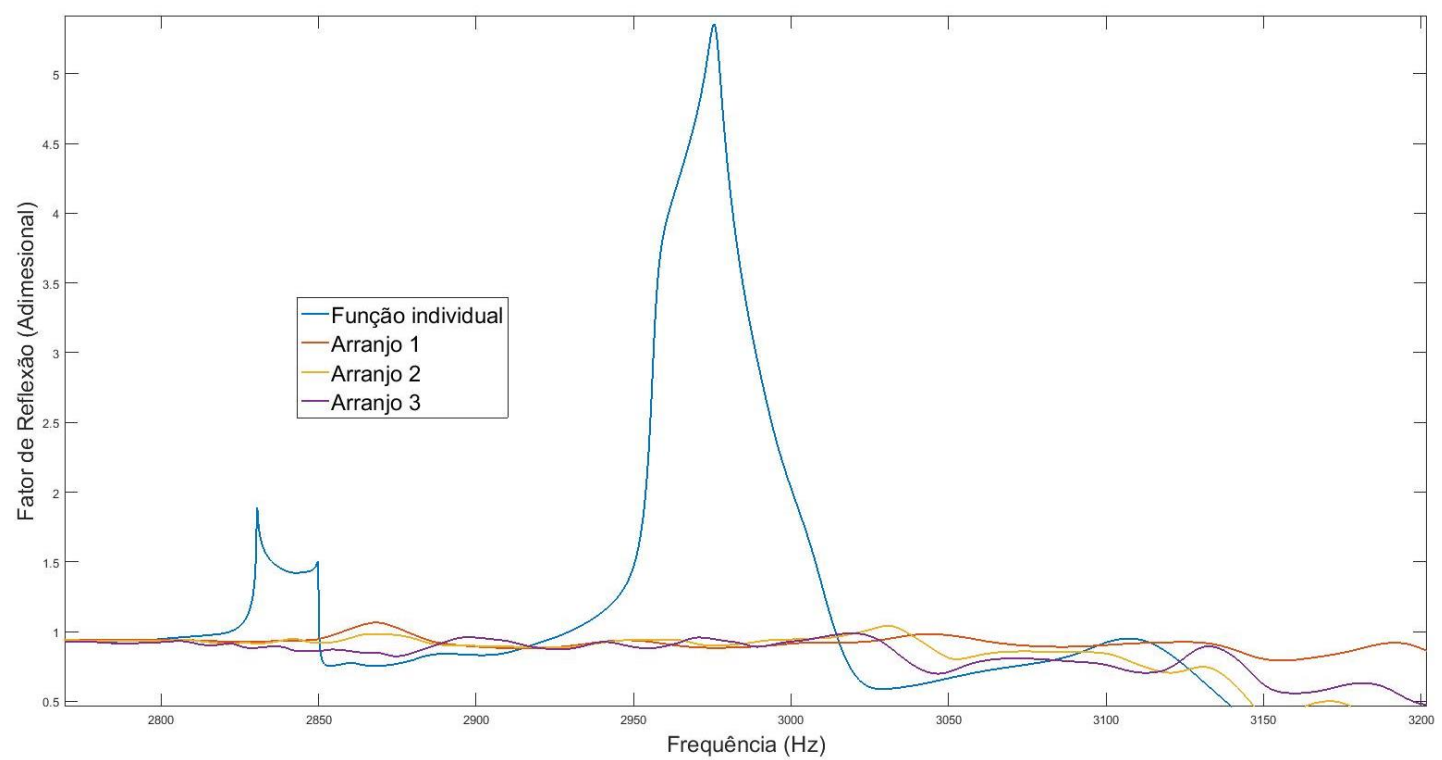

Figura 35 - Detalhe da comparação de fatores de reflexão entre os arranjos propostos com detalhe na banda de frequência superior a primeira ativação azimutal.

Ainda assim, o primeiro arranjo de medidas é muito mais uniforme para valores acima da frequência de ativação azimutal, sendo coerente com os valores para a propagação plana. Isso acontece porque, em uma mesma seção, as fases são compensadas entre si, como observado na Seção 4.3. Para os outros arranjos, a diferença de fase entre microfones alinhados ainda tem influência no cálculo, já que não se pode garantir que duas medidas tomadas aleatoriamente em seções adjacentes possuem fases inversas. 
Para visualizar melhor essas diferenças, a Tabela 5 mostra o valor RMS de fator de reflexão para essas curvas, avaliado para a banda de propagação plana, de $0 \mathrm{~Hz}$ a $2700 \mathrm{~Hz}$, e para a banda de ativação azimutal, de $2700 \mathrm{~Hz}$ a $3200 \mathrm{~Hz}$.

Tabela 4 - Comparação de médias quadráticas de fatores de reflexão entre a banda plana e a banda de ativação azimutal. Valores adimensionais em RMS.

\begin{tabular}{|c|c|c|}
\hline & $\begin{array}{c}\text { Banda } \\
\text { plana }\end{array}$ & $\begin{array}{c}\text { Banda de } \\
\text { ativação } \\
\text { azimutal }\end{array}$ \\
\hline Arranjo 1 & 0,9357 & 0,9439 \\
Arranjo 2 & 0,9185 & 0,8853 \\
\hline Arranjo 3 & 0,9058 & 0,8747 \\
Função individual & 0,9547 & 0,8669 \\
\hline
\end{tabular}

Para este estudo, ainda é necessário que se compare os métodos para uma terminação rígida o suficiente. Assim, é possível avaliar se a atenuação geral do método em relação à unidade é inerente ao cálculo ou à terminação do sistema. 



\section{Conclusões}

Este trabalho apresentou a fundamentação teórica e o desenvolvimento de protótipos físicos de uma guia de ondas acústica, mais especificamente, um tubo de impedância. Este dispositivo pode ser usado para identificação de propriedades de absorção/reflexão de amostras de materiais sujeitas a incidência de ondas planas. Contudo, há limitações no uso quanto ao diâmetro da amostra e a banda de frequência, que procuram ser abordadas neste trabalho com o uso de uma instrumentação estendida.

Desta forma, foi possível reproduzir ensaios clássicos de tubo de impedância em laboratório utilizando-se dois tubos de impedância projetados separadamente. Esses ensaios, amparados por normas internacionais e amplamente utilizado na indústria de engenharia acústica, são resultados de simplificações de equações que governam a propagação sonora no tempo e no espaço.

O processo de desenvolvimento matemático que foi explorado no trabalho buscou esclarecer quais hipóteses podem ser feitas para que seja possível reproduzir e medir fenômenos mais amplos que àqueles descritos pelas normas de estimativa de coeficiente de absorção sonora por incidência plana de ondas. Da composição da função de onda derivada, foram propostos dois sistemas de instrumentação, um para cada tubo, em que hipóteses adicionais puderam ser testadas experimentalmente.

A instalação de microfones em diferentes pontos de uma mesma seção e em seções diferentes do tubo permitiu dispor de mais dados sobre problema, possibilitando a identificação e visualização dos modos não-normais. Também foi estudado como esses modos podem se cancelar e estender o comportamento plano das frentes de onda em uma banda maior de frequência.

Para a visualização de modos azimutais, ainda que sendo um método pouco exato, pôdese identificar 10 das 14 frequências modais dos primeiros modos azimutais. Nesse caso, ainda é importante que se estude como os modos azimutais superiores ao primeiro influenciam nas medidas dessa banda de frequência. A instrumentação proposta falha em identificar modos superiores ao primeiro porque não consegue garantir a quantidade de linhas nodais azimutais entre dois pontos de medida. Isso acontece porque quanto mais se deseja aumentar a precisão do método, maior a quantidade de medidas devem ser feitas por seção do tubo. 
Somado a isto, nos modelos descritos, as dimensões dos microfones são negligenciadas, para o caso de se aumentar a quantidade de medidas por seção do tubo, deve-se estudar o efeito que as dimensões do instrumento têm sobre a medida da pressão sonora.

Para a extensão da banda útil de frequência para o tubo de impedância, foi possível atenuar os efeitos de modos não-normais causados nas medidas de coeficiente de absorção sonora para o tubo de impedância com terminação rígida. Ainda com pouca exatidão, foi possível avaliar um arranjo de medidas em que os primeiros modos azimutais de propagação se cancelam, deixando a curva mais plana nessa faixa. Nesse caso, foi verificado um offset na curva geral de coeficiente de absorção, o que sugere que o material utilizado para a construção do projeto não é exatamente rígido. Ainda seria necessário que se garanta uma terminação completamente rígida para avaliar a exatidão dos sistemas construídos.

\subsection{Trabalhos Futuros}

Os sistemas projetados e construídos durante o desenvolvimento deste trabalho foram feitos com tal versatilidade para se adaptar outros projetos na mesma bancada. Ainda há uma série de trabalhos possíveis e necessários a serem realizados nesta bancada, alguns deles:

- Instalação de instrumentação axissimétrica no tubo para identificação de modos azimutais. Uma disposição axissimétrica com 4 microfones por seção traria maior confiabilidade na identificação modal, uma vez que há dois traços de linhas nodais presentes em cada par de microfone;

- A comparação entre estimativas de coeficiente de absorção sonora feita em tubos de impedância comerciais ou certificados. Essa comparação traria insumos para se discutir sobre a exatidão dos sistemas projetados e como as eventuais imperfeições de material podem ser compensadas em código;

- A instalação de um tubo de transmissão na terminação do tubo. Além da avaliação de coeficiente de absorção, ainda é podem ser realizados ensaios de transmissão sonora na bancada realizada, com a instalação de um tubo anexo ao primeiro.

Essas propostas de trabalhos futuros são importantes para o estudo novos materiais para a engenharia acústica, no revestimento de ambientes e no isolamento de processos ruidosos; sejam esses materiais já existentes ou projetados. Nesse último caso, destaca-se o projeto de metamateriais com foco em resposta acústica. 
Por fim, destacam-se a possibilidade e importância de visitar outros formatos de resolução das equações de propagação sonora, para além do método de separação de variáveis. Avaliar as funções de pressão por métodos como o de Green podem iluminar ainda mais o comportamento desses fenômenos acústicos, como é desenvolvido em RIENSTRA e HIRSCHBERG (2013) e em ROSA (2014). 


\section{Referências Bibliográficas}

ASTM E1050, Standard Test Method for Impedance and Absorption of Acoustical Materials Using a Tube, Two Microphones and a Digital Frequency Analysis System, 1998.

BALDOCK, G. R. Mathematical theory of wave motion. Chichester: Halsted Press, 1981, $261 \mathrm{p}$.

BERANEK, L. Acoustics. Nova Iorque: Acoustical Society of America, 1990. 491p.

CHAIGNE, A. Ondes acoustiques. Palaiseau: Éditions de l'École Polytechnique, 2003. 218p.

CHLADNI, E. F. F. Treatise on Acoustics. Cham: Springer International Publishing, 2015.

CHO, Y.; NELSON, P. A; Least squares estimation of acoustic reflection coefficient. Proceedings of Institute of Acoustics Spring Conference, 2002.

CHUNG, J. Y.; BLASER, D. A. Transfer function method of measuring in-duct acoustic properties. I. Theory. The Journal of the Acoustical Society of America, v. 68, n. 3, p. 907-913, set. 1980a.

CHUNG, J. Y.; BLASER, D. A. Transfer function method of measuring in-duct acoustic properties. II. Experiment. The Journal of the Acoustical Society of America, v. 68, n. 3, p. 914-921, set. 1980 b.

DARRIGOL, O. The acoustic origins of harmonic analysis. Archive for History of Exact Sciences, v. 61, n. 4, p. 343-424, 4 jun. 2007.

DEL REY, R. et al. Characterization of Sheep Wool as a Sustainable Material for Acoustic Applications. Materials, v. 10, n. 11, p. 1277, 7 nov. 2017.

DIEDRICH, C. G. "Neanderthal bone flutes": simply products of Ice Age spotted hyena scavenging activities on cave bear cubs in European cave bear dens. Royal Society Open Science, v. 2, n. 4, p. 140022-140022, 1 abr. 2015.

DOAK, P. E. Excitation, transmission and radiation of sound from source distributions in hard-walled ducts of finite length (I): The effects of duct cross-section geometry and source distribution space-time pattern. Journal of Sound and Vibration, v. 31, n. 1, p. 1-72, nov. $1973 \mathrm{~b}$.

DOAK, P. E. Excitation, transmission and radiation of sound from source distributions in hard-walled ducts of finite length (II): The effects of duct length. Journal of Sound and Vibration, v. 31, n. 2, p. 137-174, jan. 1973a.

FAHY, F. Foundations of engineering acoustics. San Diego, Calif.: Elsevier Academic Press, 2005.

FOROUHARMAJD, F.; MOHAMMADI, Z. Experimental Study on the Effect of Air Gap, Thickness, and Density on Acoustic Impedance and Sound Absorption of Stone Wool and Rubber Samples with Transfer Function Method. Iranian Journal of Science and Technology, Transactions of Mechanical Engineering, v. 42, n. 1, p. 73-84, mar. 2018.

GÓMEZ ESCOBAR, V.; MADERUELO-SANZ, R. Acoustical performance of samples prepared with cigarette butts. Applied Acoustics, v. 125, p. 166-172, out. 2017. 
ISO 10534-2:1998, Acoustics - Determination of sound absorption coefficient and impedance in impedance tubes - Part 2: Transfer-function method

JIANG, C; MOREAU, D; DOOLAN, C. Acoustic Absorption of Porous Materials Produced by Additive Manufacturing with Varying Geometries. Proceedings of Acoustics, Perth, 2017.

KENELLY, A. E.; KUROKAWA, K. Acoustic Impedance and Its Measurement. Proceedings of the American Academy of Arts and Sciences, v. 56, n. 1, p. 3-42, 1921.

LINDSAY, R. B. The Story of Acoustics. The Journal of the Acoustical Society of America, v. 39, n. 4, p. 629-644, abr. 1966.

LINSCHEID, N; PAPACOSTA, P; An Inexpensive and Versatile Version of Kundt's Tube for Measuring the Speed of Sound in Air. The Physics Teacher, v. 54, n 1, 2016.

MAGALHÃES, L. T. Métodos de Resolução de Equações Diferenciais e Análise de Fourier com Aplicações. Abril de 2013. 378 f. Notas de aula. Acessado em https://www.math.tecnico.ulisboa.pt/ lmagal/TEED.htm

MAREZE, P. et al.. Sound absorption coefficient measurement based on the Transfer Function Method specified by the standard ISO 10534-2 using low-cost alternatives. Proceedings of 22nd International Congress of Acoustics, 2016.

MARTELLOTTA, F. et al. Sustainable sound absorbers obtained from olive pruning wastes and chitosan binder. Applied Acoustics, v. 141, p. 71-78, dez. 2018.

MORSE, P. M. Vibration and Sound. Nova Iorque: McGraw-Hill Book Co., 1948, 468p.

NASCIMENTO, L. A.; RODRIGUES, G. K.; DE OLIVEIRA, L. Revisited impedance tube for standard and metamaterial testing. Proceedings of International Conference on Noise and Vibration Engineering, Leuven, 2018.

NEPOMUCENO, L. X. Acústica Técnica. São Paulo: Etegil, 1968. 578p.

NIRESH, J.; NEELAKRISHNAN, S.; SUBHA RANI, S. Investigation and correction of error in impedance tube using intelligent techniques. Journal of Applied Research and Technology, v. 14, n. 6, p. 405-414, dez. 2016.

RAYLEIGH, J. W. S. The theory of sound. Vol. 2: ... New York: Dover Publ, 1969.

RIENSTRA, S. W.; HIRSCHBERG, A. An introduction to Acoustics. Eindhoven, 2016, 288 p. Disponível em: https://www.win.tue.nl/ sjoerdr/papers/boek.pdf

ROSA, J. L. A. O. Modal Decomposition on Sound Propagation in Ducts with and without Flow. 2014. 198 f. Dissertação (Mestrado em Ciências) - Engenharia Aeroespacial, Instituto Superior Técnico, Lisboa. 2014.

RUAN, K. Numerical and Experimental Techniques for Assessing the Acoustic Performance of Duct Systems Above the Plane Wave Cutoff Frequency. [s.1.] University of Kentucky Libraries, 2018.

SANADA, A. Extension of the frequency range of normal-incidence sound-absorptioncoefficient measurement using four or eight microphones. Acoustical Science and Technology, v. 38, n. 5, p. 261-263, 2017.

SETAKI, F. et al. Comparison of standing wave ratio method and transfer function method for measuring sound absorbing properties of $3 \mathrm{~d}$-printed samples. Proceedings of $42 \mathrm{nd}$ Annual Conference on Acoustics, Munique, 2016. 
SETO, W. W. Schaum's outline of theory and problems of acoustics. New York: McGrawHill, 1971.

SEYBERT, A. F.; ROSS, D. F. Experimental determination of acoustic properties using a two-microphone random-excitation technique. The Journal of the Acoustical Society of America, v. 61, n. 5, p. 1362-1370, maio 1977. 


\section{ANEXO A: Funções de Bessel}

Seja a equação de Bessel para um inteiro $m$ :

$$
x^{2} \frac{d^{2} y}{d x^{2}}+x \frac{d y}{d x}+\left(x^{2}-m^{2}\right) y=0
$$

A equação de Bessel é frequentemente encontrada na resolução de problemas de Dirichlet, onde se estuda uma equação diferencial com valores de fronteira ao sistema. O número $m$ determina a ordem da função de Bessel e pode assumir qualquer valor real.

Uma vez que a (A.1) é uma equação diferencial de segunda ordem, há duas soluções linearmente independentes para a equação, de modo que a solução geral é a combinação linear dessas duas soluções, que se define como as funções de Bessel, de primeiro e segundo tipo:

$$
y=A J_{m}(x)+B Y_{m}(x)
$$

onde $A$ e $B$ são constantes arbitrárias.

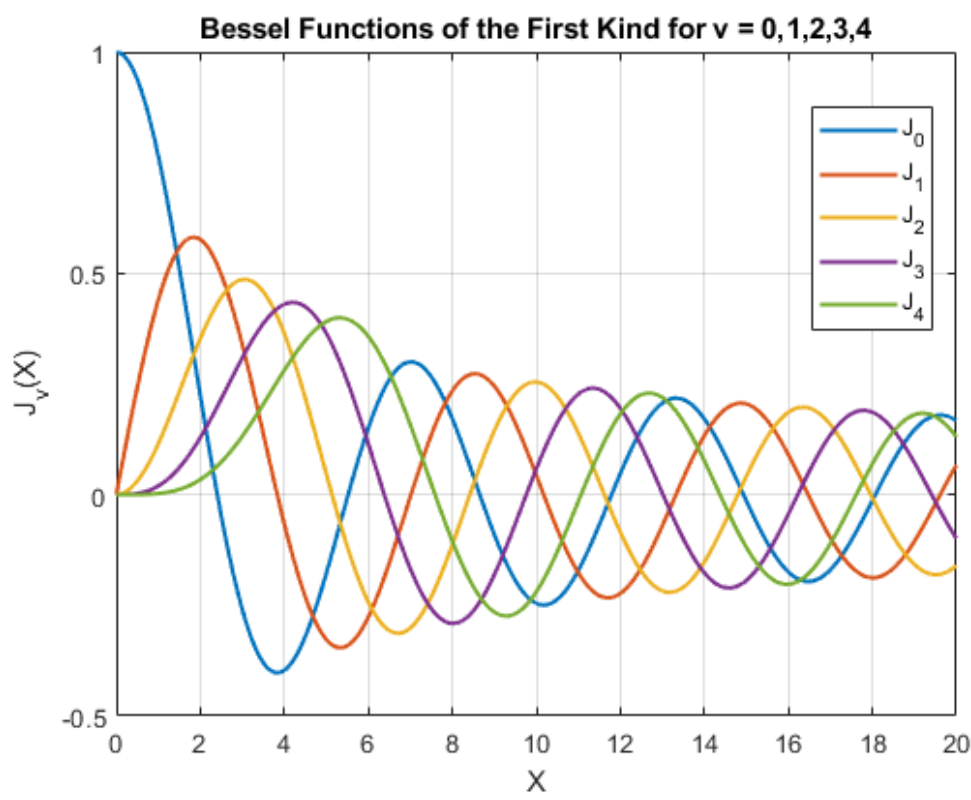

Figura 36 - Funções de Bessel de primeiro tipo, para os 5 primeiros índices inteiros.

A função de Bessel de primeiro tipo $J_{m}(x)$ é finita para $x=0$ e para todos os valores de $m$. Enquanto a função de segundo tipo $Y_{m}(x)$, também conhecida como função de Neumann, é singular para $x=0$. Por esse motivo, aborda-se neste trabalho apenas a função de Bessel de primeiro tipo. A Figura 36 mostra o comportamento de $J_{m}(x)$ para os 5 primeiros 
valores naturais de $m . J_{m}(x)$ também pode ser definida utilizando expansão em séries de potência como:

$$
J_{m}(x)=\sum_{k=0}^{\infty} \frac{(-1)^{k}\left(\frac{x}{2}\right)^{m+2 k}}{k !(m+k) !}
$$

Algumas propriedades importantes da função de Bessel de primeiro tipo:

$$
\begin{gathered}
J_{m}(x) \stackrel{x \rightarrow \infty}{\longrightarrow} \sqrt{\frac{2}{\pi x}} \cos \left(x-\frac{2 m+1}{4} \pi\right) \\
J_{m}(-x)=(-1)^{m} J_{m}(x) \\
J_{-m}(x)=(-1)^{m} J_{m}(x) \\
J_{m-1}(x)+J_{m+1}(x)=\frac{2 m}{x} J_{m}(x) \\
\frac{d}{d x} J_{m}(x)=\frac{J_{m-1}(x)-J_{m+1}(x)}{2} \\
J_{0}^{\prime}(x)=-J_{1}(x) \\
\int J_{1}(x) d x=-J_{0}(x) \\
\int x J_{0}(x) d x=x J_{1}(x)
\end{gathered}
$$

As funções $J_{m}(x)$ e $J_{m}^{\prime}(x)$ têm um infinito número de zeros reais. Denota-se o n-ésimo zero das funções como $j_{m n}$ e $j_{m n}^{\prime}$, respectivamente. Exceto para quando $x=0$, que é contado como o primeiro zero de $J_{0}^{\prime}$, ou seja, $j_{01}^{\prime}=0$, segue que $j_{0, n}^{\prime}=j_{1, n-1}$.

Descreve-se o comportamento assintótico de $J_{m}(x)$ :

$$
\begin{gathered}
J_{m}(x) \stackrel{x \rightarrow 0}{\longrightarrow} \frac{1}{m !}\left(\frac{x}{2}\right)^{m} \\
J_{m}(x) \stackrel{|x| \rightarrow \infty}{\longrightarrow}\left(\frac{\pi x}{2}\right)^{-1 / 2} \cos \left(x-\frac{m \pi}{2}-\frac{\pi}{4}\right) \\
J_{m}(x) \stackrel{m \rightarrow \infty}{\longrightarrow}(2 \pi m)^{-1 / 2}\left(\frac{e x}{2 m}\right)^{m}
\end{gathered}
$$


Abaixo, as Tabelas 6 e 7 mostram os 5 primeiros zeros para as funções de Bessel de ordem 0 a 5 , assim como os zeros de suas respectivas derivadas.

Tabela 5 - Cinco primeiros zeros para a função de Bessel de primeiro tipo, para os 5 primeiros índices inteiros.

\begin{tabular}{|c|c|c|c|c|c|c|}
\hline$n$ & $J_{0}(x)$ & $J_{1}(x)$ & $J_{2}(x)$ & $J_{3}(x)$ & $J_{4}(x)$ & $J_{5}(x)$ \\
\hline 1 & 2.4048 & 3.8317 & 5.1356 & 6.3802 & 7.5883 & 8.7715 \\
\hline 2 & 5.5201 & 7.0156 & 8.4172 & 9.7610 & 11.0647 & 12.3386 \\
\hline 3 & 8.6537 & 10.1735 & 11.6198 & 13.0152 & 14.3725 & 15.7002 \\
\hline 4 & 11.7915 & 13.3237 & 14.7960 & 16.2235 & 17.6160 & 18.9801 \\
\hline 5 & 14.9309 & 16.4706 & 17.9598 & 19.4094 & 20.8269 & 22.2178 \\
\hline
\end{tabular}

Tabela 6 - Cinco primeiros zeros para a primeira derivada da função de Bessel de primeiro tipo, para os 5 primeiros índices inteiros.

\begin{tabular}{|c|c|c|c|c|c|c|}
\hline$n$ & $J_{0}^{\prime}(x)$ & $J_{1}^{\prime}(x)$ & $J_{2}^{\prime}(x)$ & $J_{3}^{\prime}(x)$ & $J_{4}^{\prime}(x)$ & $J_{5}^{\prime}(x)$ \\
\hline 1 & 3.8317 & 1.8412 & 3.0542 & 4.2012 & 5.3175 & 6.4156 \\
\hline 2 & 7.0156 & 5.3314 & 6.7061 & 8.0152 & 9.2824 & 10.5199 \\
\hline 3 & 10.1735 & 8.5363 & 9.9695 & 11.3459 & 12.6819 & 13.9872 \\
\hline 4 & 13.3237 & 11.7060 & 13.1704 & 14.5858 & 15.9641 & 17.3128 \\
\hline 5 & 16.4706 & 14.8636 & 16.3475 & 17.7887 & 19.1960 & 20.5755 \\
\hline
\end{tabular}





\section{ANEXO B: Especificações da linha PPR Industrial}

Abaixo os componentes selecionados da linha PPR Industrial. A especificação selecionada para a construção do sistema está destacada na imagem. Além disso, consta uma tabela de propriedades físico-químicas do material fornecida no catálogo do fabricante.

\section{Tubo}

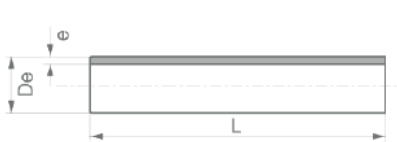

\begin{tabular}{|c|c|c|c|c|c|c|c|c|c|}
\hline \multicolumn{10}{|c|}{ DIMENSÕES (mm) } \\
\hline Cotas & DN20 & DN25 & DN32 & DN40 & DN50 & DN63 & DN75 & DN90 & DN110 \\
\hline e & 1.9 & 2.3 & 3 & 3.7 & 4.6 & 5.8 & 6.9 & 8.2 & 10 \\
\hline De & 20 & 25 & 32 & 40 & 50 & 63 & 75 & 90 & 110 \\
\hline L & 4000 & 4000 & 4000 & 4000 & 4000 & 4000 & 4000 & 4000 & 4000 \\
\hline
\end{tabular}

Figura 37 - Dimensões catalogadas do tubo.

\section{Selim de derivação}

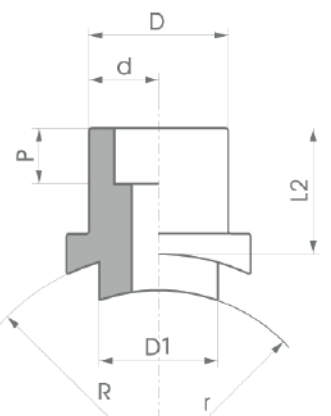

\begin{tabular}{|c|c|c|c|c|c|c|c|c|c|c|}
\hline \multicolumn{11}{|c|}{ DIMENSÕES (mm) } \\
\hline Cotas & DN63×20 & DN75x20 & DN90 $\times 20$ & DN63×25 & DN75x25 & DN90×25 & DN75x32 & DN63×32 & DN90x32 & DN1 $10 \times 25$ \\
\hline D & 35 & 35 & 35 & 35 & 35 & 35 & 42 & 35 & 42 & 47,5 \\
\hline D1 & 25 & 25 & 25 & 25 & 25 & 25 & 32 & 25 & 32 & 36 \\
\hline$P$ & 15.25 & 15.25 & 15.25 & 16.75 & 16.75 & 16.75 & 18.75 & 16.75 & 18.75 & 16.75 \\
\hline L & 32 & 38 & 45 & 32 & 38 & 45 & 31 & 32 & 45 & 40 \\
\hline L1 & 34 & 35 & 36 & 34 & 34 & 36 & 37 & 34 & 38 & 37 \\
\hline H & 28 & 28 & 28 & 28 & 28 & 28 & 30 & 28 & 30 & 30 \\
\hline
\end{tabular}

Figura 38 - Dimensões catalogadas do selim de derivação

\section{Cap}

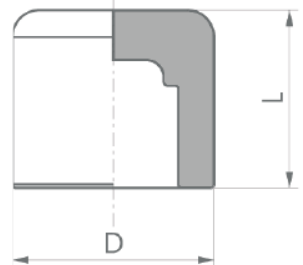

\begin{tabular}{|c|c|c|c|c|c|c|c|c|c|}
\hline \multicolumn{10}{|c|}{ DIMENSÕES (mm) } \\
\hline Cotas & DN20 & DN25 & DN32 & DN40 & DN50 & DN63 & DN75 & DN90 & DN110 \\
\hline D & 30 & 36 & 43 & 55.2 & 66.1 & 84.2 & 106.5 & 126.5 & 140,5 \\
\hline L & 26.5 & 30 & 34 & 36.5 & 41 & 48 & 58 & 64 & 37,75 \\
\hline
\end{tabular}

Figura 39 - Dimensões catalogadas do cap de terminação. 


\section{União parafusada}

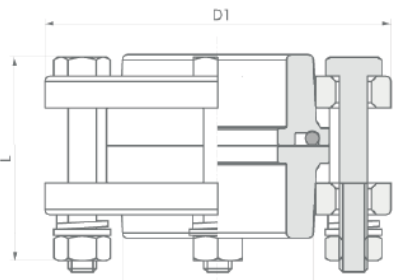

\begin{tabular}{|c|c|c|c|c|c|}
\hline \multicolumn{6}{|c|}{ DIMENSÕES (mm) } \\
\hline Cotas & DN40 $\times 11 / 2$ & DN50 $\times 11 / 2$ & DN63 $\times 2$ & DN75x21/2 & DN90x3 \\
\hline D & 60 & 70 & 88 & 110 & 130 \\
\hline L & 60 & 65 & 67 & 76 & 80 \\
\hline D1 & 98 & 113.5 & 122 & 154 & 180 \\
\hline
\end{tabular}

Figura 40 - Dimensões catalogadas da união parafusada.

\section{Propriedades físico-químicas}

\begin{tabular}{|c|c|c|}
\hline PROPRIEDADES & UN. MEDIDA & VALOR \\
\hline Indice de fluência MFI $190^{\circ} \mathrm{C} / 5 \mathrm{Kg}$ & $\mathrm{g} / 10 \mathrm{~min}$ & 0,55 \\
\hline Indice de fluência MFI $230^{\circ} \mathrm{C} / 2,16 \mathrm{Kg}$ & $\mathrm{g} / 10 \mathrm{~min}$ & 0,3 \\
\hline Indice de fluência MFI $230^{\circ} \mathrm{C} / 5 \mathrm{Kg}$ & $\mathrm{g} / 10 \mathrm{~min}$ & 1,3 \\
\hline Densidade a $23^{\circ} \mathrm{C}$ & $\mathrm{g} / \mathrm{cm}^{3}$ & 0,909 \\
\hline Zona de fusão & ${ }^{\circ} \mathrm{C}$ & $150-154$ \\
\hline Carga de ruptura alongamento à ruptura & $\mathrm{N} / \mathrm{mm}^{2}$ & $>20$ \\
\hline Módulo de elasticidade & $\mathrm{N} / \mathrm{mm}^{2}$ & $>800$ \\
\hline Coeficiente de dilatação térmica linear & $\mathrm{MM} / \mathrm{M}^{\circ} \mathrm{C}$ & 0,15 \\
\hline Condutividade térmica a $20^{\circ} \mathrm{C}(\sim)$ & $\mathrm{W} / \mathrm{m} \mathrm{K}^{\mathrm{K}}$ & 0,24 \\
\hline Temperatura específica a $20^{\circ} \mathrm{C}$ & $\mathrm{Kj} / \mathrm{Kg} \mathrm{K}$ & 2 \\
\hline Teste de impacto a $23^{\circ} \mathrm{C}$ com entalhe & $\mathrm{Kj} / \mathrm{m}^{2}$ & 30 \\
\hline Teste de impacto a $0^{\circ} \mathrm{C}$ com entalhe & $\mathrm{Kj} / \mathrm{m}^{2}$ & 3 \\
\hline Teste de impacto a - $30^{\circ} \mathrm{C}$ com entalhe & $\mathrm{Kj} / \mathrm{m}^{2}$ & 1,8 \\
\hline Coeficiente de viscosidade & $\mathrm{cm}^{3} / \mathrm{g}$ & 430 \\
\hline Resistência à tração & $\mathrm{N} / \mathrm{mm}^{2}$ & 40 \\
\hline Dureza à penetração & $\mathrm{N} / \mathrm{mm}^{2}$ & 45 \\
\hline
\end{tabular}

Figura 41 - Propriedades físico-químicas do PPR Industrial. 


\section{ANEXO C: Visualização de modos azimutais}

Abaixo, as visualizações dos modos azimutais identificados pela análise acústica modal em LMS Scadas.

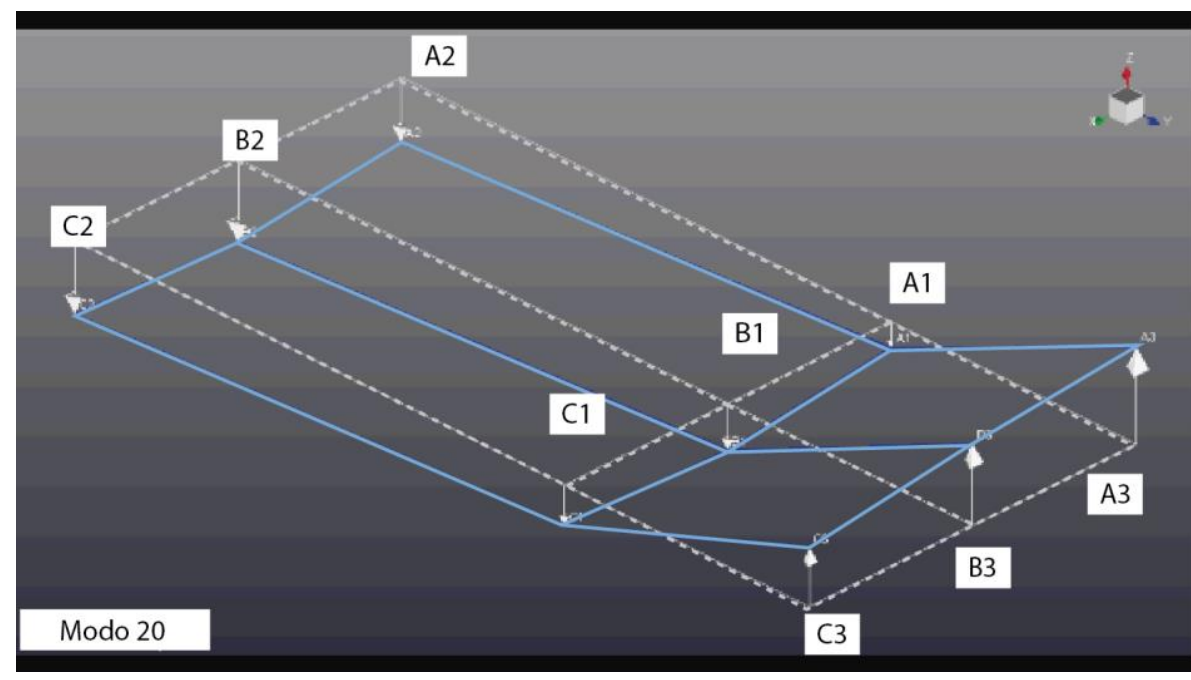

Figura 42 - Modo 20 identificado pelo LMS Scadas.

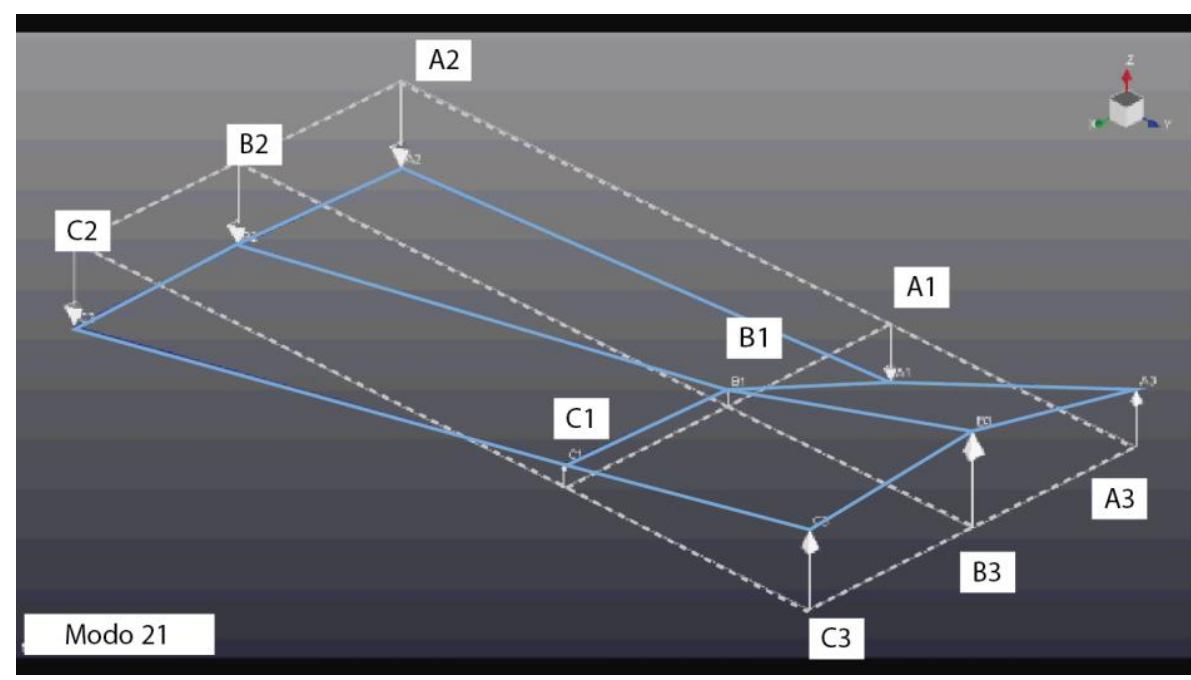

Figura 43 - Modo 21 identificado pelo LMS Scadas 


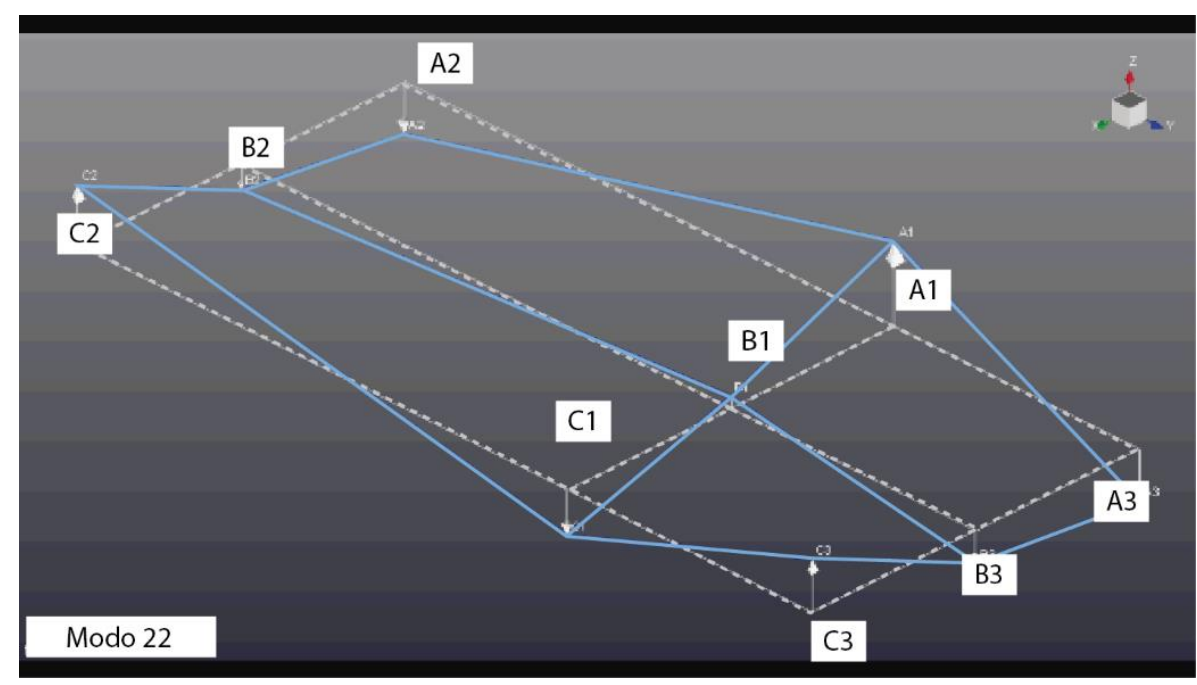

Figura 44 - Modo 22 identificado pelo LMS Scadas

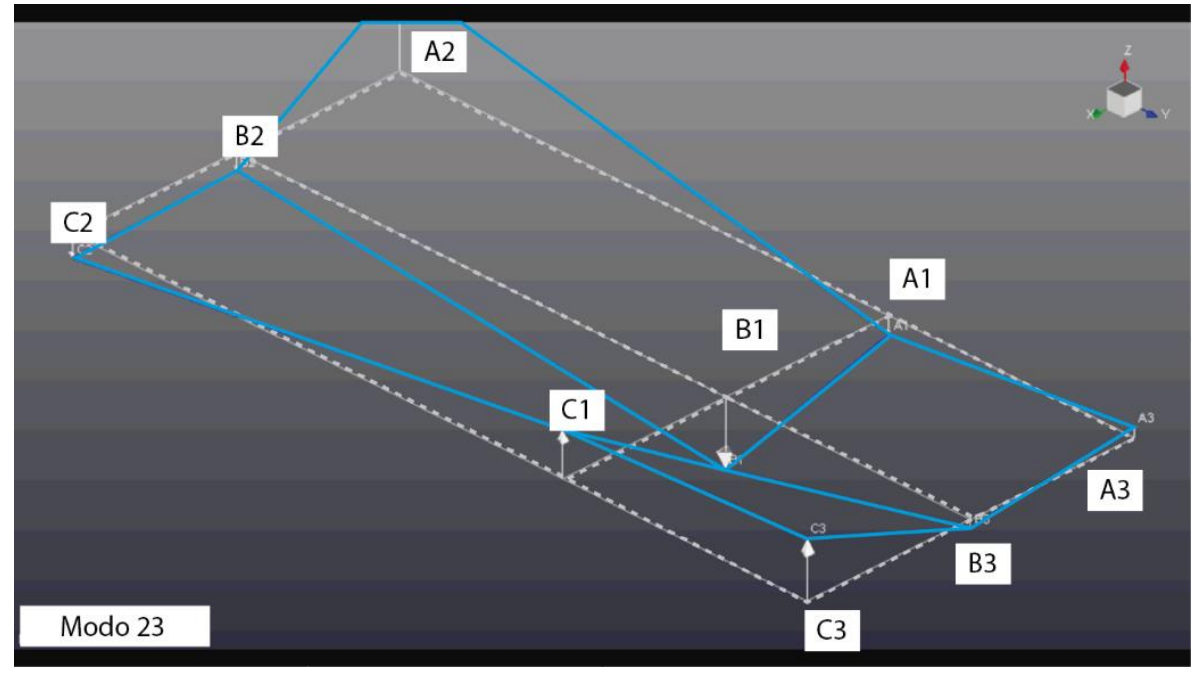

Figura 45 - Modo 23 identificado pelo LMS Scadas. 


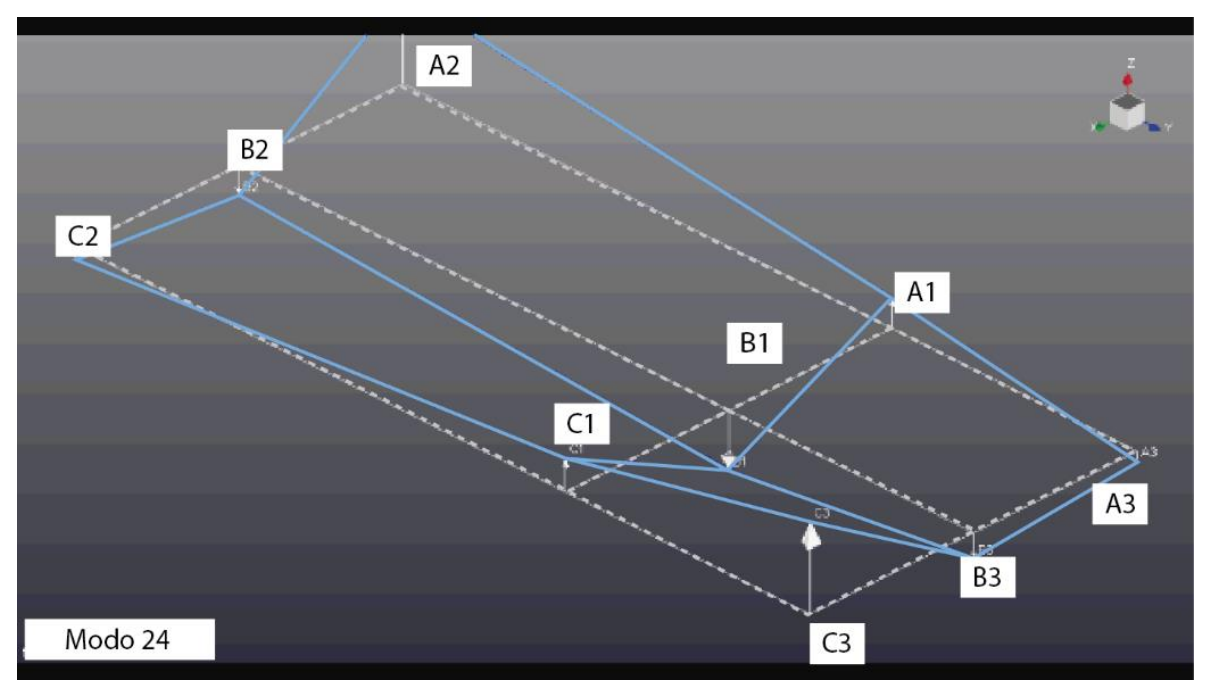

Figura 46 - Modo 24 identificado pelo LMS Scadas

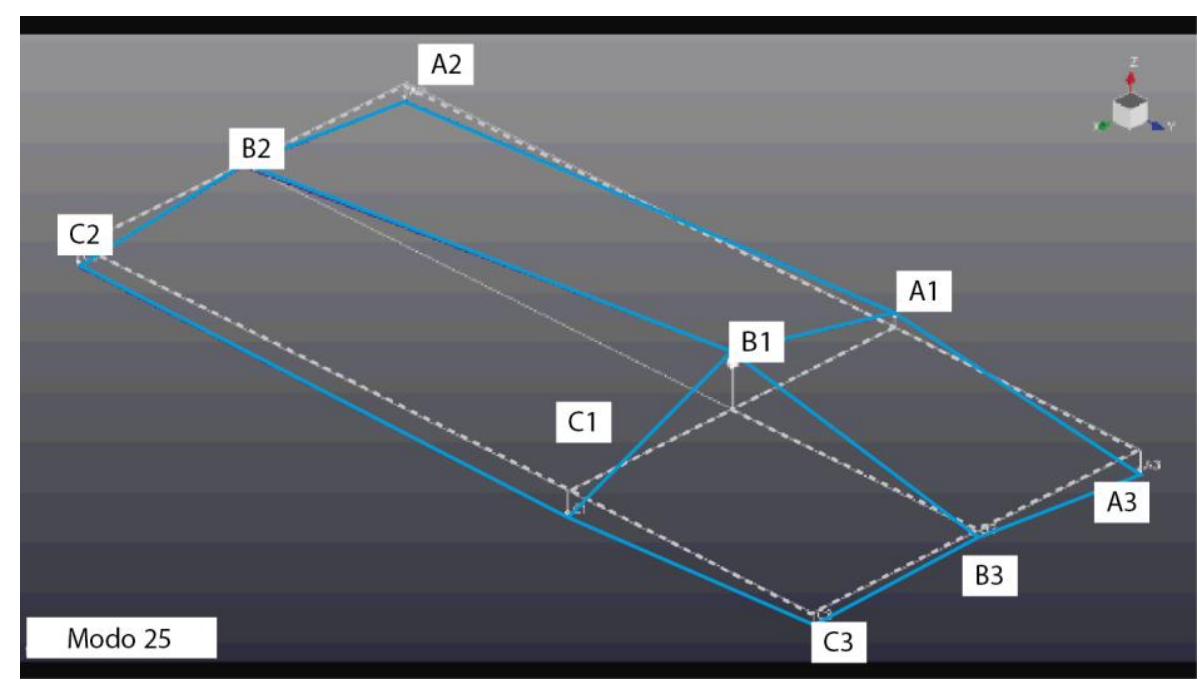

Figura 47 - Modo 25 identificado pelo LMS Scadas.

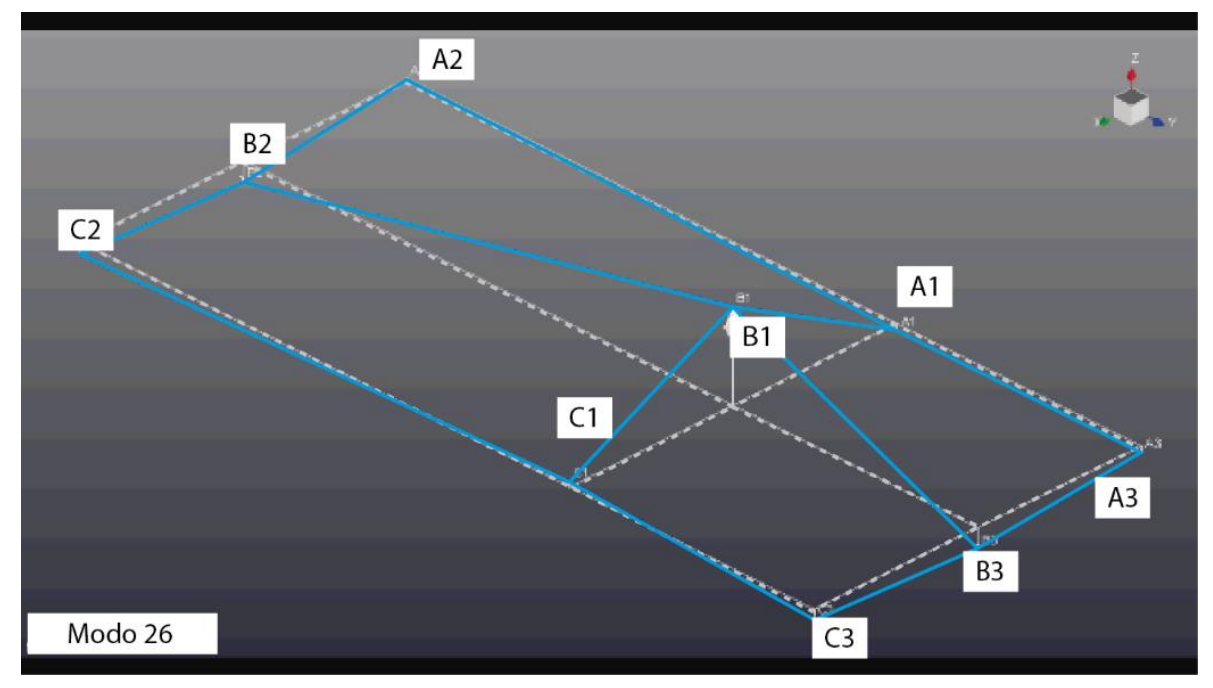

Figura 48 - Modo 26 identificado pelo LMS Scadas. 


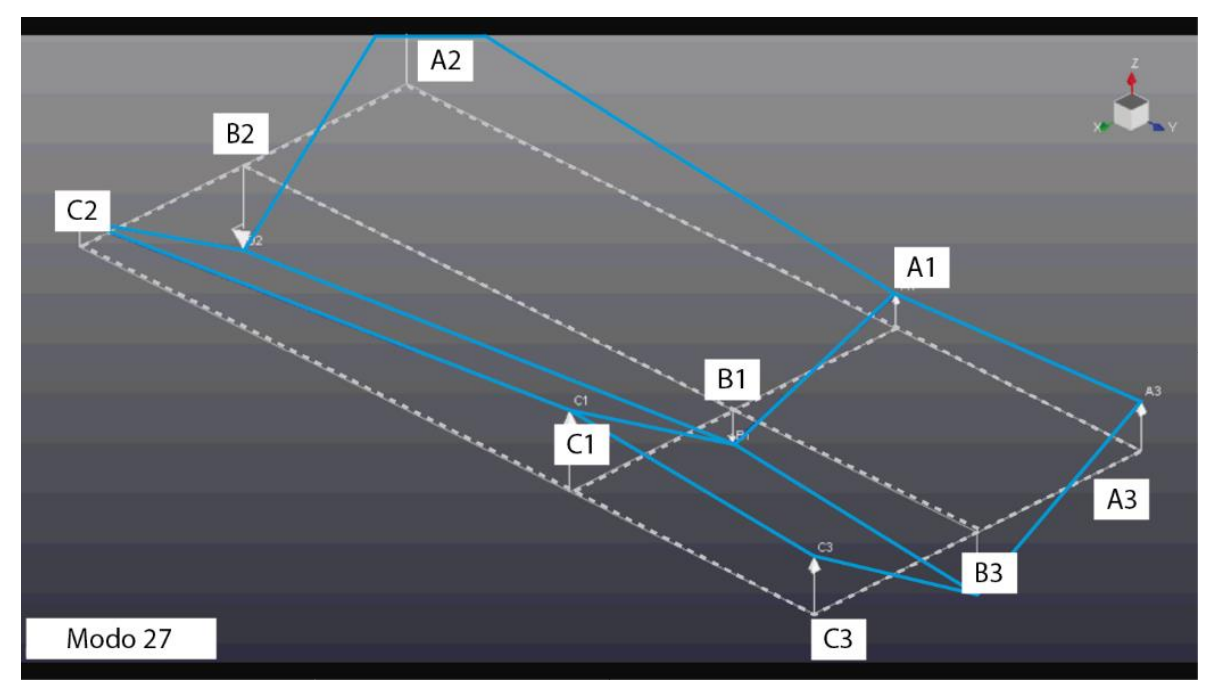

Figura 49 - Modo 27 identificado pelo LMS Scadas.

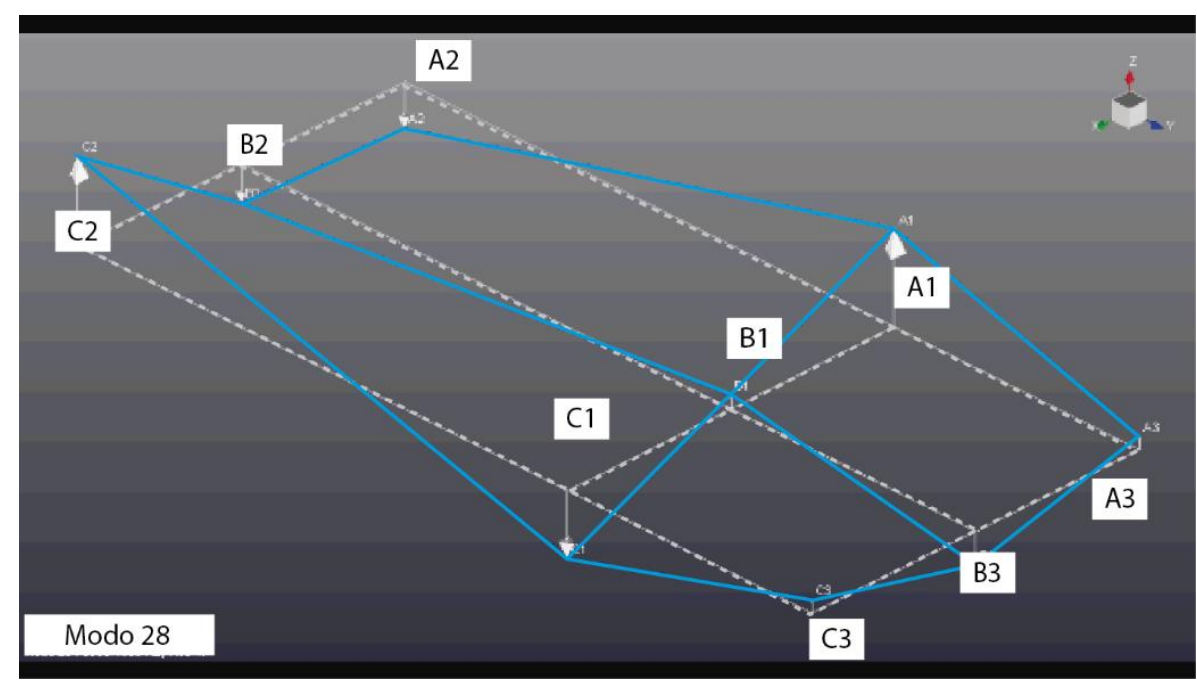

Figura 50 - Modo 28 identificado pelo LMS Scadas.

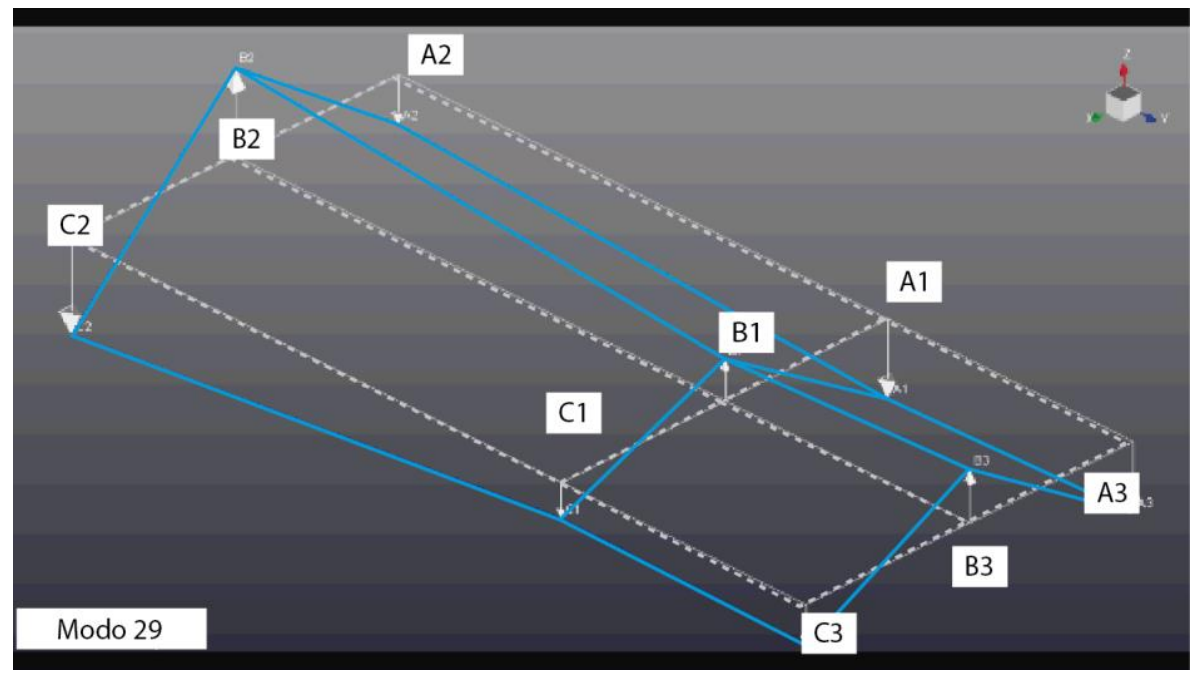

Figura 51 - Modo 29 identificado pelo LMS Scadas. 


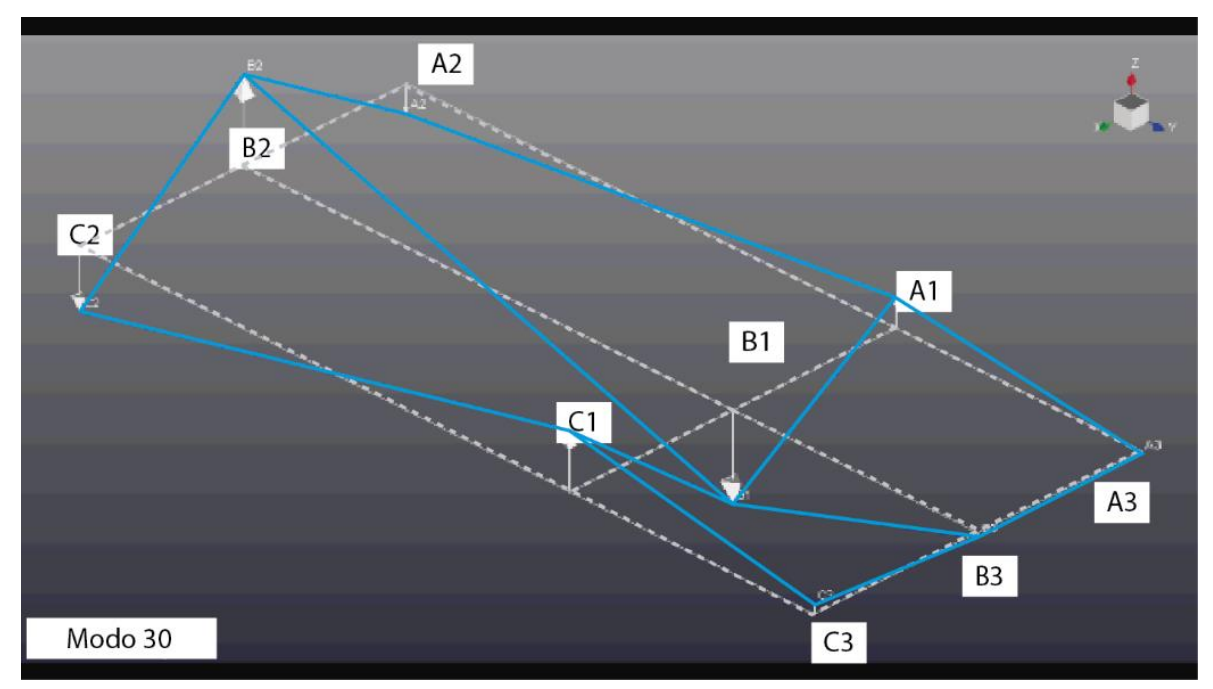

Figura 52 - Modo 30 identificado pelo LMS Scadas.

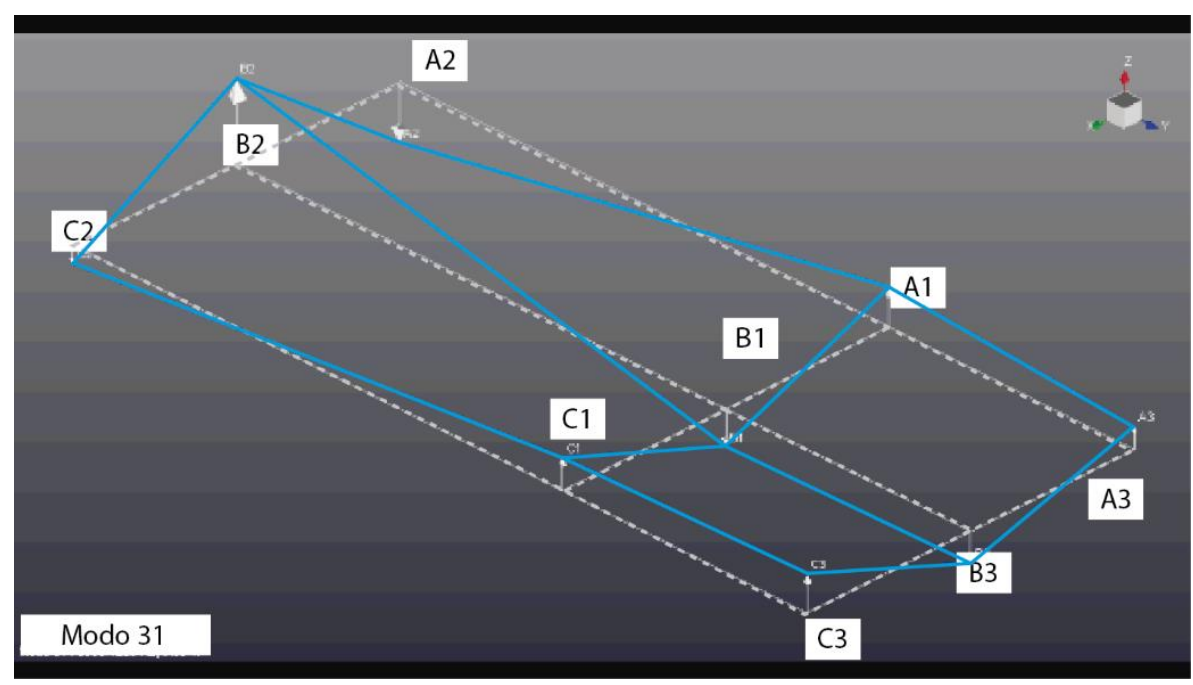

Figura 53 - Modo 31 identificado pelo LMS Scadas.

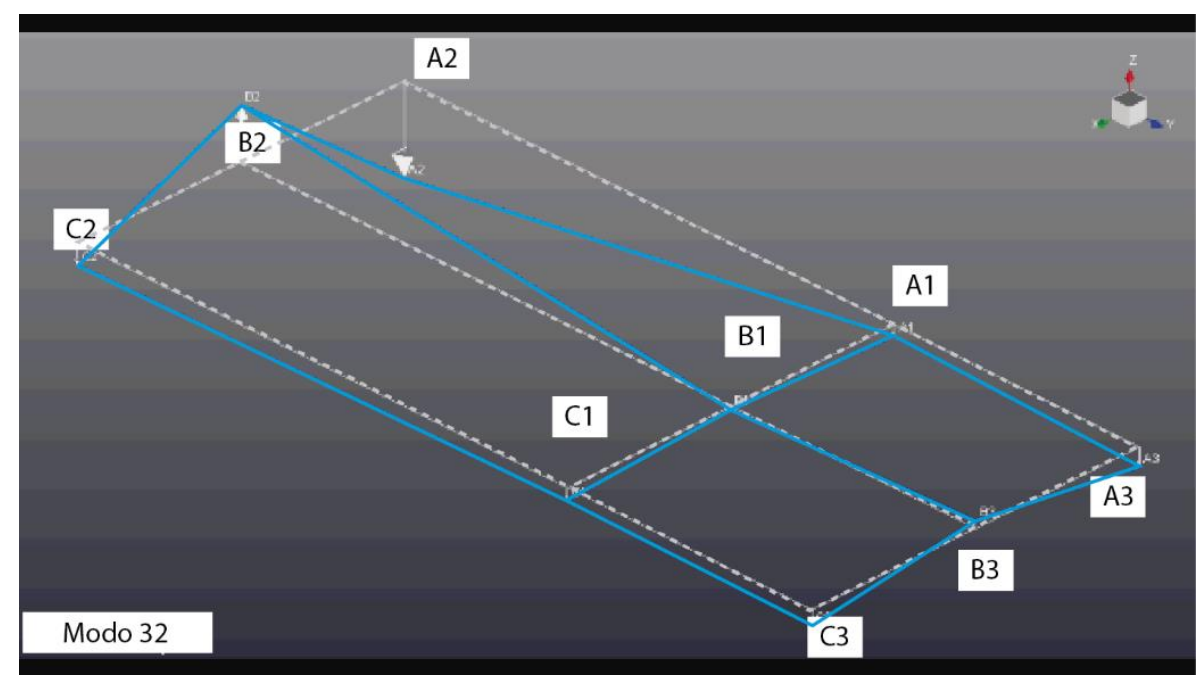

Figura 54 - Modo 32 identificado pelo LMS Scadas. 


\section{ANEXO D: Código para visualização de modos azimutais}

Este anexo traz o código, escrito em MATLAB, que mostra a visualização de modos azimutais, dados os 9 microfones instalados no sistema. Esse código iguala a curva à unidade caso a soma das magnitudes das pressões acústicas cada seção seja menor que as suas parcelas individualmente, caracterizando o que se chamou de soma destrutiva. Caso isso não aconteça, o código igual a curva à zero.

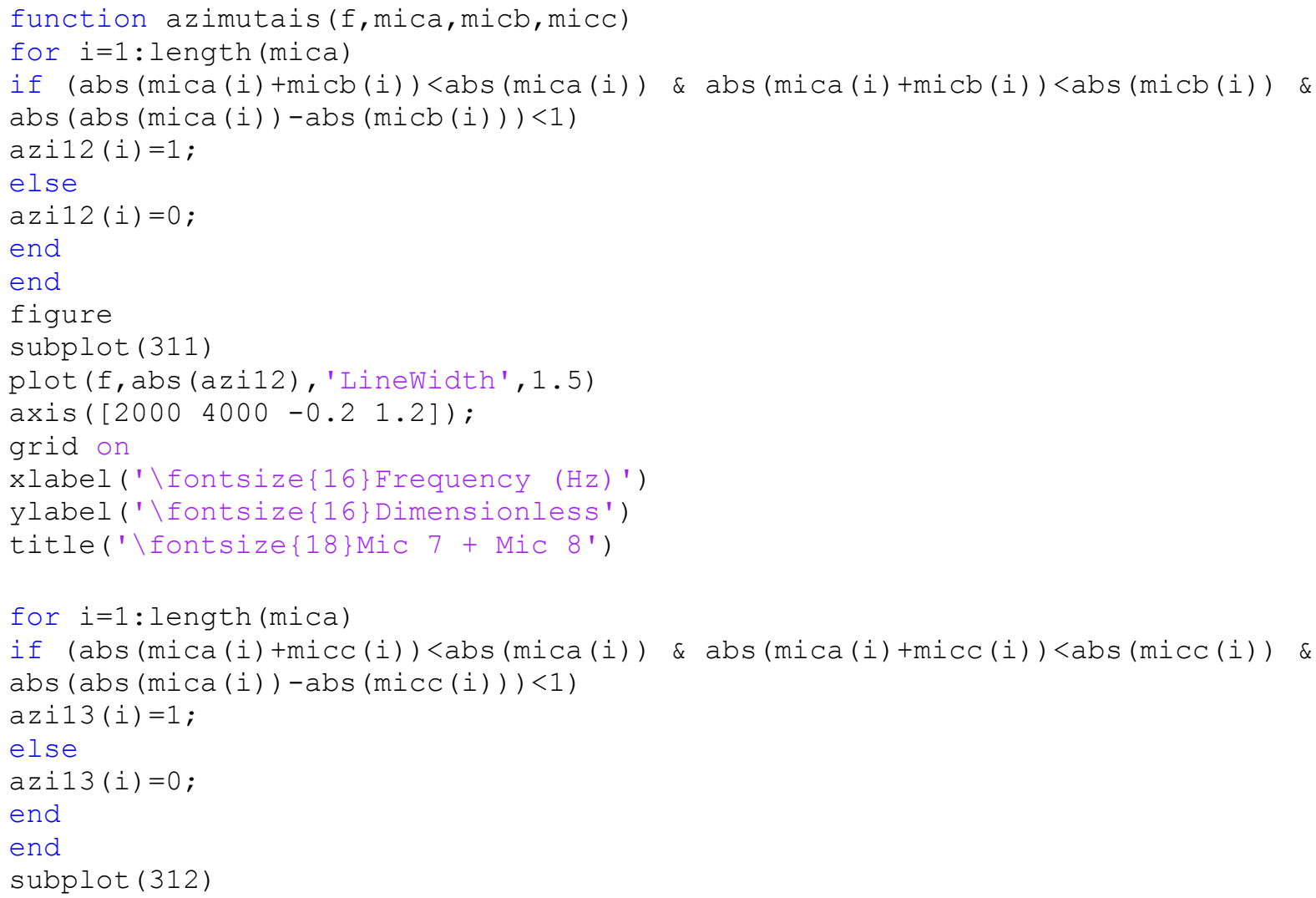




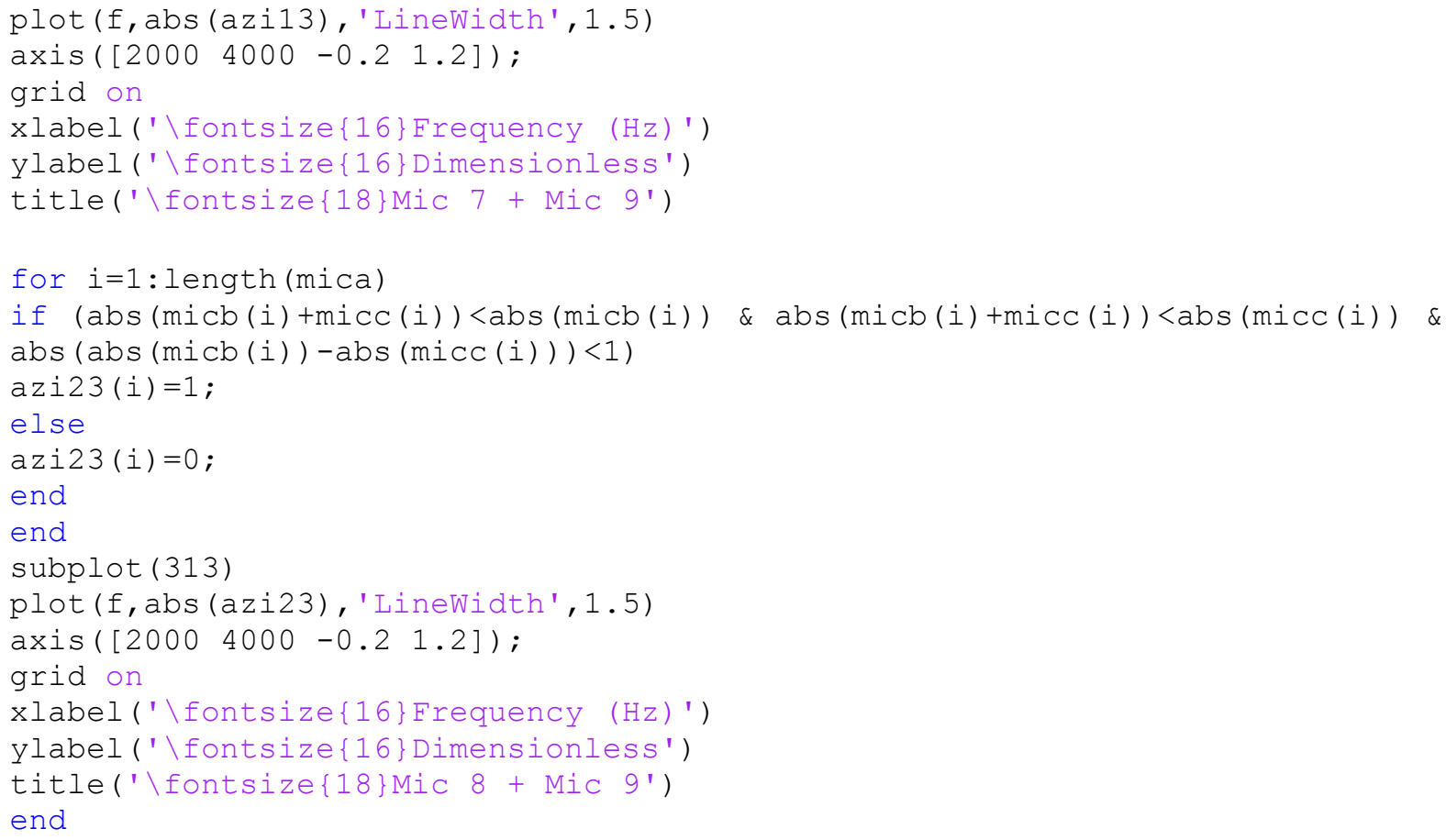





\section{ANEXO E: Código de processamento de dados}

O código abaixo foi escrito em MATLAB para processar os dados exportados do LMS Scadas. Este código processa dados de 9 microfones instalados, considerando as dimensões do tubo de impedância projetado para 9 microfones e com 1 metro de comprimento, como mostrado na Figura 23. Este código é facilmente adaptado para o tubo com 5 microfones instalados, alterando as variáveis de dimensões, como comprimento do tubo e distâncias dos microfones.

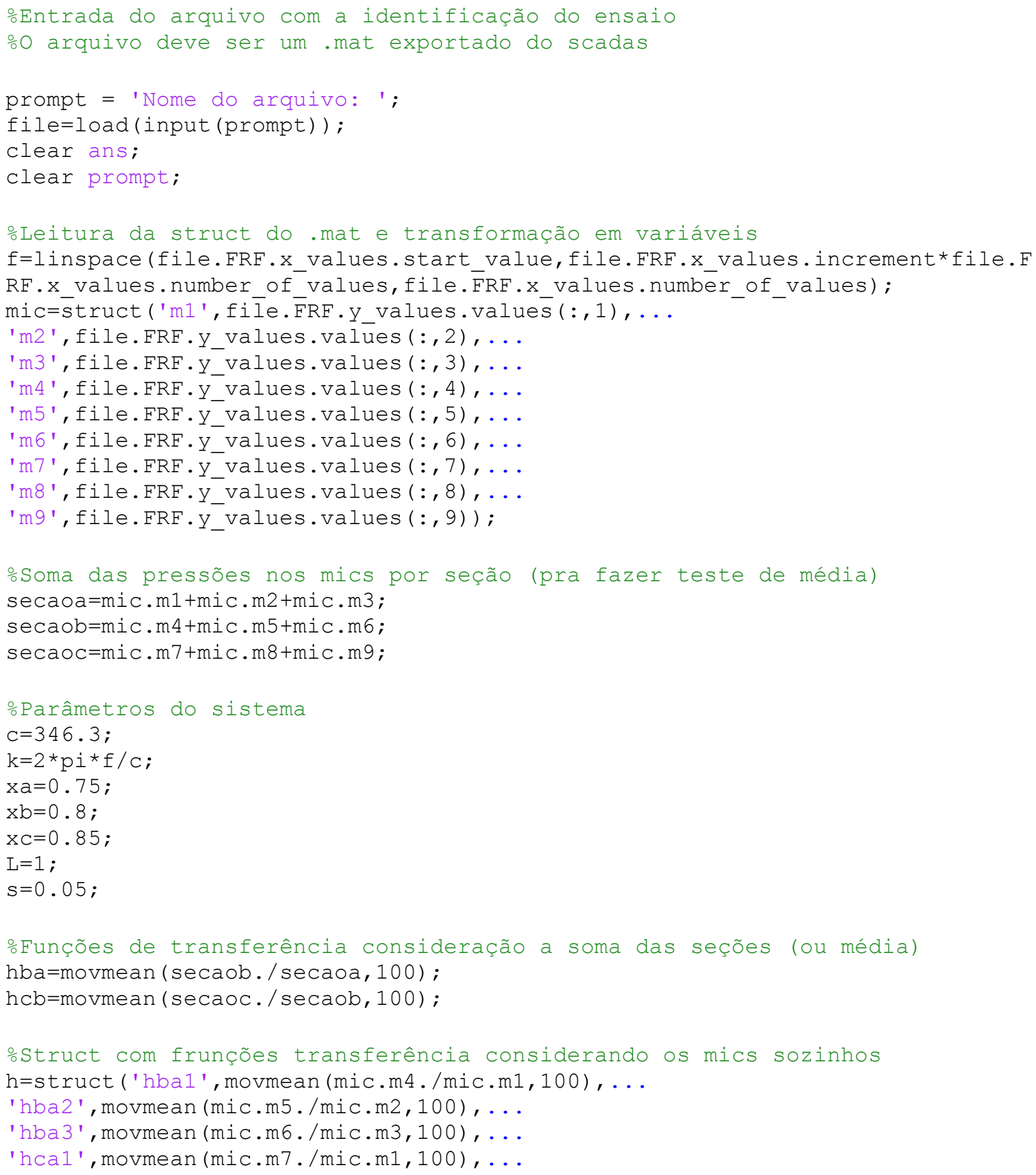


'hca2 ', movmean (mic.m8./mic.m2,100), ...
'hca3 ', movmean (mic.m9./mic.m3, 100$), \ldots$
'hcb1', movmean (mic.m7./mic.m4,100), ..
'hcb2 ', movmean (mic.m8./mic.m5,100), ..
'hcb3 ', movmean (mic.m9./mic.m6, 100));

oCalcula o coeficiente de reflexão R a partir das funções de transferência oCoeficientes de reflexão entre os microfones das seçõas A e B

OIdealmente, esses valores devem ser iguais (propagação plana + terminação orígida)

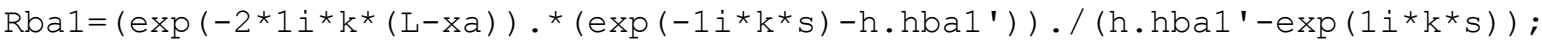

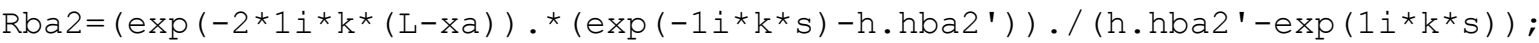

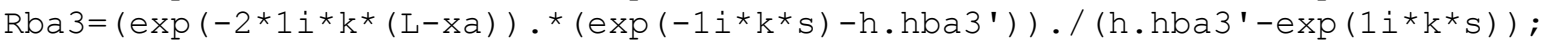

ocoeficientes de reflexão entre os microfones das seções B e C

$\mathrm{Rcb} 1=\left(\exp \left(-2 * 1 i * k^{*}(\mathrm{~L}-\mathrm{xb})\right) \cdot{ }^{*}\left(\exp \left(-1 i^{*} \mathrm{k}^{*} \mathrm{~S}\right)-\mathrm{h} \cdot \mathrm{hcb} 1^{\prime}\right)\right) \cdot /\left(\mathrm{h} \cdot \mathrm{hcb} 1^{\prime}-\exp \left(1 i * k^{*} \mathrm{~s}\right)\right) ;$

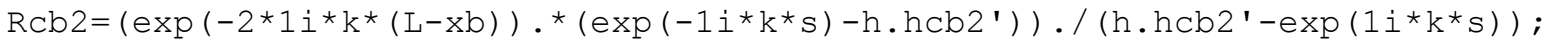

$\mathrm{Rcb} 3=\left(\exp \left(-2 * 1 i * \mathrm{k}^{\star}(\mathrm{L}-\mathrm{xb})\right) \cdot *\left(\exp \left(-1 i * \mathrm{k}^{\star} \mathrm{s}\right)-\mathrm{h} \cdot \mathrm{hcb} 3^{\prime}\right)\right) \cdot /\left(\mathrm{h} \cdot \mathrm{hcb} \mathrm{3}^{\prime}-\exp \left(1 i * \mathrm{k}^{\star} \mathrm{s}\right)\right)$;

oCoeficientes de reflexão entre A e B e entre B e C, considerando a soma odasseção (ou média)

$\mathrm{Rba}=\left(\exp \left(-2 * 1 i * \mathrm{k}^{*}(\mathrm{~L}-\mathrm{xa})\right) . *\left(\exp \left(-1 i * \mathrm{k}^{*} \mathrm{~S}\right)-\mathrm{hba} \mathrm{a}^{\prime}\right)\right) . /\left(\mathrm{hba} \mathrm{g}^{\prime}-\exp \left(1 i * \mathrm{k}^{*} \mathrm{~S}\right)\right)$;

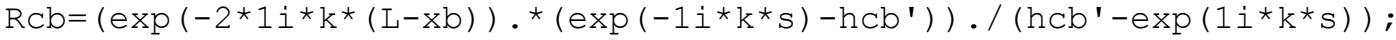

oCàlculo dos coeficientes de absorção a partir dos coeficientes de reflexão oentre A e B e entre B e C considerando a soma

oDá pra fazer também por microfone sozinho, usando os outros coeficientes alfaba $=1-a b s(R b a) \cdot \wedge 2$;

alfacb=1-abs (Rcb) .^2; 


\section{ANEXO F: Código de cálculo da aproximação quadrática}

Abaixo, são mostrados os códigos, feitos em MATLAB, para o cálculo das aproximações quadráticas, trabalhadas na Seção 5.4.

O código abaixo é referente ao primeiro arranjo de medidas, que leva em consideração a soma das medidas de uma mesma seção, comparando funções de transferência de seções adjacentes do tubo.

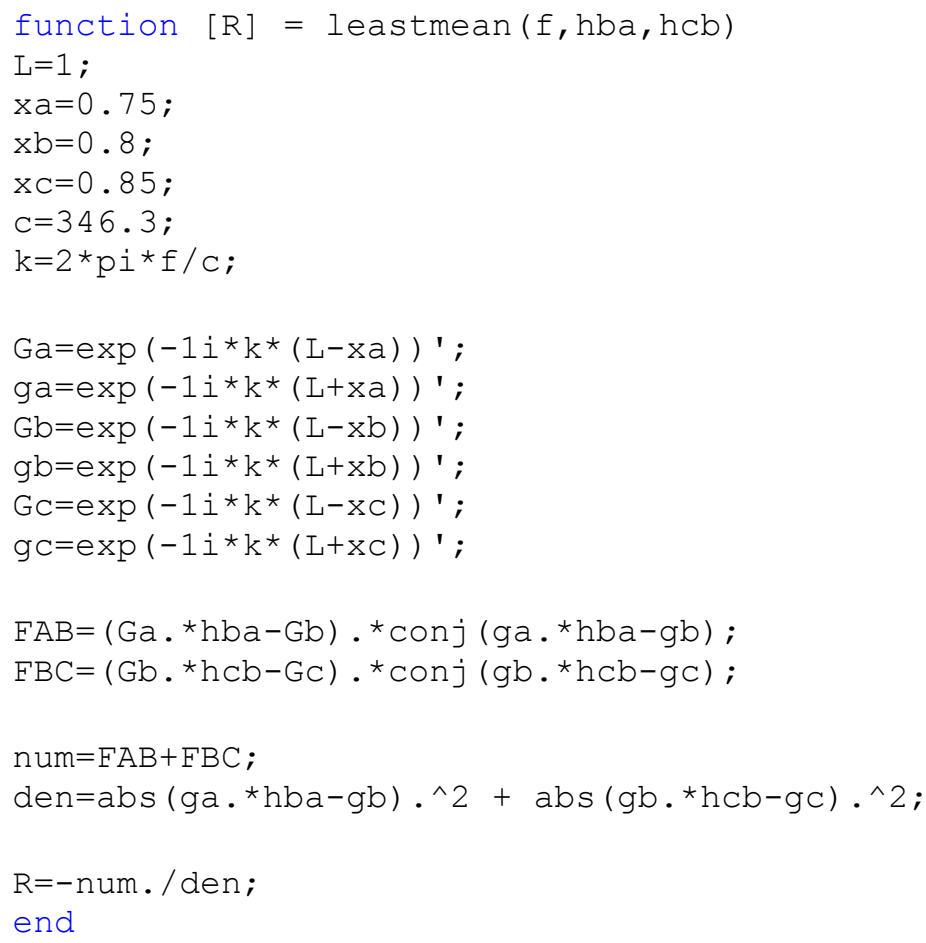

O código abaixo é referente ao segundo arranjo de medidas, que leva em consideração a soma de medidas duas a duas de uma mesma seção, comparando funções de transferência dessas somas de duas seções adjacentes do tubo.

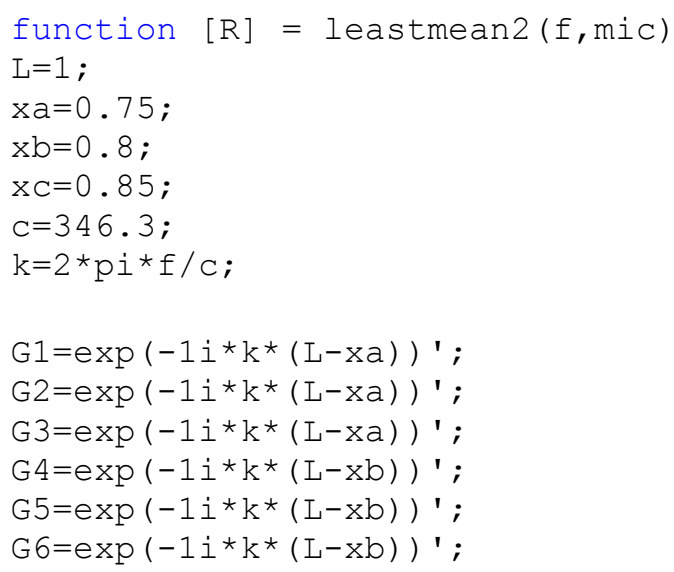




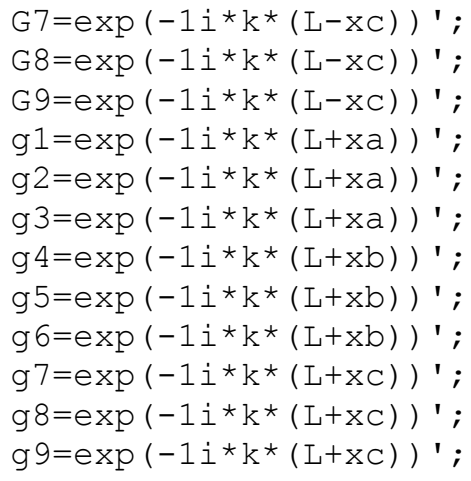


$\mathrm{R}=-\mathrm{num}$ • / den ;

end

Por fim, o código abaixo é referente ao terceiro arranjo de medidas, que leva em consideração as funções de transferência tomadas individualmente de cada medida de duas seções adjacentes do tubo.

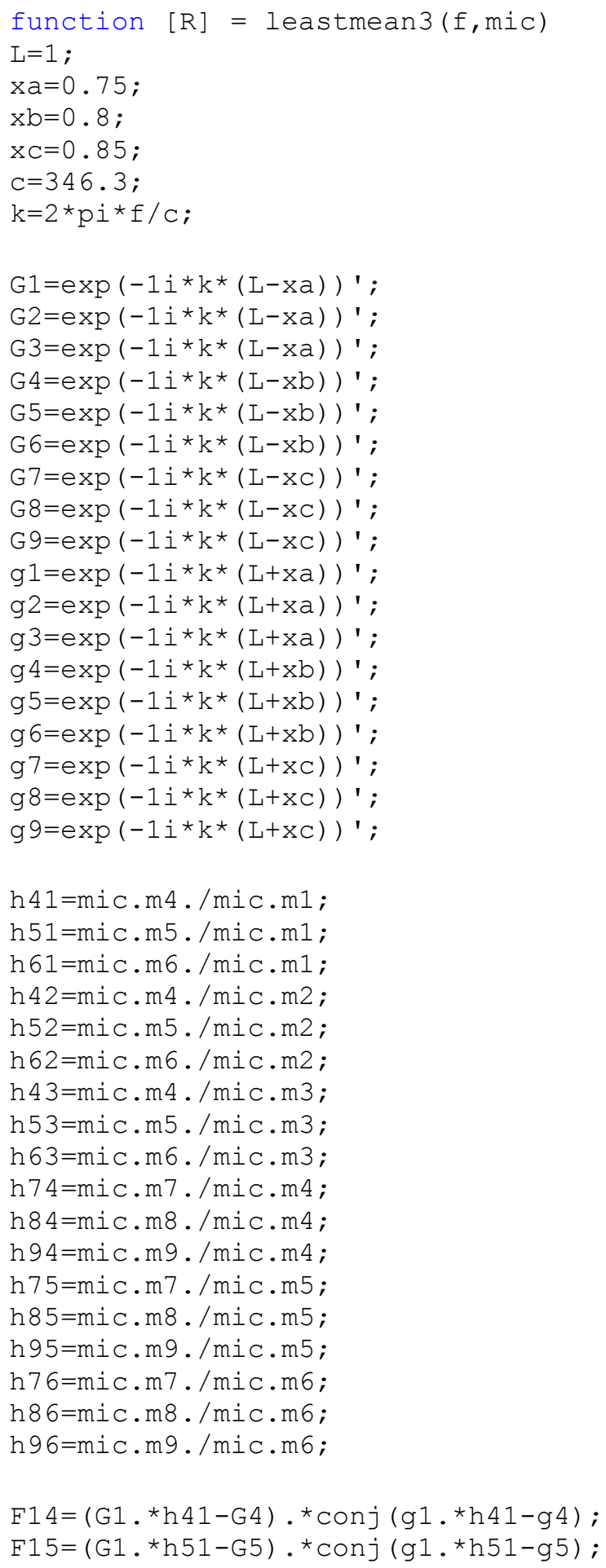




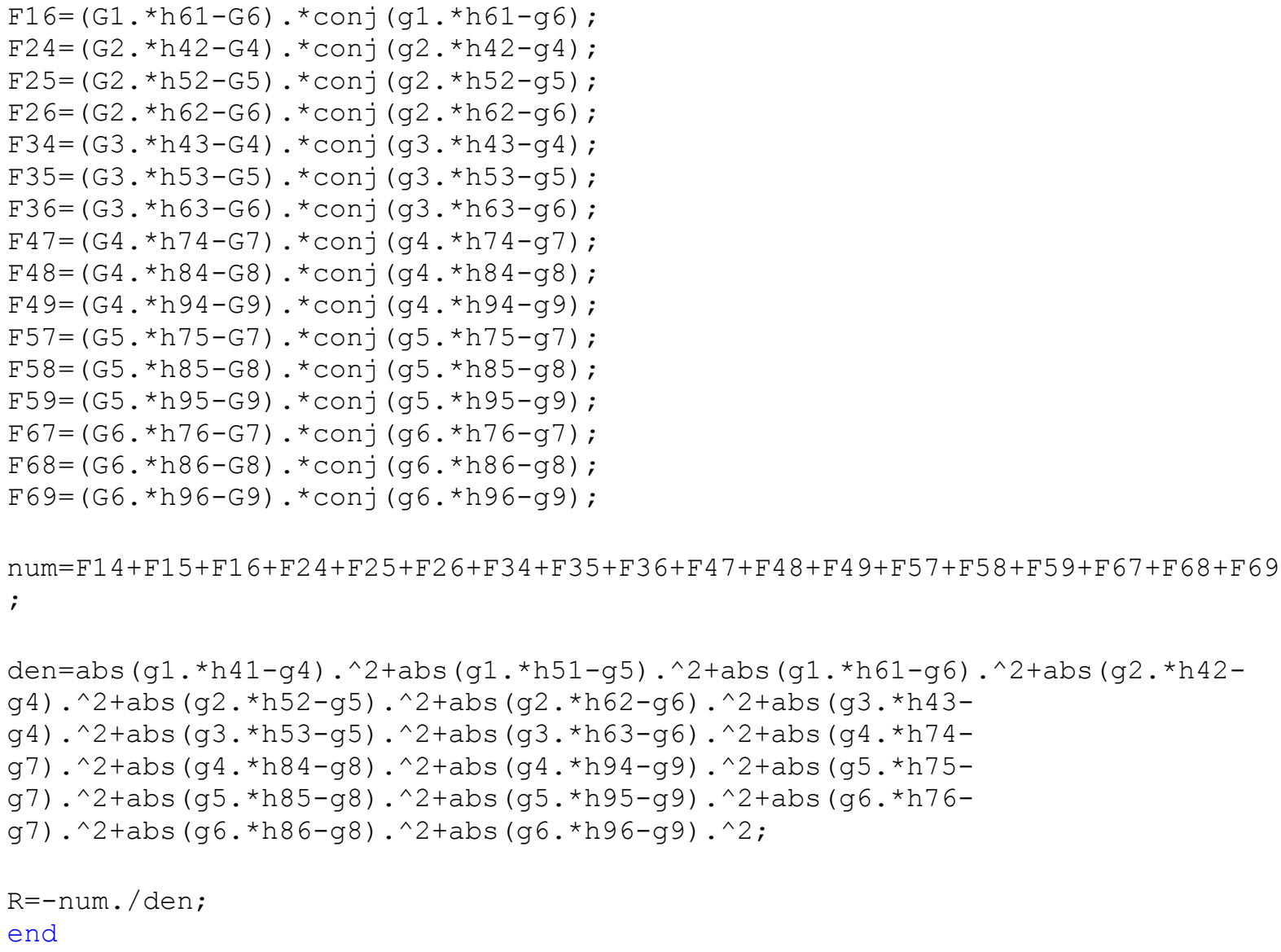

